Prepared for the U. S. Department of Energy Under

Contract Number DE-AC09-08SR22470

Keywords: Tank Farm, Tank Closure, Tank 18F

Retention Time: Permanent

\title{
Characterization of the Tank 18F Samples
}

\author{
L. N. Oji, D. Diprete, D.R. Click
}

Issue Date: December 17, 2009 


\section{DISCLAIMER}

This work was prepared under an agreement with and funded by the U.S. Government. Neither the U. S. Government or its employees, nor any of its contractors, subcontractors or their employees, makes any express or implied: 1. warranty or assumes any legal liability for the accuracy, completeness, or for the use or results of such use of any information, product, or process disclosed; or 2. representation that such use or results of such use would not infringe privately owned rights; or

3. endorsement or recommendation of any specifically identified commercial product, process, or service.

Any views and opinions of authors expressed in this work do not necessarily state or reflect those of the United States Government, or its contractors, or subcontractors.

Printed in the United States of America

Prepared for

U.S. Department of Energy 


\section{TABLE OF CONTENTS}

SUMMARY

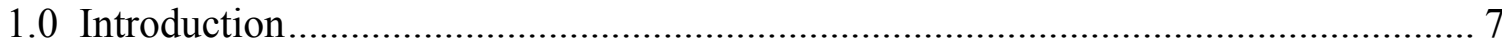

2.0 Sampling and Sample Preparation for Characterization ............................................ 7

2.1 Leaching Characterization of Tank 18F Wet Solid ................................................. 8

2.2 Floor Scrape Bottom Sample …………………............................................... 9

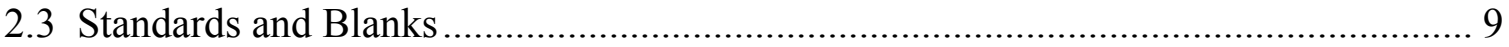

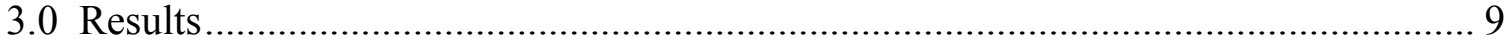

3.1 Tank 18F Wet Solid Fraction Analytical Results-North Hemisphere ....................... 14

3.2 Tank 18F Solid Fraction Analytical Results-South Hemisphere............................... 18

3.3 Tank 18F Liquid Fraction-North and South Hemispheres ………........................... 22

3.4 Tank 18F Scrape Bottom Floor Sample...………….............................................. 27

3.5 Wet Cake Sample Homogeneity for Tank 18F ………........................................ 27

3.6 Blank Evaluations and Detection Limits ............................................................ 28

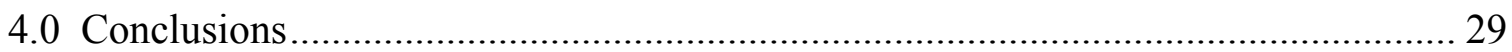

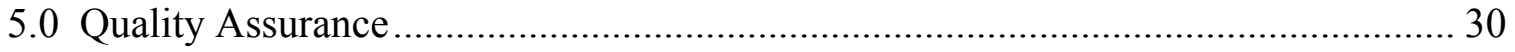

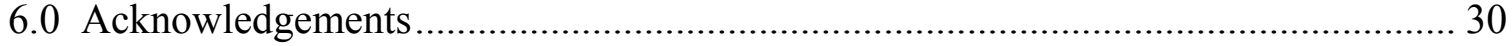

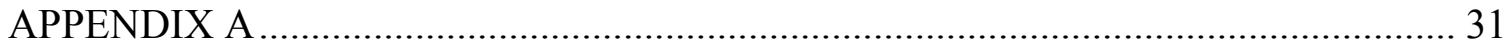

Table AP-1. Radiological Constituents Analyzed. …………......................................... 31

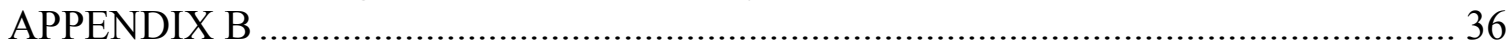

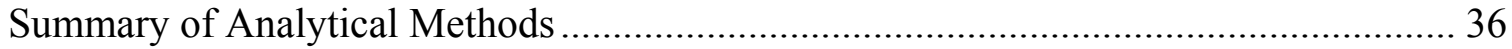

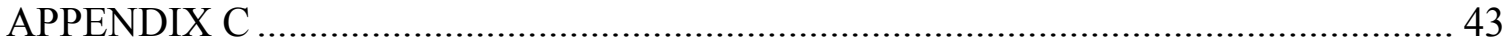




\section{LIST OF FIGURES}

Figure 1 Unsettled and settled Tank 18F composite sample slurry from the South hemisphere.

Figure 2: (A) A typical wet solid fraction in a centrifuge tube from Tank 18F North Hemisphere sample, and (B) Tank 18F North and South Hemisphere sample filtrates (liquid fraction).

Figure 3: Insert (A) shows a picture of undigested Tank 18F South Hemisphere sample solids found at the bottom of a volumetric flask (undigested components are black solids) and insert (B) is a Tank 18F floor scrape bottom sample inside a PMP bottle container.

Figure 4. XRD spectra of black solids observed in AQR digestions for Tank 18 South (insert A) and North (insert B) Hemisphere dry solid samples.

\section{LIST OF TABLES}

Table 1. Tank 18F North and South Hemisphere Slurry, Wet Cake and Floor Scrape Sample Characteristics.

Table 2. Radiological Constituents Analyzed in Six Replicates for Tank 18F North Hemisphere Solid Fraction (Analyses on a wet solids basis).

Table 3. Tank 18F North Hemisphere Combined Peroxide Fusion (PF) and Aqua Regia (AQR) Digestion Data for Solid Fractions (Analyses on a dried solids basis)..................................15

Table 4. Constituents Analyzed in Triplicate from Tank 18F North Hemisphere Solid Fraction (Analyses on a dried solids basis).

Table 5. Elemental Constituents from Tank 18F North Hemisphere Combined Peroxide Fusion and Aqua Regia Digestion Data for Solid Fraction (Analyses on a dried solids basis).........16

Table 6. Amount of non-Radiological Constituents Leached per gram of Tank 18F North Hemisphere wet solid fraction. -Analysis in Triplicate...

Table 7. Radiological Constituents Analyzed in Six Replicates for Tank 18F South Hemisphere Solid Fraction (Analyses on a wet solids basis).

Table 8. Tank 18F South Hemisphere Combined Peroxide Fusion (PF) and Aqua Regia (AQR) Digestion Data for Solid Fractions (Analyses on a dried solids basis).

Table 9. Constituents Analyzed in Triplicate from Tank 18F South Hemisphere Solid Fraction (Analyses on a dried solids basis).

Table 10. Elemental Constituents from Tank 18F South Hemisphere Combined Peroxide Fusion and Aqua Regia Digestions of Solid Fractions (Analyses on a dried solids basis)................20

Table 11. Amount of non-Radiological Constituents Leached per gram of Tank 18F South Hemisphere wet solid fraction. -Analysis in Triplicate.

Table 12. Elemental Constituents from Tank 18F North and South Hemisphere Liquid FractionsSingle Analysis.

Table 13. Chemical Constituents from Tank 18F North and South Hemisphere Liquid FractionSingle Analysis.

Table 14. Radiological Constituents from Tank 18F North and South Hemisphere Liquid Fraction-Single Analysis.

Table 14 (continued) Radiological Constituents from Tank 18F North and South Hemisphere Liquid Fraction-Single Analysis. 
Table 15 Analytical Result for Tank 18F Floor Scrape Bottom Sample Solids (Analyses on a dried solids basis).

Table 16. Selected Plutonium Analyses Results for Tank 18F North Hemisphere .28

Table 17 Selected Plutonium Analyses Results for Tank 18F South Hemisphere .28

\section{SUMMARY}

The Savannah River National Laboratory (SRNL) was asked by Liquid Waste Operations to characterize Tank $18 \mathrm{~F}$ closure samples. Tank $18 \mathrm{~F}$ slurry samples analyzed included the liquid and solid fractions derived from the "as-received" slurry materials along with the floor scrape bottom Tank $18 \mathrm{~F}$ wet solids. These samples were taken from Tank $18 \mathrm{~F}$ in March 2009 and made available to SRNL in the same month. Because of limited amounts of solids observed in Tank 18F samples, the samples from the north quadrants of the tank were combined into one North Tank $18 \mathrm{~F}$ Hemisphere sample and similarly the south quadrant samples were combined into one South Tank 18F Hemisphere sample. These samples were delivered to the SRNL shielded cell.

The Tank 18F samples were analyzed for radiological, chemical and elemental components. Where analytical methods yielded additional contaminants other than those requested by the customer, these results were also reported. The target detection limits for isotopes analyzed were $1 \mathrm{E}-04 \mu \mathrm{Ci} / \mathrm{g}$ for most radionuclides and customer desired detection values of $1 \mathrm{E}-05 \mu \mathrm{Ci} / \mathrm{g}$ for I-129, Pa-231, Np-237, and Ra-226. While many of the minimum detection limits, as specified in the technical task request and task technical and quality assurance plans were met for the species characterized for Tank 18F, some were not met due to spectral interferences. In a number of cases, the relatively high levels of radioactive species of the same element or a chemically similar element precluded the ability to measure some isotopes to low levels. SRNL, in conjunction with the plant customer, reviewed all these cases and determined that the impacts were negligible. 


\subsection{Introduction}

The composite Tank 18F samples were analyzed in accordance with Technical Task Request number HLE-TTR-2008-066, Task Technical Quality Assurance and Characterization Plan for Tanks 18F and 19F Solid Fraction Analysis - TTP/QA SRNLRP-2008-01202, Rev. 2 and waste determination sample plan -LWO-LWE-2008-00392.

SRNL began receiving Tank 18F quadrant samples in March of 2009. Each Tank 18F quadrant sample was contained in a polymer-coated $125-\mathrm{mL}$ capacity glass container. The estimated volume of each quadrant slurry sample was about $100 \mathrm{~mL}$. Because of the limited amount of solids contained in each Tank $18 \mathrm{~F}$ quadrant sample, selected samples from the north quadrants of the tank were combined into one Tank 18F North hemisphere sample and similarly a selected South quadrant samples were combined into one Tank 18F South hemisphere sample, as shown in Figure 1 and Appendix A (Table Ap-5). Tank 18F floor scrape samples were later on sent to SRNL for select radionuclide characterization as well.

\subsection{Sampling and Sample Preparation for Characterization}

The preparations and analytical approach were to hold all the Tank $18 \mathrm{~F}$ quadrant samples until all the samples were received in the SRNL shielded cells facility. The samples were then batched together for consistency before proceeding to prepare samples in the shielded cells for characterization and analysis. Several $125-\mathrm{mL}$ capacity quadrant slurry samples from Tank $18 \mathrm{~F}$ were combined in a 2-Liter graduated poly-bottle (Figure 1) to ensure a minimum of 30 grams of solids fraction from each tank hemisphere. After combining the selected slurries, the remaining $125-\mathrm{mL}$ capacity quadrant slurry containers were archived and some retained for contingency analysis purposes. Analyses were provided by Analytical Development (AD) of SRNL.

Because of the inherent risk of cross-contamination of these samples in the shielded cells environment, certain actions where taken to minimize the risks. Actions taken to control cross-contaminations in the cell included wiping down the cell (cell decontaminated), covering the cell floor, and changing manipulator fingers prior to initiating work.

Prior to initiating liquid/solid separation of composite samples, contained in the 2-liter poly-bottle, the mixture was mechanically agitated to ensure effective blending and uniform distribution of the slurry particles within the container. Separation of the composite tank slurries into liquid and solid fractions was attained by centrifuging $45 \mathrm{~mL}$ portions of the Tank $18 \mathrm{~F}$ composite slurry from each hemisphere in $50 \mathrm{~mL}$ capacity polypropylene centrifuge tubes for a total of 15 minutes. At the end of each centrifuge cycle, the fairly clear supernatant liqueurs from the centrifuge tubes were decanted into a common transparent poly-methyl pentane (PMP) container. The weight of the wet solid fraction from each $50-\mathrm{mL}$ capacity centrifuge tube was determined by difference. The resulting combined supernatant liqueur fraction was filtered through 0.45 micron nylon filter membranes. The filtrate was capped and saved for further characterization (Figure 2, insert B). 
There were two main approaches to processing and characterizing the resulting solid fractions from both the North and South composite Tank 18F samples. The lower whole body dose of both the liquid fraction (filtrates) and the wet cakes from both North and South hemispheres provided an opportunity to submit samples directly to the AD radiochemistry laboratories. This made it possible to perform direct digestions and analyses for selected analytes outside the shielded cells to minimize cross contamination. In this case, substantially fewer digestions in the shielded cells were necessary to meet the desired detection limits specified by the customer. These samples were prepared as six replicates per hemisphere. Some radiochemical analyses were traced from the digestion steps through the instrumental analyses with a radio-isotopic tracer or with the analyte's stable elemental carrier. Each preparation batch included a zeolite preparation blank or other type of laboratory blank. Digestion methodologies for the solid fractions ranged from HF/Aqua-Regia wet-ashing for the various actinides and a number of nonvolatile beta species to dilute acid leaching for tritium. In cases where analyte activities exceed levels that the method tracers could measure, analyses were run on small aliquots of the dissolutions conducted for those spectroscopy methods. Where sample activities met specified requirements, gamma analyses were conducted directly on small aliquots of the "as-received" and un-dissolved sample. Analysis of volatile species, such as C-14 and $\mathrm{I}-129$, were performed using current $\mathrm{AD}$ methodology for those samples and involved working directly with the solid samples. Elemental concentrations were determined by digestion of each consolidated hemisphere sample by peroxide fusion (PF) and aqua regia $(\mathrm{AQR})$ or other acid digestions in triplicate. An additional set of $\mathrm{PF}$ digestions, performed in triplicate, were also done to determine the $\mathrm{Np}-237$ concentration by ICP-MS. The results from both types of digestions were based on total dried solids in the sample.

The combined liquid fraction resulting from solid/liquid separations of the Tanks $18 \mathrm{~F}$ consolidated hemisphere samples was sent to $\mathrm{AD}$ for analyses for radionuclides and nonradionuclides. Analytical methods employed in the characterization of the Tank $18 \mathrm{~F}$ samples are summarized in Appendix B.

\subsection{Leaching Characterization of Tank 18F Wet Solid}

Known amounts of wet solid fraction obtained by centrifuging of the composite Tank 18F quadrant samples, were leached with distilled and de-ionized water in triplicate.

For the South hemisphere Tank 18F sample, an average of $1.86 \pm 0.20$ grams of the wet solid fraction was leached with an average of $50.01 \pm 0.01$ grams of distilled and deionized water leading to an average dilution factor of $38.63 \pm 3.82$ (density of wet solid fraction at $1.39 \mathrm{~g} / \mathrm{mL}$ ). Similarly, for the North hemisphere Tank $18 \mathrm{~F}$ sample, $1.82 \pm$ 0.14 grams of wet solid fraction was leached with an average of $50.01 \pm 0.01$ grams of distilled and de-ionized water leading to an average dilution factor of $39.28 \pm 2.77$. In this process each solid fraction or wet cake was thoroughly mixed with the given amount of distilled and de-ionized water and the mixture was hand agitated (shielded cell manipulator) for a total of about five minutes and left to stand for another 24 hours before another agitation and filtering of the mixture. The filtrate from the mixture was analyzed in triplicate for radionuclide and non-radionuclide contaminants as required. 
Thus, only surface bound and water soluble contaminants are assumed to be accounted for in the resulting leachate analyses.

\subsection{Floor Scrape Bottom Sample}

Scrape bottom sample, taken from the NE riser in tank 18F as shown in Figure $3 \mathrm{~B}$ along with appropriate blanks, was digested by peroxide fusion in triplicate and analyzed for radioisotopes (plutonium and uranium isotopes and Americium-241). As requested by the customer, the analyte list was considerably smaller than the full suite of analyses performed on the slurry. As shown in Table 15, the limited floor sample analysis was mainly performed for comparison.

\subsection{Standards and Blanks}

Two types of standards were used during characterization of Tank 18F material. The first standard material was simply a zeolite ion exchange material (IE-95 from UOP) which was not exposed to any radionuclide containing environment. The second was IE-95 zeolite material which was exposed to the shielded cell radiation environment in which the Tank18F radionuclide material was processed prior to analysis.

Prior to the processing of the Tank 18F samples, which normally involved the opening of selected quadrant samples to be blended together, four in-cell reference zeolite IE-95 samples in $250-\mathrm{mL}$ capacity poly-bottles were placed at strategic locations in the shielded cell. Each zeolite reference sample container consisted of $5.00 \pm 0.01$ grams of zeolite IE-95 in $50.00 \pm 0.01$ grams of distilled water. The containers were opened when the Tank 18 samples were being processed and closed at the end of each day of work in the cell. At the end of each hemisphere sample preparation, the wet solid zeolites standards were dissolved using each of the two dissolution methods (aqua regia and peroxide fusion digestions) and these were prepared and run along with each set of hemisphere sample. The liquid portion from the zeolite-in-water mixture was also analyzed. Laboratory generated blanks were also prepared using each dissolution method. The standards and blanks were submitted for the same analyses as the actual samples from Tank $18 \mathrm{~F}$.

\subsection{Results}

In the result tables below, values preceded by " $<$ " (less than sign) indicate values were below detection limits and values preceded by " $\leq$ " (less than or equal to sign) indicate that for replicate, at least one of the analysis values was above the instrument or method detection limit. Thus, where replicate analyses were both above and below the detection limit, the average of all replicates above and below the detection limit is given and a $\leq$ sign precedes the average value. The standard deviation values were calculated for values that were above the detection limits or where replicate analyses showed values both above and below the detection limit.

With the exception of wet solid fraction leaching analyses results and values reported in Tables 2 and 7 for the radionuclides, the reporting units for all other radionuclides including PF and AQR digestion analytical results are presented per gram of dry solid fraction. Values for leaching analyses and those reported in Tables 2 and 7 are presented on wet solids basis. The conversion factor, if required (dry wet basis to wet basis), can be accomplished through the use of the dry solid weight percent (wt.\%) values 67.39 \pm 9.90 , 
$70.54 \pm 10.55$ and $79.26 \pm 2.24$ for the North hemisphere, South hemisphere and floor scrape sample solids, respectively. For example, $\mu \mathrm{Ci} / \mathrm{g}$ dried solids*70.54 $\mathrm{g}$ of dried solids $/ 100 \mathrm{~g}$ of wet solids gives units of $\mu \mathrm{Ci} / \mathrm{g}$ wet solids. Similarly, all wet solid fraction analysis results may be converted to slurry basis, if so required, by using the slurry weight percent solids data for the North and South hemisphere samples presented in Table 1 below (For example: $\mu \mathrm{Ci} / \mathrm{g}$ dried solids* $1.95 \mathrm{~g}$ of dried solids $/ 100 \mathrm{~g}$ of slurry gives units of $\mu \mathrm{Ci} / \mathrm{g}$ slurry).

Leaching results are presented per gram of wet solid fractions. For reference and unit conversion purposes if required, the slurry weight percent solids have also been determined for Tank 18F North and South hemisphere solid wet cake. The reporting units for transition metals and other cations are in weight percent and those for the liquid fractions are reported on a "per milliliter" or "per liter" basis.

For elemental analysis, no results are given for sodium from sodium peroxide fusion digestions because this technique adds considerable amounts of sodium as a reagent. Because of the use of zirconium crucible for peroxide fusion digestion (PF), analytical results for zirconium are only reported for aqua regia digestions (AQR) and not for PF. Additionally; volatile elements such as $\mathrm{Hg}$ are reported from the sealed vessel digestions only. In most PF and $\mathrm{AQR}$ digestion cases, the average of all six determinations (three peroxide fusion digestions and three aqua regia digestions) is reported. The ICP-MS results are given for each atomic mass and, in most cases, each mass number represents only one isotope. In the case of mass number-238, both uranium and plutonium can be represented by this mass number. Hence, $\mathrm{Pu}-238$ and $\mathrm{Pu}-241$ results were measured by PuTTA to distinguish the values from uranium-238 and americium-241 values, respectively. In cases where ICP-MS and radiochemistry data give similar results for a species, radiochemistry is typically selected due to better sensitivity and uncertainty.

The total "as-received" slurry volume, liquid fraction and wet cake volumes were determined for each combined or composite hemisphere slurry sample. As shown in Table 1, the density of the composite slurry sample and solid fraction for each hemisphere was determined for each Tank $18 \mathrm{~F}$ sample. In addition to the analyses specified by the customer, additional analysis results are also provided for other radiological and non-radiological contaminants where available.

The results for radiological constituents in the solid fraction analyzed in six replicates by special preparation methods (cesium-removed gamma, I-129 methods, C-14 and Am/Cm methods) for Tank 18F North and South hemispheres, respectively, are shown in Tables 2 and 7. The combined PF and $\mathrm{AQR}$ digestion data for the North hemisphere solid fractions and those for the combined $\mathrm{PF}$ and $\mathrm{AQR}$ for the South hemisphere solid fractions are shown in Tables 3 and 8. The PF and AQR digestions for non-radionuclide constituents were performed in triplicate for each method (Tables 5 and 10). Some of the nonradionuclide components $(\mathrm{Co}, \mathrm{Ag}, \mathrm{Sn}$ and $\mathrm{Pb})$, as shown in Table 5 and 10 , are based on the ICP-Mass spectral abundance data from those digestions because direct PF and AQR data for these components were less than detection limits for these methods. A summary 
of the $\mathrm{PF}$ and $\mathrm{AQR}$ digestion results for the components $(\mathrm{Co}, \mathrm{Ag}, \mathrm{Sn}$ and $\mathrm{Pb})$ not directly reported in Tables 5 and 10 are included in Appendix AP-3 and AP-4 for reference.

Similarly, because direct PF and AQR digestion analytical results for select uranium and plutonium isotopes, including neptunium-237 did not meet the required detection limits, special separation and analytical methods were developed to obtain the specified detection limits in the technical task plan (See Appendix B). The results for these components using these special separation methods are included in Tables 3 and 8 for these components. A summary of the PF and AQR digestion analytical results for these components (uranium and plutonium isotopes and $\mathrm{Np}-237$ ), which did not meet the detection limits are also presented in Appendix AP-3 and AP-4 for reference.

Constituents analyzed in triplicate from Tank $18 \mathrm{~F}$ North and South hemisphere solid fractions (Pm-147, Sm-151, gross alpha and gross beta) are presented in Tables 4 and 9, respectively. The analyses of the liquid fractions from both the North and South hemispheres are presented in Tables 12 and 13 for the non-radiological constituents and Table 14 for the radiological constituents.

Anion leachate analyses results for the wet cakes derived from the composite North and South Tank 18F hemisphere solid fractions are presented in Tables 6 and 11, respectively.

A summary of the analyses results for Tank $18 \mathrm{~F}$ scrape bottom sample is given in Table 15 for uranium and plutonium isotopes, cesium-137, cobalt-60, neptunium-237 and americium-241. The analytical results for radionuclides like Co-60 and Cs-137, though not specifically requested by the customer, have been included because gamma scan analytical results showed that these were also present in the sample analyzed.

During some routine AQR digestions of Tank 18 South and North hemisphere dry solids, black solid material, which settled at the bottom of the digestion liquid matrix (Figure 3 insert A), was observed. Figure 4 shows the XRD characterization spectra of the black undigested residual material. The XRD pattern indicated the black material was graphite and aluminosilicate. However, all the materials could not be identified since some of the XRD patterns could not be matched to any known crystallographic pattern. 


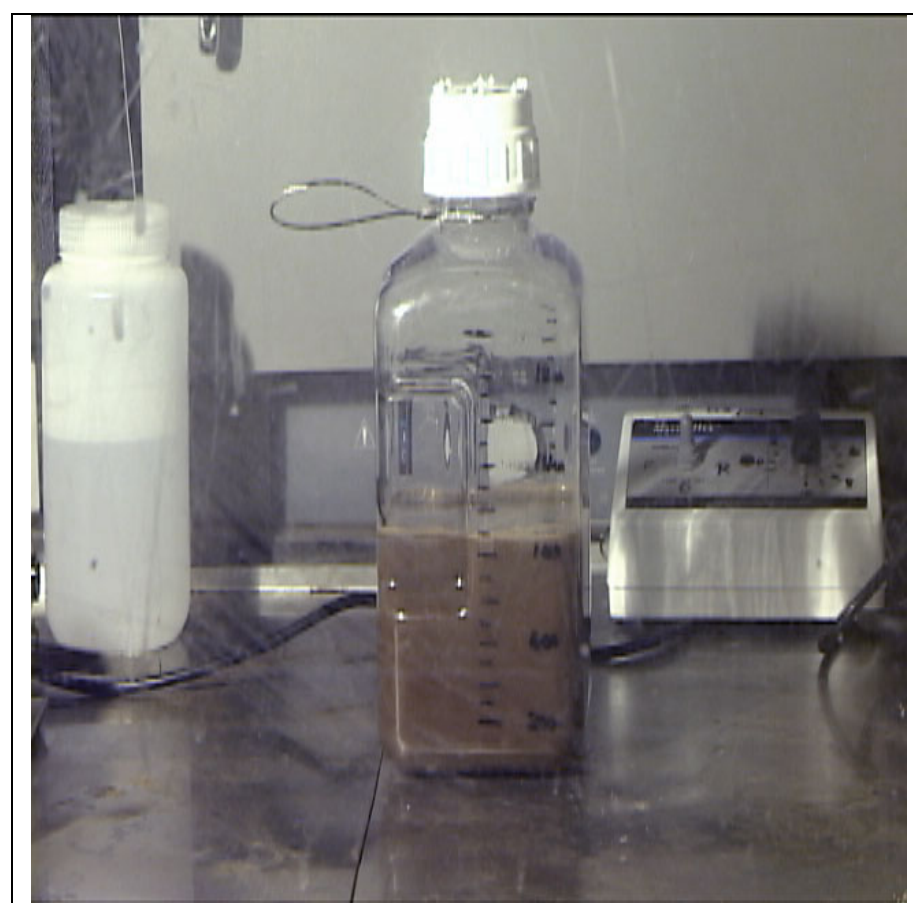

A:

Unsettled Tank 18F "as-received" composite sample slurry from the south hemisphere.

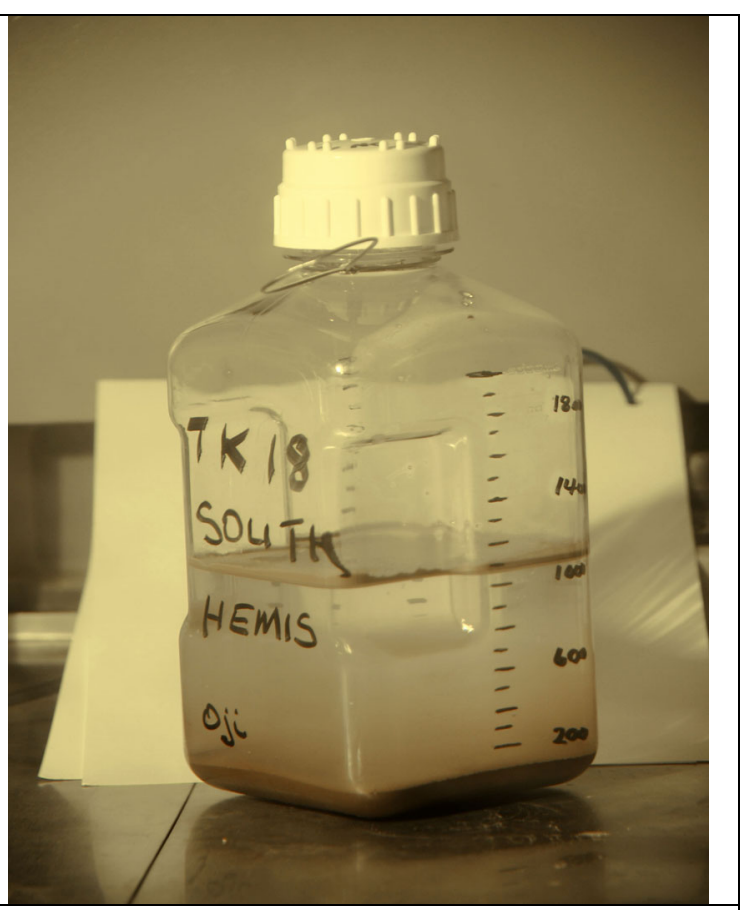

B:

Settled Tank $18 \mathrm{~F}$ "as-received" composite sample slurry from the south hemisphere.

\section{Figure 1 Unsettled and settled Tank 18F composite sample slurry from the South hemisphere.}

Table 1. Tank 18F North and South Hemisphere Slurry, Wet Cake and Floor Scrape Sample Characteristics.

\begin{tabular}{|l|c|c|c|}
\hline Parameter & North Hemisphere sample & South Hemisphere sample & Units \\
\hline Slurry weight percent solids & $1.95 \pm 0.03$ & $1.92 \pm 0.07$ & $\mathrm{Wt} \%$ \\
\hline Filtrate weight percent dissolved solids & $0.11 \pm 0.10$ & $0.08 \pm 0.07$ & $\mathrm{Wt} \%$ \\
\hline Wet cake weight percent total solids & $67.39 \pm 9.90$ & $70.54 \pm 10.55$ & $\mathrm{Wt} \%$ \\
\hline & & & \\
\hline Slurry density & $1.01 \pm 0.01$ & $1.01 \pm 0.03$ & $\mathrm{~g} / \mathrm{mL}$ \\
\hline Wet cake density & $1.39 \pm 0.01$ & $1.39 \pm 0.04$ & $\mathrm{~g} / \mathrm{mL}$ \\
\hline & & & \\
\hline Total volume of composite slurry sample & $1400 \pm 25$ & $1100 \pm 25$ & $\mathrm{~mL}$ \\
\hline Corresponding volume of settled sludge & $125 \pm 10$ & $100 \pm 10$ & $\mathrm{~mL}$ \\
\hline Liquid fraction volume & $1300 \pm 25$ & $1000 \pm 25$ & $\mathrm{~mL}$ \\
\hline
\end{tabular}




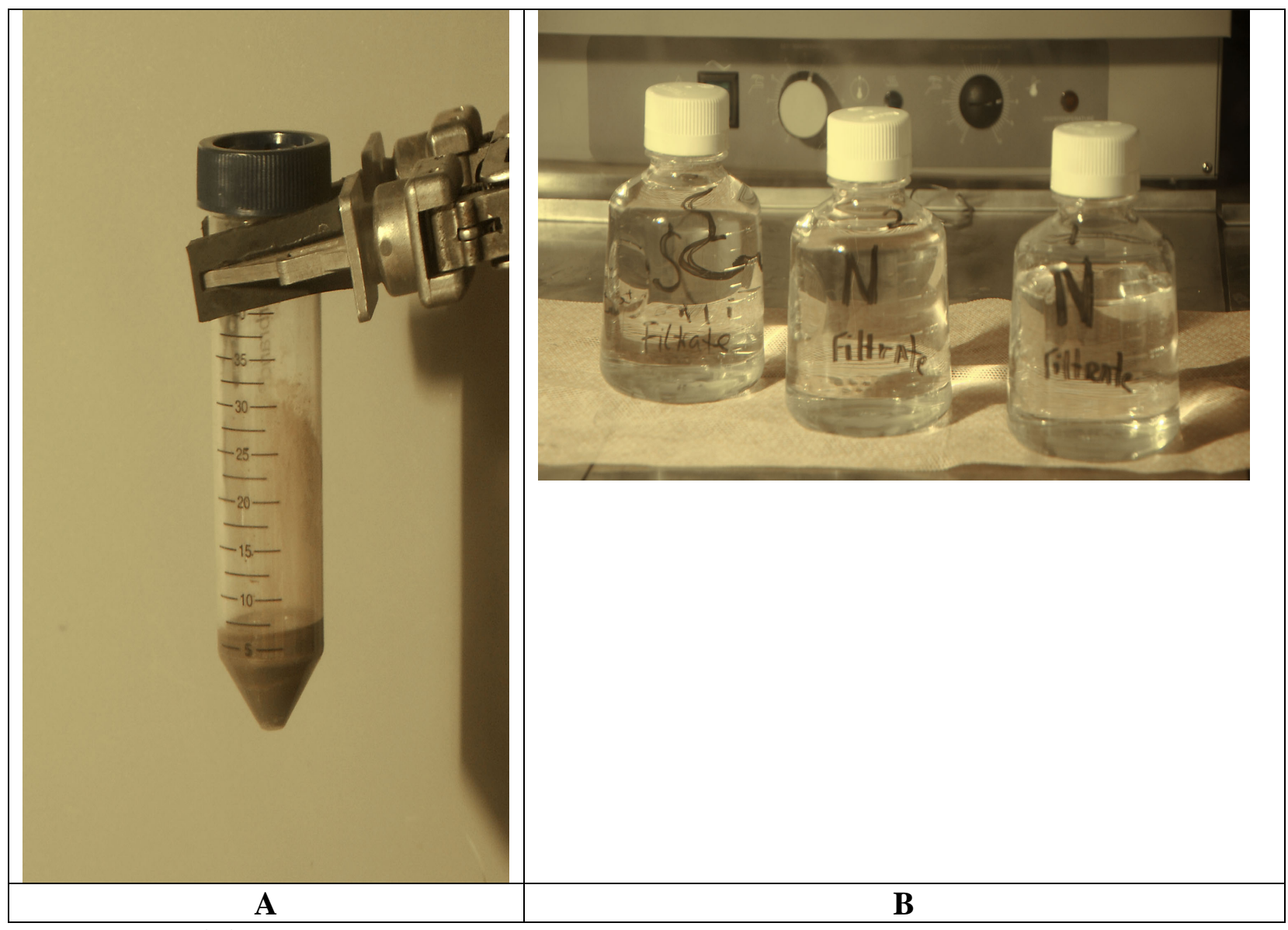

Figure 2: (A) A typical wet solid fraction in a centrifuge tube from Tank 18F North Hemisphere sample, and (B) Tank 18F North and South Hemisphere sample filtrates (liquid fraction). 


\subsection{Tank 18F Wet Solid Fraction Analytical Results-North Hemisphere}

Table 2. Radiological Constituents Analyzed in Six Replicates for Tank 18F North Hemisphere Solid Fraction (Analyses on a wet solids basis).

\begin{tabular}{|c|c|c|c|c|c|c|c|c|c|}
\hline Constituents & Run 1 & Run 2 & Run 3 & Run 4 & Run 5 & Run 6 & Average & Stdev & Units \\
\hline $\mathrm{Na}-22$ & $<5.90 \mathrm{E}-04$ & $<5.63 \mathrm{E}-04$ & $<3.86 \mathrm{E}-04$ & $<5.18 \mathrm{E}-04$ & $<6.89 \mathrm{E}-04$ & $<6.22 \mathrm{E}-04$ & $<5.61 \mathrm{E}-04$ & & $\mu \mathrm{Ci} / \mathrm{g}$ \\
\hline $\mathrm{Al}-26$ & $<7.12 \mathrm{E}-05$ & $<7.43 \mathrm{E}-05$ & $<7.43 \mathrm{E}-05$ & $<7.39 \mathrm{E}-05$ & $<1.01 \mathrm{E}-04$ & $<8.33 \mathrm{E}-05$ & $<7.97 \mathrm{E}-05$ & & $\mu \mathrm{Ci} / \mathrm{g}$ \\
\hline Co-60 & $1.73 \mathrm{E}-02$ & $1.74 \mathrm{E}-02$ & $2.02 \mathrm{E}-02$ & $1.79 \mathrm{E}-02$ & $1.89 \mathrm{E}-02$ & $2.04 \mathrm{E}-02$ & $1.87 \mathrm{E}-02$ & $1.36 E-03$ & $\mu \mathrm{Ci} / \mathrm{g}$ \\
\hline $\mathrm{Nb}-94$ & $<2.59 \mathrm{E}-04$ & $<2.50 \mathrm{E}-04$ & $<2.57 \mathrm{E}-04$ & $<2.58 \mathrm{E}-04$ & $<3.14 \mathrm{E}-04$ & $<3.04 \mathrm{E}-04$ & $<2.73 \mathrm{E}-04$ & & $\mu \mathrm{Ci} / \mathrm{g}$ \\
\hline Ru-106 & $<2.71 \mathrm{E}-03$ & $<1.60 \mathrm{E}-03$ & $<1.90 \mathrm{E}-03$ & $<2.63 \mathrm{E}-03$ & $<2.63 \mathrm{E}-03$ & $<3.03 \mathrm{E}-03$ & $<2.42 \mathrm{E}-03$ & & $\mu \mathrm{Ci} / \mathrm{g}$ \\
\hline Rh-106 & $<2.71 \mathrm{E}-03$ & $<1.60 \mathrm{E}-03$ & $<1.90 \mathrm{E}-03$ & $<2.63 \mathrm{E}-03$ & $<2.63 \mathrm{E}-03$ & $<3.03 \mathrm{E}-03$ & $<2.42 \mathrm{E}-03$ & & $\mu \mathrm{Ci} / \mathrm{g}$ \\
\hline Sb-125 & $<1.03 \mathrm{E}-03$ & $<8.92 \mathrm{E}-04$ & $<1.00 \mathrm{E}-03$ & $<9.91 \mathrm{E}-04$ & $<1.22 \mathrm{E}-03$ & $<1.15 \mathrm{E}-03$ & $<1.05 \mathrm{E}-03$ & & $\mu \mathrm{Ci} / \mathrm{g}$ \\
\hline Sb-126 & $3.29 \mathrm{E}-04$ & $3.52 \mathrm{E}-04$ & $4.05 \mathrm{E}-04$ & $3.77 \mathrm{E}-04$ & $4.23 \mathrm{E}-04$ & $3.64 \mathrm{E}-04$ & $3.75 \mathrm{E}-04$ & $3.47 E-05$ & $\mu \mathrm{Ci} / \mathrm{g}$ \\
\hline Sn-126 & $3.29 \mathrm{E}-04$ & $3.52 \mathrm{E}-04$ & $4.05 \mathrm{E}-04$ & $3.77 \mathrm{E}-04$ & $4.23 \mathrm{E}-04$ & $3.64 \mathrm{E}-04$ & $3.75 \mathrm{E}-04$ & $3.47 E-05$ & $\mu \mathrm{Ci} / \mathrm{g}$ \\
\hline Sb-126m & $3.29 \mathrm{E}-04$ & $3.52 \mathrm{E}-04$ & $4.05 \mathrm{E}-04$ & $3.77 \mathrm{E}-04$ & $4.23 \mathrm{E}-04$ & $3.64 \mathrm{E}-04$ & $3.75 \mathrm{E}-04$ & 3.47E-05 & $\mu \mathrm{Ci} / \mathrm{g}$ \\
\hline Te-125m & $<1.03 \mathrm{E}-03$ & $<8.92 \mathrm{E}-04$ & $<1.00 \mathrm{E}-03$ & $<9.91 \mathrm{E}-04$ & $<1.22 \mathrm{E}-03$ & $<1.15 \mathrm{E}-03$ & $<1.05 \mathrm{E}-03$ & & $\mu \mathrm{Ci} / \mathrm{g}$ \\
\hline Ce-144 & $<4.77 \mathrm{E}-03$ & $<3.64 \mathrm{E}-03$ & $<4.59 \mathrm{E}-03$ & $<4.55 \mathrm{E}-03$ & $<5.63 \mathrm{E}-03$ & $<5.32 \mathrm{E}-03$ & $<4.75 \mathrm{E}-03$ & & $\mu \mathrm{Ci} / \mathrm{g}$ \\
\hline Pr-144 & $<4.77 \mathrm{E}-03$ & $<3.64 \mathrm{E}-03$ & $<4.59 \mathrm{E}-03$ & $<4.55 \mathrm{E}-03$ & $<5.63 \mathrm{E}-03$ & $<5.32 \mathrm{E}-03$ & $<4.75 \mathrm{E}-03$ & & $\mu \mathrm{Ci} / \mathrm{g}$ \\
\hline Eu-152 & $<5.95 \mathrm{E}-04$ & $<5.77 \mathrm{E}-04$ & $<5.86 \mathrm{E}-04$ & $<5.90 \mathrm{E}-04$ & $<6.89 \mathrm{E}-04$ & $<7.12 \mathrm{E}-04$ & $<6.25 \mathrm{E}-04$ & & $\mu \mathrm{Ci} / \mathrm{g}$ \\
\hline Eu-154 & $1.49 \mathrm{E}-02$ & $1.36 \mathrm{E}-02$ & $1.61 \mathrm{E}-02$ & $1.46 \mathrm{E}-02$ & $1.61 \mathrm{E}-02$ & $1.65 \mathrm{E}-02$ & $1.53 \mathrm{E}-02$ & $1.10 E-03$ & $\mu \mathrm{Ci} / \mathrm{g}$ \\
\hline Eu-155 & $2.70 \mathrm{E}-03$ & $5.18 \mathrm{E}-03$ & $5.63 \mathrm{E}-03$ & $5.68 \mathrm{E}-03$ & $3.01 \mathrm{E}-03$ & $5.95 \mathrm{E}-03$ & $4.69 \mathrm{E}-03$ & $1.45 E-03$ & $\mu \mathrm{Ci} / \mathrm{g}$ \\
\hline $\mathrm{Ra}-226$ & $<7.52 \mathrm{E}-03$ & $<1.02 \mathrm{E}-02$ & $<1.12 \mathrm{E}-02$ & $<1.16 \mathrm{E}-02$ & $<1.26 \mathrm{E}-02$ & $<1.12 \mathrm{E}-02$ & $<1.07 \mathrm{E}-02$ & & $\mu \mathrm{Ci} / \mathrm{g}$ \\
\hline Ra-228 & $<8.69 \mathrm{E}-04$ & $<7.12 \mathrm{E}-04$ & $<8.33 \mathrm{E}-04$ & $<8.33 \mathrm{E}-04$ & $<1.03 \mathrm{E}-03$ & $<9.73 \mathrm{E}-04$ & $<8.75 \mathrm{E}-04$ & & $\mu \mathrm{Ci} / \mathrm{g}$ \\
\hline Ac- 227 & $<8.20 \mathrm{E}-02$ & $<6.58 \mathrm{E}-02$ & $<7.88 \mathrm{E}-02$ & $<7.84 \mathrm{E}-02$ & $<9.68 \mathrm{E}-02$ & $<9.14 \mathrm{E}-02$ & $<8.22 \mathrm{E}-02$ & & $\mu \mathrm{Ci} / \mathrm{g}$ \\
\hline Am-241 & $3.59 \mathrm{E}+00$ & $2.85 \mathrm{E}+00$ & $3.04 \mathrm{E}+00$ & $3.35 \mathrm{E}+00$ & $3.08 \mathrm{E}+00$ & $3.59 \mathrm{E}+00$ & $3.25 \mathrm{E}+00$ & 3.10E-01 & $\mu \mathrm{Ci} / \mathrm{g}$ \\
\hline $\mathrm{Am}-243$ & $2.54 \mathrm{E}-03$ & $1.90 \mathrm{E}-03$ & $2.13 \mathrm{E}-03$ & $2.34 \mathrm{E}-03$ & $1.85 \mathrm{E}-03$ & $2.08 \mathrm{E}-03$ & $2.14 \mathrm{E}-03$ & 2.62E-04 & $\mu \mathrm{Ci} / \mathrm{g}$ \\
\hline Am-242m & $9.95 \mathrm{E}-05$ & $2.66 \mathrm{E}-05$ & $4.29 \mathrm{E}-05$ & $1.33 \mathrm{E}-05$ & $1.05 \mathrm{E}-05$ & $1.39 \mathrm{E}-05$ & $3.45 \mathrm{E}-05$ & 3.41E-05 & $\mu \mathrm{Ci} / \mathrm{g}$ \\
\hline $\mathrm{Cm}-243$ & $<6.76 \mathrm{E}-04$ & $<8.15 \mathrm{E}-04$ & $<1.56 \mathrm{E}-03$ & $<7.16 \mathrm{E}-04$ & $<3.71 \mathrm{E}-03$ & $<1.80 \mathrm{E}-03$ & $<1.55 \mathrm{E}-03$ & & $\mu \mathrm{Ci} / \mathrm{g}$ \\
\hline $\mathrm{Cm}-245$ & $<2.82 \mathrm{E}-03$ & $<5.90 \mathrm{E}-04$ & $<1.31 \mathrm{E}-03$ & $<4.34 \mathrm{E}-04$ & $<8.92 \mathrm{E}-04$ & $<1.50 \mathrm{E}-03$ & $<1.26 \mathrm{E}-03$ & & $\mu \mathrm{Ci} / \mathrm{g}$ \\
\hline $\mathrm{Cm}-247$ & $<2.79 \mathrm{E}-04$ & $<1.73 \mathrm{E}-04$ & $<6.04 \mathrm{E}-04$ & $<1.34 \mathrm{E}-04$ & $<2.76 \mathrm{E}-04$ & $<6.22 \mathrm{E}-04$ & $<3.48 \mathrm{E}-04$ & & $\mu \mathrm{Ci} / \mathrm{g}$ \\
\hline Cf-249 & $<2.91 \mathrm{E}-04$ & $<1.73 \mathrm{E}-04$ & $<6.53 \mathrm{E}-04$ & $<1.37 \mathrm{E}-04$ & $<2.61 \mathrm{E}-04$ & $<6.58 \mathrm{E}-04$ & $<3.62 \mathrm{E}-04$ & & $\mu \mathrm{Ci} / \mathrm{g}$ \\
\hline Cf-251 & $<2.92 \mathrm{E}-04$ & $<1.48 \mathrm{E}-04$ & $<5.72 \mathrm{E}-04$ & $<1.25 \mathrm{E}-04$ & $<2.33 \mathrm{E}-04$ & $<6.22 \mathrm{E}-04$ & $<3.32 \mathrm{E}-04$ & & $\mu \mathrm{Ci} / \mathrm{g}$ \\
\hline Cf- 252 & $<8.24 \mathrm{E}-05$ & $<2.20 \mathrm{E}-05$ & $<3.55 \mathrm{E}-05$ & $<1.10 \mathrm{E}-05$ & $<8.69 \mathrm{E}-06$ & $<1.15 \mathrm{E}-05$ & $<2.85 \mathrm{E}-05$ & & $\mu \mathrm{Ci} / \mathrm{g}$ \\
\hline $\mathrm{Cm}-242$ & $8.24 \mathrm{E}-05$ & $2.20 \mathrm{E}-05$ & $3.55 \mathrm{E}-05$ & $1.10 \mathrm{E}-05$ & $8.69 \mathrm{E}-06$ & $1.15 \mathrm{E}-05$ & $2.85 \mathrm{E}-05$ & 2.82E-05 & $\mu \mathrm{Ci} / \mathrm{g}$ \\
\hline $\mathrm{Cm}-244$ & 1.49E-01 & 1.09E-01 & $9.73 \mathrm{E}-02$ & $1.36 \mathrm{E}-01$ & $1.26 \mathrm{E}-01$ & 1.61E-01 & $1.30 \mathrm{E}-01$ & $2.41 E-02$ & $\mu \mathrm{Ci} / \mathrm{g}$ \\
\hline $\mathrm{Cm}-248$ & $<7.25 \mathrm{E}-02$ & $<7.70 \mathrm{E}-02$ & $<1.49 \mathrm{E}-01$ & $<1.01 \mathrm{E}-01$ & $<6.85 \mathrm{E}-02$ & $<8.24 \mathrm{E}-02$ & $<9.17 \mathrm{E}-02$ & & $\mu \mathrm{Ci} / \mathrm{g}$ \\
\hline $\mathrm{H}-3$ & $<1.20 \mathrm{E}-02$ & $<9.63 \mathrm{E}-02$ & $<3.36 \mathrm{E}-01$ & $<6.19 \mathrm{E}-01$ & $<1.48 \mathrm{E}-01$ & $<1.58 \mathrm{E}-02$ & $<2.05 \mathrm{E}-01$ & & $\mu \mathrm{Ci} / \mathrm{g}$ \\
\hline $\mathrm{C}-14$ & $4.55 \mathrm{E}-03$ & $6.53 \mathrm{E}-03$ & $2.21 \mathrm{E}-03$ & $3.24 \mathrm{E}-03$ & $3.17 \mathrm{E}-03$ & $9.68 \mathrm{E}-04$ & $3.44 \mathrm{E}-03$ & $1.93 \mathrm{E}-03$ & $\mu \mathrm{Ci} / \mathrm{g}$ \\
\hline Ni-59 & $5.68 \mathrm{E}-03$ & $3.59 \mathrm{E}-03$ & $3.55 \mathrm{E}-03$ & $3.16 \mathrm{E}-03$ & $3.66 \mathrm{E}-03$ & $3.28 \mathrm{E}-03$ & $3.82 \mathrm{E}-03$ & $9.30 E-04$ & $\mu \mathrm{Ci} / \mathrm{g}$ \\
\hline Ni-63 & $4.55 \mathrm{E}-01$ & $3.56 \mathrm{E}-01$ & $4.55 \mathrm{E}-01$ & $4.08 \mathrm{E}-01$ & $4.55 \mathrm{E}-01$ & $4.27 \mathrm{E}-01$ & $4.26 \mathrm{E}-01$ & $3.94 E-02$ & $\mu \mathrm{Ci} / \mathrm{g}$ \\
\hline Se-79 & $<7.30 \mathrm{E}-02$ & $<3.42 \mathrm{E}-01$ & $<1.73 \mathrm{E}-02$ & $<1.01 \mathrm{E}-01$ & $<5.32 \mathrm{E}-03$ & $<1.06 \mathrm{E}-02$ & $<9.16 \mathrm{E}-02$ & & $\mu \mathrm{Ci} / \mathrm{g}$ \\
\hline Tc-99 & $4.42 \mathrm{E}-02$ & $3.67 \mathrm{E}-02$ & $4.05 \mathrm{E}-02$ & $5.54 \mathrm{E}-02$ & $4.64 \mathrm{E}-02$ & $3.56 \mathrm{E}-02$ & $4.31 \mathrm{E}-02$ & $7.31 E-03$ & $\mu \mathrm{Ci} / \mathrm{g}$ \\
\hline I-129 & $<2.06 \mathrm{E}-04$ & $<5.45 \mathrm{E}-05$ & $<3.91 \mathrm{E}-05$ & $<8.20 \mathrm{E}-05$ & $<1.57 \mathrm{E}-04$ & $<6.13 \mathrm{E}-05$ & $<9.99 \mathrm{E}-05$ & & $\mu \mathrm{Ci} / \mathrm{g}$ \\
\hline Th-229 & $<1.20 \mathrm{E}-05$ & $<1.77 \mathrm{E}-04$ & $<1.16 \mathrm{E}-05$ & $<1.76 \mathrm{E}-05$ & $<9.30 \mathrm{E}-06$ & $<2.04 \mathrm{E}-05$ & $<3.63 \mathrm{E}-05$ & & $\mu \mathrm{Ci} / \mathrm{g}$ \\
\hline Th-230 & $<8.82 \mathrm{E}-06$ & $<6.82 \mathrm{E}-05$ & $<7.32 \mathrm{E}-06$ & $<1.63 \mathrm{E}-05$ & $<1.12 \mathrm{E}-05$ & $<1.66 \mathrm{E}-05$ & $<1.91 \mathrm{E}-05$ & & $\mu \mathrm{Ci} / \mathrm{g}$ \\
\hline Pa-231 & $<8.13 \mathrm{E}-04$ & $<1.41 \mathrm{E}-03$ & $<7.87 \mathrm{E}-04$ & $<8.24 \mathrm{E}-04$ & $<1.09 \mathrm{E}-03$ & $<9.08 \mathrm{E}-04$ & $<9.72 \mathrm{E}-04$ & & $\mu \mathrm{Ci} / \mathrm{g}$ \\
\hline
\end{tabular}


Table 3. Tank 18F North Hemisphere Combined Peroxide Fusion (PF) and Aqua Regia (AQR) Digestion Data for Solid Fractions (Analyses on a dried solids basis).

\begin{tabular}{|c|c|c|c|c|c|c|c|c|c|}
\hline Constituents & PF1 & PF2 & PF3 & AQR1 & AQR2 & AQR3 & Average & Stdev & Units \\
\hline Th-232 & $<1.64 \mathrm{E}-05$ & $<1.69 \mathrm{E}-05$ & $<1.32 \mathrm{E}-05$ & $<1.96 \mathrm{E}-06$ & $<2.50 \mathrm{E}-06$ & $<2.49 \mathrm{E}-06$ & $<8.90 \mathrm{E}-06$ & & $\mu \mathrm{Ci} / \mathrm{g}$ \\
\hline $\mathrm{U}-232$ & $5.45 \mathrm{E}-05$ & $3.58 \mathrm{E}-05$ & $4.59 \mathrm{E}-05$ & $4.07 \mathrm{E}-05$ & $4.07 \mathrm{E}-05$ & $3.12 \mathrm{E}-05$ & $4.15 \mathrm{E}-05$ & $8.11 E-06$ & $\mu \mathrm{Ci} / \mathrm{g}$ \\
\hline U-233 & $7.67 \mathrm{E}-04$ & 7.02E-04 & $3.21 \mathrm{E}-04$ & $3.36 \mathrm{E}-04$ & $2.38 \mathrm{E}-04$ & $3.14 \mathrm{E}-04$ & $4.46 \mathrm{E}-04$ & $2.27 E-04$ & $\mu \mathrm{Ci} / \mathrm{g}$ \\
\hline U-234 & $5.80 \mathrm{E}-03$ & $6.62 \mathrm{E}-03$ & $2.91 \mathrm{E}-03$ & $2.54 \mathrm{E}-03$ & $2.25 \mathrm{E}-03$ & $2.84 \mathrm{E}-03$ & $3.83 \mathrm{E}-03$ & $1.88 E-03$ & $\mu \mathrm{Ci} / \mathrm{g}$ \\
\hline U-235 & $2.52 \mathrm{E}-04$ & $2.86 \mathrm{E}-04$ & $1.27 \mathrm{E}-04$ & $1.10 \mathrm{E}-04$ & $9.69 \mathrm{E}-05$ & $1.23 \mathrm{E}-04$ & $1.66 \mathrm{E}-04$ & $8.12 E-05$ & $\mu \mathrm{Ci} / \mathrm{g}$ \\
\hline U-236 & $2.02 \mathrm{E}-04$ & $2.30 \mathrm{E}-04$ & $1.01 \mathrm{E}-04$ & $<3.84 \mathrm{E}-04$ & $<4.90 \mathrm{E}-04$ & $<4.88 \mathrm{E}-04$ & $\leq 3.16 \mathrm{E}-04$ & $1.62 E-04$ & $\mu \mathrm{Ci} / \mathrm{g}$ \\
\hline Np-237 & $5.87 \mathrm{E}-03$ & 7.53E-03 & $5.95 \mathrm{E}-03$ & $5.09 \mathrm{E}-03$ & $8.91 \mathrm{E}-03$ & $8.08 \mathrm{E}-03$ & $6.91 \mathrm{E}-03$ & $1.49 E-03$ & $\mu \mathrm{Ci} / \mathrm{g}$ \\
\hline $\mathrm{U}-238$ & $6.85 \mathrm{E}-03$ & 7.52E-03 & $3.60 \mathrm{E}-03$ & $2.75 \mathrm{E}-03$ & $2.51 \mathrm{E}-03$ & $2.88 \mathrm{E}-03$ & $4.35 \mathrm{E}-03$ & $2.23 E-03$ & $\mu \mathrm{Ci} / \mathrm{g}$ \\
\hline $\mathrm{Pu}-239$ & $5.03 \mathrm{E}+00$ & $7.29 \mathrm{E}+00$ & $5.14 \mathrm{E}+00$ & $4.48 \mathrm{E}+00$ & $9.77 \mathrm{E}+00$ & $7.88 \mathrm{E}+00$ & $6.60 \mathrm{E}+00$ & $2.06 E+00$ & $\mu \mathrm{Ci} / \mathrm{g}$ \\
\hline $\mathrm{Pu}-242$ & $6.49 \mathrm{E}-04$ & 7.77E-04 & $3.59 \mathrm{E}-04$ & $3.11 \mathrm{E}-04$ & $3.26 \mathrm{E}-04$ & $3.66 \mathrm{E}-04$ & $4.65 \mathrm{E}-04$ & $1.98 E-04$ & $\mu \mathrm{Ci} / \mathrm{g}$ \\
\hline $\mathrm{Pu}-244$ & $<1.57 \mathrm{E}-06$ & $<1.28 \mathrm{E}-06$ & $<1.13 \mathrm{E}-06$ & $<7.51 \mathrm{E}-07$ & $<5.35 \mathrm{E}-07$ & $<1.15 \mathrm{E}-06$ & $<1.07 \mathrm{E}-06$ & & $\mu \mathrm{Ci} / \mathrm{g}$ \\
\hline $\mathrm{Pu}-241$ & $9.37 \mathrm{E}+00$ & $1.06 \mathrm{E}+01$ & $4.82 \mathrm{E}+00$ & NA & NA & NA & $8.27 \mathrm{E}+00$ & $3.06 E+00$ & $\mu \mathrm{Ci} / \mathrm{g}$ \\
\hline $\mathrm{Pu}-238$ & $2.51 \mathrm{E}+00$ & $3.25 \mathrm{E}+00$ & $2.73 \mathrm{E}+00$ & $2.15 \mathrm{E}+00$ & $4.45 \mathrm{E}+00$ & $3.77 \mathrm{E}+00$ & $3.14 \mathrm{E}+00$ & $8.59 E-01$ & $\mu \mathrm{Ci} / \mathrm{g}$ \\
\hline $\mathrm{Pu}-239 / 240$ & $6.13 \mathrm{E}+00$ & $8.87 \mathrm{E}+00$ & $6.26 \mathrm{E}+00$ & $5.45 \mathrm{E}+00$ & $1.19 \mathrm{E}+01$ & $9.59 \mathrm{E}+00$ & $8.03 \mathrm{E}+00$ & $2.51 E+00$ & $\mu \mathrm{Ci} / \mathrm{g}$ \\
\hline $\mathrm{Pu}-240$ & $1.95 \mathrm{E}+00$ & $2.23 \mathrm{E}+00$ & $9.82 \mathrm{E}-01$ & $1.39 \mathrm{E}+00$ & $1.72 \mathrm{E}+00$ & $1.72 \mathrm{E}+00$ & $1.66 \mathrm{E}+00$ & $4.34 E-01$ & $\mu \mathrm{Ci} / \mathrm{g}$ \\
\hline Sr-90 & $3.31 \mathrm{E}+01$ & $6.67 \mathrm{E}+01$ & $4.37 \mathrm{E}+01$ & NA & NA & NA & $4.78 \mathrm{E}+01$ & $1.72 E+01$ & $\mu \mathrm{Ci} / \mathrm{g}$ \\
\hline Y-90 & $3.31 \mathrm{E}+01$ & $6.67 \mathrm{E}+01$ & $4.37 \mathrm{E}+01$ & NA & NA & NA & $4.78 \mathrm{E}+01$ & $1.72 E+01$ & $\mu \mathrm{Ci} / \mathrm{g}$ \\
\hline Cs-134 & $<6.26 \mathrm{E}-02$ & $<6.53 \mathrm{E}-02$ & $<6.22 \mathrm{E}-02$ & NA & NA & NA & $<6.34 \mathrm{E}-02$ & & $\mu \mathrm{Ci} / \mathrm{g}$ \\
\hline Cs-135 & $1.98 \mathrm{E}-03$ & $1.87 \mathrm{E}-03$ & $2.40 \mathrm{E}-03$ & $<5.67 \mathrm{E}-03$ & $<1.21 \mathrm{E}-02$ & $<6.98 \mathrm{E}-03$ & $\leq 2.63 \mathrm{E}-03$ & $1.75 E-03$ & $\mu \mathrm{Ci} / \mathrm{g}$ \\
\hline Cs-137 & $4.11 \mathrm{E}+02$ & $3.16 \mathrm{E}+02$ & $3.29 \mathrm{E}+02$ & NA & NA & NA & $3.52 \mathrm{E}+02$ & $5.16 E+01$ & $\mu \mathrm{Ci} / \mathrm{g}$ \\
\hline Ba-137m & $3.89 \mathrm{E}+02$ & $2.99 \mathrm{E}+02$ & $3.11 \mathrm{E}+02$ & NA & NA & NA & $3.33 \mathrm{E}+02$ & $4.89 E+01$ & $\mu \mathrm{Ci} / \mathrm{g}$ \\
\hline
\end{tabular}

- $\quad$ NA, Not Applicable means that analysis was not performed or not valid because of the nature of that method.

Table 4. Constituents Analyzed in Triplicate from Tank 18F North Hemisphere Solid Fraction (Analyses on a dried solids basis).

\begin{tabular}{|c|c|c|c|c|c|c|}
\hline Constituent & Run 1 & Run 2 & Run 3 & Average & Stdev & Unit \\
\hline Pm-147\# & $<4.39 \mathrm{E}-01$ & $<4.37 \mathrm{E}-01$ & $<3.83 \mathrm{E}-01$ & $<4.20 \mathrm{E}-01$ & & $\mu \mathrm{Ci} / \mathrm{g}$ \\
\hline Sm-151 & $2.89 \mathrm{E}+00$ & $2.62 \mathrm{E}+00$ & $2.34 \mathrm{E}+00$ & $2.62 \mathrm{E}+00$ & $2.73 \mathrm{E}-01$ & $\mu \mathrm{Ci} / \mathrm{g}$ \\
\hline Gross alpha & $<3.25 \mathrm{E}+07$ & $<3.97 \mathrm{E}+07$ & $<3.84 \mathrm{E}+07$ & $<3.69 \mathrm{E}+07$ & & $\mathrm{dpm} / \mathrm{g}$ \\
\hline Gross beta & $2.59 \mathrm{E}+09$ & $2.19 \mathrm{E}+09$ & $2.44 \mathrm{E}+09$ & $2.41 \mathrm{E}+09$ & $1.65 \mathrm{E}+08$ & $\mathrm{dpm} / \mathrm{g}$ \\
\hline
\end{tabular}

\# Detection limits for Pm-147 were limited by high activities of Sm-151 in the sample. 
Table 5. Elemental Constituents from Tank 18F North Hemisphere Combined Peroxide Fusion and Aqua Regia Digestion Data for Solid Fraction (Analyses on a dried solids basis).

\begin{tabular}{|c|c|c|c|c|c|c|c|c|c|}
\hline Analytes & PF1 & PF2 & PF3 & AQR1 & AQR2 & AQR3 & Average & Std. Dev & Units \\
\hline $\mathrm{Ag}$ & $5.72 \mathrm{E}-02$ & $5.16 \mathrm{E}-02$ & $5.23 \mathrm{E}-02$ & $1.63 \mathrm{E}-02$ & $9.99 \mathrm{E}-02$ & $6.79 \mathrm{E}-02$ & $5.75 E-02$ & $2.71 E-02$ & $\mathrm{Wt} \%$ \\
\hline $\mathrm{Al}$ & $1.48 \mathrm{E}+01$ & $1.57 \mathrm{E}+01$ & $8.90 \mathrm{E}+00$ & $1.06 \mathrm{E}+01$ & $1.77 \mathrm{E}+01$ & $1.45 \mathrm{E}+01$ & $1.370 \mathrm{E}+01$ & $3.30 E+00$ & $\mathrm{Wt} \%$ \\
\hline $\mathrm{B}$ & $<5.93 \mathrm{E}-02$ & $<6.12 \mathrm{E}-02$ & $<4.78 \mathrm{E}-02$ & $<9.35 \mathrm{E}-03$ & $<1.19 \mathrm{E}-02$ & $<1.19 \mathrm{E}-02$ & $<3.36 \mathrm{E}-02$ & & $\mathrm{Wt} \%$ \\
\hline $\mathrm{Ba}$ & $2.54 \mathrm{E}-02$ & $2.89 \mathrm{E}-02$ & $1.50 \mathrm{E}-02$ & $9.88 \mathrm{E}-03$ & $2.11 \mathrm{E}-02$ & $1.51 \mathrm{E}-02$ & $1.92-02$ & $7.176 E-03$ & $\mathrm{Wt} \%$ \\
\hline $\mathrm{Be}$ & $<4.15 \mathrm{E}-03$ & $<4.28 \mathrm{E}-03$ & $<3.35 \mathrm{E}-03$ & $<1.98 \mathrm{E}-03$ & $<2.53 \mathrm{E}-03$ & $<2.51 \mathrm{E}-03$ & $<3.13 \mathrm{E}-03$ & & $\mathrm{Wt} \%$ \\
\hline $\mathrm{Ca}$ & $2.73 \mathrm{E}+00$ & $2.39 \mathrm{E}+00$ & $2.52 \mathrm{E}+00$ & $2.56 \mathrm{E}+00$ & $4.15 \mathrm{E}+00$ & $2.76 \mathrm{E}+00$ & $2.85 \mathrm{E}+00$ & $6.51 E-01$ & $\mathrm{Wt} \%$ \\
\hline $\mathrm{Co}$ & $1.87 \mathrm{E}-02$ & $1.93 \mathrm{E}-02$ & $1.51 \mathrm{E}-02$ & $9.34 \mathrm{E}-03$ & $1.18 \mathrm{E}-02$ & $1.12 \mathrm{E}-02$ & $1.42 \mathrm{E}-02$ & $4.13 E-03$ & $\mathrm{Wt} \%$ \\
\hline $\mathrm{Cd}$ & $7.96 \mathrm{E}-01$ & $7.47 \mathrm{E}-01$ & $4.52 \mathrm{E}-01$ & $6.58 \mathrm{E}-01$ & $9.65 \mathrm{E}-01$ & $8.99 \mathrm{E}-01$ & $7.53 \mathrm{E}-01$ & $1.83 E-01$ & $\mathrm{Wt} \%$ \\
\hline $\mathrm{Ce}$ & $<6.29 \mathrm{E}-02$ & $<6.49 \mathrm{E}-02$ & $<5.07 \mathrm{E}-02$ & $<1.51 \mathrm{E}-02$ & $<1.93 \mathrm{E}-02$ & $<1.92 \mathrm{E}-02$ & $<3.87 \mathrm{E}-02$ & & $\mathrm{Wt} \%$ \\
\hline $\mathrm{Cr}$ & $6.37 \mathrm{E}-02$ & $6.88 \mathrm{E}-02$ & $4.54 \mathrm{E}-02$ & $5.42 \mathrm{E}-02$ & $6.30 \mathrm{E}-02$ & $6.36 \mathrm{E}-02$ & $5.98 \mathrm{E}-02$ & $8.48 E-03$ & $\mathrm{Wt} \%$ \\
\hline $\mathrm{Cu}$ & $<4.15 \mathrm{E}-02$ & $<4.28 \mathrm{E}-02$ & $<3.34 \mathrm{E}-02$ & $<1.41 \mathrm{E}-02$ & $<1.74 \mathrm{E}-02$ & $<1.98 \mathrm{E}-02$ & $<2.82 \mathrm{E}-02$ & & $\mathrm{Wt} \%$ \\
\hline $\mathrm{Fe}$ & $8.15 \mathrm{E}+00$ & $9.44 \mathrm{E}+00$ & $3.76 \mathrm{E}+00$ & $7.28 \mathrm{E}+00$ & $6.46 \mathrm{E}+00$ & $7.09 \mathrm{E}+00$ & $7.03 \mathrm{E}+00$ & $1.91 E+00$ & $\mathrm{Wt} \%$ \\
\hline $\mathrm{Gd}$ & $<1.49 \mathrm{E}-02$ & $<1.53 \mathrm{E}-02$ & $<1.20 \mathrm{E}-02$ & $<9.90 \mathrm{E}-03$ & $<1.27 \mathrm{E}-02$ & $<1.26 \mathrm{E}-02$ & $<1.29 \mathrm{E}-02$ & & $\mathrm{Wt} \%$ \\
\hline $\mathrm{K}$ & NA & NA & NA & $<2.45 \mathrm{E}-02$ & $<3.13 \mathrm{E}-02$ & $<4.75 \mathrm{E}-02$ & $<2.70 \mathrm{E}-01$ & $2.65 E-01$ & $\mathrm{Wt} \%$ \\
\hline $\mathrm{La}$ & $<1.29 \mathrm{E}-02$ & $<1.34 \mathrm{E}-02$ & $<1.04 \mathrm{E}-02$ & $<9.90 \mathrm{E}-03$ & $<1.27 \mathrm{E}-02$ & $<1.26 \mathrm{E}-02$ & $<1.20 \mathrm{E}-02$ & & $\mathrm{Wt} \%$ \\
\hline $\mathrm{Li}$ & $<1.22 \mathrm{E}-01$ & $<1.26 \mathrm{E}-01$ & $<9.82 \mathrm{E}-02$ & $<9.90 \mathrm{E}-03$ & $<1.27 \mathrm{E}-02$ & $<1.26 \mathrm{E}-02$ & $<6.36 \mathrm{E}-02$ & & $\mathrm{Wt} \%$ \\
\hline $\mathrm{Mg}$ & $2.38 \mathrm{E}+00$ & $2.77 \mathrm{E}+00$ & $1.18 \mathrm{E}+00$ & $3.31 \mathrm{E}-01$ & $6.32 \mathrm{E}-01$ & $6.00 \mathrm{E}-01$ & $1.32 \mathrm{E}+00$ & $1.02 E+00$ & $\mathrm{Wt} \%$ \\
\hline $\mathrm{Mn}$ & $1.14 \mathrm{E}+00$ & $1.26 \mathrm{E}+00$ & $7.29 \mathrm{E}-01$ & $1.31 \mathrm{E}+00$ & $1.39 \mathrm{E}+00$ & $1.47 \mathrm{E}+00$ & $1.22 \mathrm{E}+00$ & $2.64 E-01$ & $\mathrm{Wt} \%$ \\
\hline Mo & $<3.44 \mathrm{E}-02$ & $<3.55 \mathrm{E}-02$ & $<2.77 \mathrm{E}-02$ & $<5.28 \mathrm{E}-03$ & $<6.75 \mathrm{E}-03$ & $<6.69 \mathrm{E}-03$ & $<1.94 \mathrm{E}-02$ & & $\mathrm{Wt} \%$ \\
\hline $\mathrm{Na}$ & NA & NA & NA & $3.28 \mathrm{E}+00$ & $5.80 \mathrm{E}+00$ & $4.81 \mathrm{E}+00$ & $4.63 \mathrm{E}+00$ & $1.27 E+00$ & $\mathrm{Wt} \%$ \\
\hline $\mathrm{Ni}$ & $1.13 \mathrm{E}-01$ & $1.21 \mathrm{E}-01$ & $<7.80 \mathrm{E}-02$ & $8.72 \mathrm{E}-02$ & $6.98 \mathrm{E}-02$ & $8.18 \mathrm{E}-02$ & $\leq 9.18 \mathrm{E}-02$ & $8.91 E-03$ & $\mathrm{Wt} \%$ \\
\hline $\mathrm{P}$ & $<1.40 \mathrm{E}-01$ & $<1.45 \mathrm{E}-01$ & $<1.13 \mathrm{E}-01$ & $1.25 \mathrm{E}-01$ & $1.10 \mathrm{E}-01$ & $1.24 \mathrm{E}-01$ & $\leq 1.26 \mathrm{E}-01$ & $8.39 E-03$ & $\mathrm{Wt} \%$ \\
\hline $\mathrm{Pb}$ & 7.04E-02 & $9.56 \mathrm{E}-02$ & $4.46 \mathrm{E}-02$ & $5.23 \mathrm{E}-02$ & $7.08 \mathrm{E}-02$ & $6.77 \mathrm{E}-02$ & $6.69 \mathrm{E}-02$ & $1.77 E-02$ & $\mathrm{Wt} \%$ \\
\hline $\mathrm{S}$ & $<1.74 \mathrm{E}+0$ & $<1.79 \mathrm{E}+0$ & $<1.40 \mathrm{E}+0$ & $<2.67 \mathrm{E}-01$ & $<3.41 \mathrm{E}-01$ & $<3.38 \mathrm{E}-01$ & $<9.79$ E-01 & & $\mathrm{Wt} \%$ \\
\hline $\mathrm{Sb}$ & $<8.93 \mathrm{E}-02$ & $<9.21 \mathrm{E}-02$ & $<7.20 \mathrm{E}-02$ & $<2.56 \mathrm{E}-02$ & $<3.26 \mathrm{E}-02$ & $<3.24 \mathrm{E}-02$ & $<5.73 \mathrm{E}-02$ & & $\mathrm{Wt} \%$ \\
\hline $\mathrm{Si}$ & $4.45 \mathrm{E}+00$ & $3.59 \mathrm{E}+00$ & $3.32 \mathrm{E}+00$ & NA & NA & NA & $3.79 \mathrm{E}+00$ & $5.90 E-01$ & $\mathrm{Wt} \%$ \\
\hline $\mathrm{Sn}$ & $8.00 \mathrm{E}-02$ & $6.26 \mathrm{E}-02$ & $4.83 \mathrm{E}-02$ & $7.91 \mathrm{E}-03$ & $7.30 \mathrm{E}-03$ & $6.63 \mathrm{E}-03$ & $3.55 \mathrm{E}-02$ & $3.25 E-02$ & $\mathrm{Wt} \%$ \\
\hline $\mathrm{Sr}$ & $1.65 \mathrm{E}-02$ & $1.68 \mathrm{E}-02$ & $9.98 \mathrm{E}-03$ & $7.06 \mathrm{E}-03$ & $1.16 \mathrm{E}-02$ & $8.73 \mathrm{E}-03$ & $1.18 \mathrm{E}-02$ & $4.06 E-03$ & $\mathrm{Wt} \%$ \\
\hline $\mathrm{Ti}$ & $<2.68 \mathrm{E}-03$ & $<2.76 \mathrm{E}-03$ & $<2.16 \mathrm{E}-03$ & $<1.96 \mathrm{E}-02$ & $<2.79 \mathrm{E}-02$ & $<2.3 \mathrm{E}-02$ & $<1.30 \mathrm{E}-02$ & & $\mathrm{Wt} \%$ \\
\hline $\mathrm{U}$ & $1.62 \mathrm{E}+00$ & $1.56 \mathrm{E}+00$ & $<1.04 \mathrm{E}+0$ & 9.60E-01 & $9.16 \mathrm{E}-01$ & $9.61 \mathrm{E}-01$ & $\leq 1.18 \mathrm{E}+00$ & $3.24 E-01$ & $\mathrm{Wt} \%$ \\
\hline $\mathrm{V}$ & $<7.80 \mathrm{E}-03$ & $<8.05 \mathrm{E}-03$ & $<6.29 \mathrm{E}-03$ & $<1.20 \mathrm{E}-02$ & $<1.53 \mathrm{E}-02$ & $<1.52 \mathrm{E}-02$ & $<1.08 \mathrm{E}-02$ & & $\mathrm{Wt} \%$ \\
\hline $\mathrm{Zn}$ & $1.97 \mathrm{E}-02$ & $2.20 \mathrm{E}-02$ & $<1.04 \mathrm{E}-02$ & $1.73 \mathrm{E}-02$ & $1.72 \mathrm{E}-02$ & $2.21 \mathrm{E}-02$ & $\leq 1.812 \mathrm{E}-02$ & $4.35 E-03$ & $\mathrm{Wt} \%$ \\
\hline $\mathrm{Zr}$ & NA & NA & NA & $4.470 \mathrm{E}-03$ & $4.040 \mathrm{E}-03$ & $4.940 \mathrm{E}-03$ & $4.48 \mathrm{E}-03$ & $4.50 E-04$ & $\mathrm{Wt} \%$ \\
\hline As & NA & NA & NA & $<1.09 \mathrm{E}-03$ & $<1.39 \mathrm{E}-03$ & $<1.38 \mathrm{E}-03$ & $<1.29 \mathrm{E}-03$ & & $\mathrm{Wt} \%$ \\
\hline $\mathrm{Se}$ & NA & NA & NA & $<2.17 \mathrm{E}-03$ & $<2.78 \mathrm{E}-03$ & $<2.76 \mathrm{E}-03$ & $<2.57 \mathrm{E}-03$ & & $\mathrm{Wt} \%$ \\
\hline $\mathrm{Hg}$ & NA & NA & NA & $8.56 \mathrm{E}-02$ & $1.52 \mathrm{E}-01$ & $1.51 \mathrm{E}-01$ & $1.30 \mathrm{E}-01$ & $3.81 E-02$ & $\mathrm{Wt} \%$ \\
\hline
\end{tabular}

- NA, Not Applicable means that analysis was not performed or not valid because of the nature of that method. 
Table 6. Amount of non-Radiological Constituents Leached per gram of Tank 18F North Hemisphere wet solid fraction. -Analysis in Triplicate.

\begin{tabular}{|c|c|c|c|c|c|c|}
\hline Analytes & Run-1 & Run-2 & Run-3 & Average & Std. Dev. & Unit \\
\hline $\mathrm{F}^{-1}$ & $2.56 \mathrm{E}+01$ & $2.78 \mathrm{E}+01$ & $2.89 \mathrm{E}+01$ & $2.74 \mathrm{E}+01$ & $1.66 \mathrm{E}+00$ & $\mu \mathrm{g} / \mathrm{g}$ \\
\hline $\mathrm{Cl}^{-1}$ & $6.26 \mathrm{E}+01$ & $5.55 \mathrm{E}+01$ & $6.07 \mathrm{E}+01$ & $5.96 \mathrm{E}+01$ & $3.67 \mathrm{E}+00$ & $\mu \mathrm{g} / \mathrm{g}$ \\
\hline $\mathrm{NO}_{3}^{-1}$ & $2.56 \mathrm{E}+02$ & $2.27 \mathrm{E}+02$ & $2.89 \mathrm{E}+02$ & $2.57 \mathrm{E}+02$ & $3.09 \mathrm{E}+01$ & $\mu \mathrm{g} / \mathrm{g}$ \\
\hline $\mathrm{NO}_{2}^{-1}$ & $4.27 \mathrm{E}+01$ & $3.79 \mathrm{E}+01$ & $4.33 \mathrm{E}+01$ & $4.13 \mathrm{E}+01$ & $2.99 \mathrm{E}+00$ & $\mu \mathrm{g} / \mathrm{g}$ \\
\hline $\mathrm{SO}_{4}^{-2}$ & $3.99 \mathrm{E}+01$ & $3.53 \mathrm{E}+01$ & $4.33 \mathrm{E}+01$ & $3.95 \mathrm{E}+01$ & $4.01 \mathrm{E}+00$ & $\mu \mathrm{g} / \mathrm{g}$ \\
\hline $\mathrm{C}_{2} \mathrm{O}_{4}^{-2}$ & $3.42 \mathrm{E}+01$ & $3.03 \mathrm{E}+01$ & $3.47 \mathrm{E}+01$ & $3.30 \mathrm{E}+01$ & $2.40 \mathrm{E}+00$ & $\mu \mathrm{g} / \mathrm{g}$ \\
\hline $\mathrm{CO}_{3}^{-2}$ & $3.93 \mathrm{E}+03$ & $3.43 \mathrm{E}+03$ & $3.84 \mathrm{E}+03$ & $3.74 \mathrm{E}+03$ & $2.65 \mathrm{E}+02$ & $\mu \mathrm{g} / \mathrm{g}$ \\
\hline $\mathrm{PO}_{4}^{-3}$ & $<2.85 \mathrm{E}+01$ & $<2.52 \mathrm{E}+01$ & $<2.89 \mathrm{E}+01$ & $<2.75 \mathrm{E}+01$ & - & $\mu \mathrm{g} / \mathrm{g}$ \\
\hline $\mathrm{CHO}_{2}^{-1}$ & $<2.85 \mathrm{E}+01$ & $<2.52 \mathrm{E}+01$ & $<2.89 \mathrm{E}+01$ & $<2.75 \mathrm{E}+01$ & - & $\mu \mathrm{g} / \mathrm{g}$ \\
\hline
\end{tabular}




\subsection{Tank 18F Solid Fraction Analytical Results-South Hemisphere}

Table 7. Radiological Constituents Analyzed in Six Replicates for Tank 18F South Hemisphere Solid Fraction (Analyses on a wet solids basis).

\begin{tabular}{|c|c|c|c|c|c|c|c|c|c|}
\hline Constituent & Run 1 & Run 2 & Run 3 & Run 4 & Run 5 & Run 6 & Average & Stdev & Unit \\
\hline $\mathrm{Na}-22$ & $<3.65 \mathrm{E}-04$ & $<5.36 \mathrm{E}-04$ & $<3.98 \mathrm{E}-04$ & $<4.50 \mathrm{E}-04$ & $<5.45 \mathrm{E}-04$ & $<7.03 \mathrm{E}-04$ & $<5.00 \mathrm{E}-04$ & & $\mu \mathrm{Ci} / \mathrm{g}$ \\
\hline Al-26 & $<8.33 \mathrm{E}-05$ & $<7.75 \mathrm{E}-05$ & $<7.66 \mathrm{E}-05$ & $<8.15 \mathrm{E}-05$ & $<9.05 \mathrm{E}-05$ & $<1.00 \mathrm{E}-04$ & $<8.49 \mathrm{E}-05$ & & $\mu \mathrm{Ci} / \mathrm{g}$ \\
\hline Co-60 & $1.83 \mathrm{E}-02$ & $1.86 \mathrm{E}-02$ & $1.88 \mathrm{E}-02$ & $1.68 \mathrm{E}-02$ & $1.87 \mathrm{E}-02$ & $1.43 \mathrm{E}-02$ & $1.76 \mathrm{E}-02$ & $1.78 \mathrm{E}-03$ & $\mu \mathrm{Ci} / \mathrm{g}$ \\
\hline $\mathrm{Nb}-94$ & $<2.71 \mathrm{E}-04$ & $<2.73 \mathrm{E}-04$ & $<2.89 \mathrm{E}-04$ & $<2.59 \mathrm{E}-04$ & $<2.75 \mathrm{E}-04$ & $<3.73 \mathrm{E}-04$ & $<2.90 \mathrm{E}-04$ & & $\mu \mathrm{Ci} / \mathrm{g}$ \\
\hline Ru-106 & $<2.85 \mathrm{E}-03$ & $<2.41 \mathrm{E}-03$ & $<2.85 \mathrm{E}-03$ & $<1.92 \mathrm{E}-03$ & $<2.18 \mathrm{E}-03$ & $<3.97 \mathrm{E}-03$ & $<2.70 \mathrm{E}-03$ & & $\mu \mathrm{Ci} / \mathrm{g}$ \\
\hline Rh-106 & $<2.85 \mathrm{E}-03$ & $<2.41 \mathrm{E}-03$ & $<2.85 \mathrm{E}-03$ & $<1.92 \mathrm{E}-03$ & $<2.18 \mathrm{E}-03$ & $<3.97 \mathrm{E}-03$ & $<2.70 \mathrm{E}-03$ & & $\mu \mathrm{Ci} / \mathrm{g}$ \\
\hline Sb-125 & $<1.06 \mathrm{E}-03$ & $<1.06 \mathrm{E}-03$ & $<1.10 \mathrm{E}-03$ & $<9.77 \mathrm{E}-04$ & $<1.05 \mathrm{E}-03$ & $<1.54 \mathrm{E}-03$ & $<1.13 \mathrm{E}-03$ & & $\mu \mathrm{Ci} / \mathrm{g}$ \\
\hline Sb-126 & $3.49 \mathrm{E}-04$ & $3.64 \mathrm{E}-04$ & $3.14 \mathrm{E}-04$ & $3.22 \mathrm{E}-04$ & $3.22 \mathrm{E}-04$ & $6.08 \mathrm{E}-04$ & $3.80 \mathrm{E}-04$ & 1.13E-04 & $\mu \mathrm{Ci} / \mathrm{g}$ \\
\hline Sn-126 & $3.49 \mathrm{E}-04$ & 3.64E-04 & $3.14 \mathrm{E}-04$ & $3.22 \mathrm{E}-04$ & $3.22 \mathrm{E}-04$ & $6.08 \mathrm{E}-04$ & $3.80 \mathrm{E}-04$ & 1.13E-04 & $\mu \mathrm{Ci} / \mathrm{g}$ \\
\hline $\mathrm{Sb}-126 \mathrm{~m}$ & $3.49 \mathrm{E}-04$ & 3.64E-04 & $3.14 \mathrm{E}-04$ & $3.22 \mathrm{E}-04$ & $3.22 \mathrm{E}-04$ & $6.08 \mathrm{E}-04$ & $3.80 \mathrm{E}-04$ & $1.13 E-04$ & $\mu \mathrm{Ci} / \mathrm{g}$ \\
\hline $\mathrm{Te}-125 \mathrm{~m}$ & $<1.06 \mathrm{E}-03$ & $<1.06 \mathrm{E}-03$ & $<1.10 \mathrm{E}-03$ & $<9.77 \mathrm{E}-04$ & $<1.05 \mathrm{E}-03$ & $<1.54 \mathrm{E}-03$ & $<1.13 \mathrm{E}-03$ & & $\mu \mathrm{Ci} / \mathrm{g}$ \\
\hline $\mathrm{Ce}-144$ & $<4.82 \mathrm{E}-03$ & $<4.82 \mathrm{E}-03$ & $<5.05 \mathrm{E}-03$ & $<4.47 \mathrm{E}-03$ & $<4.77 \mathrm{E}-03$ & $<7.30 \mathrm{E}-03$ & $<5.20 \mathrm{E}-03$ & & $\mu \mathrm{Ci} / \mathrm{g}$ \\
\hline Pr-144 & $<4.82 \mathrm{E}-03$ & $<4.82 \mathrm{E}-03$ & $<5.05 \mathrm{E}-03$ & $<4.47 \mathrm{E}-03$ & $<4.77 \mathrm{E}-03$ & $<7.30 \mathrm{E}-03$ & $<5.20 \mathrm{E}-03$ & & $\mu \mathrm{Ci} / \mathrm{g}$ \\
\hline Eu-152 & $<6.31 \mathrm{E}-04$ & $<6.35 \mathrm{E}-04$ & $<6.40 \mathrm{E}-04$ & $<5.90 \mathrm{E}-04$ & $<6.58 \mathrm{E}-04$ & $<7.84 \mathrm{E}-04$ & $<6.56 \mathrm{E}-04$ & & $\mu \mathrm{Ci} / \mathrm{g}$ \\
\hline Eu-154 & $1.48 \mathrm{E}-02$ & $1.41 \mathrm{E}-02$ & $1.50 \mathrm{E}-02$ & $1.25 \mathrm{E}-02$ & $1.41 \mathrm{E}-02$ & $1.72 \mathrm{E}-02$ & $1.46 \mathrm{E}-02$ & $1.55 E-03$ & $\mu \mathrm{Ci} / \mathrm{g}$ \\
\hline Eu-155 & $<6.26 \mathrm{E}-03$ & $5.36 \mathrm{E}-03$ & $5.59 \mathrm{E}-03$ & $<5.32 \mathrm{E}-03$ & $4.43 \mathrm{E}-03$ & $<3.53 \mathrm{E}-03$ & $\leq 5.08 \mathrm{E}-03$ & $9.61 E-04$ & $\mu \mathrm{Ci} / \mathrm{g}$ \\
\hline Ra-226 & $<2.66 \mathrm{E}-04$ & $<3.03 \mathrm{E}-04$ & $<1.96 \mathrm{E}-04$ & NA & NA & NA & $<2.55 \mathrm{E}-04$ & & $\mu \mathrm{Ci} / \mathrm{g}$ \\
\hline Ra-228 & $<8.83 \mathrm{E}-04$ & $<8.87 \mathrm{E}-04$ & $<9.23 \mathrm{E}-04$ & $<8.20 \mathrm{E}-04$ & $<8.74 \mathrm{E}-04$ & $<1.32 \mathrm{E}-03$ & $<9.50 \mathrm{E}-04$ & & $\mu \mathrm{Ci} / \mathrm{g}$ \\
\hline Ac- 227 & $<8.33 \mathrm{E}-02$ & $<8.33 \mathrm{E}-02$ & $<8.65 \mathrm{E}-02$ & $<7.70 \mathrm{E}-02$ & $<8.20 \mathrm{E}-02$ & $<1.05 \mathrm{E}-01$ & $<8.63 \mathrm{E}-02$ & & $\mu \mathrm{Ci} / \mathrm{g}$ \\
\hline Am-241 & $3.52 \mathrm{E}+00$ & $3.43 \mathrm{E}+00$ & $3.44 \mathrm{E}+00$ & $3.43 \mathrm{E}+00$ & $3.09 \mathrm{E}+00$ & $1.79 \mathrm{E}+00$ & $3.12 \mathrm{E}+00$ & $6.66 E-01$ & $\mu \mathrm{Ci} / \mathrm{g}$ \\
\hline Am-243 & $1.86 \mathrm{E}-03$ & $2.08 \mathrm{E}-03$ & $2.68 \mathrm{E}-03$ & $1.68 \mathrm{E}-03$ & $1.90 \mathrm{E}-03$ & $8.74 \mathrm{E}-04$ & $1.84 \mathrm{E}-03$ & $5.88 E-04$ & $\mu \mathrm{Ci} / \mathrm{g}$ \\
\hline Am-242m & $6.80 \mathrm{E}-05$ & $8.74 \mathrm{E}-05$ & $5.95 \mathrm{E}-05$ & $3.74 \mathrm{E}-05$ & $<1.12 \mathrm{E}-05$ & $6.58 \mathrm{E}-05$ & $\leq 5.49 \mathrm{E}-05$ & $2.68 E-05$ & $\mu \mathrm{Ci} / \mathrm{g}$ \\
\hline $\mathrm{Cm}-243$ & $<3.92 \mathrm{E}-04$ & $<1.20 \mathrm{E}-03$ & $<1.43 \mathrm{E}-03$ & $<5.59 \mathrm{E}-04$ & $<2.07 \mathrm{E}-03$ & $<3.47 \mathrm{E}-04$ & $<9.99 \mathrm{E}-04$ & & $\mu \mathrm{Ci} / \mathrm{g}$ \\
\hline $\mathrm{Cm}-245$ & $<5.95 \mathrm{E}-04$ & $<2.27 \mathrm{E}-04$ & $<2.83 \mathrm{E}-04$ & $<2.53 \mathrm{E}-04$ & $<2.63 \mathrm{E}-04$ & $<4.23 \mathrm{E}-04$ & $<3.40 \mathrm{E}-04$ & & $\mu \mathrm{Ci} / \mathrm{g}$ \\
\hline Cm-247 & $<2.34 \mathrm{E}-04$ & $<7.03 \mathrm{E}-05$ & $<5.50 \mathrm{E}-05$ & $<1.15 \mathrm{E}-04$ & $<9.32 \mathrm{E}-05$ & $<4.86 \mathrm{E}-05$ & $<1.03 \mathrm{E}-04$ & & $\mu \mathrm{Ci} / \mathrm{g}$ \\
\hline Cf-249 & $<2.73 \mathrm{E}-04$ & $<7.30 \mathrm{E}-05$ & $<5.27 \mathrm{E}-05$ & $<1.12 \mathrm{E}-04$ & $<1.00 \mathrm{E}-04$ & $<5.41 \mathrm{E}-05$ & $<1.11 \mathrm{E}-04$ & & $\mu \mathrm{Ci} / \mathrm{g}$ \\
\hline Cf-251 & $<1.76 \mathrm{E}-04$ & $<7.25 \mathrm{E}-05$ & $<1.43 \mathrm{E}-04$ & $<7.52 \mathrm{E}-05$ & $<1.30 \mathrm{E}-04$ & $<1.33 \mathrm{E}-04$ & $<1.22 \mathrm{E}-04$ & & $\mu \mathrm{Ci} / \mathrm{g}$ \\
\hline Cf-252 & $<5.63 \mathrm{E}-05$ & $<7.25 \mathrm{E}-05$ & $<4.91 \mathrm{E}-05$ & $<3.09 \mathrm{E}-05$ & $<9.28 \mathrm{E}-06$ & $<5.45 \mathrm{E}-05$ & $<4.54 \mathrm{E}-05$ & & $\mu \mathrm{Ci} / \mathrm{g}$ \\
\hline $\mathrm{Cm}-242$ & $5.63 \mathrm{E}-05$ & $7.25 \mathrm{E}-05$ & $4.91 \mathrm{E}-05$ & $3.09 \mathrm{E}-05$ & $<9.28 \mathrm{E}-06$ & $5.45 \mathrm{E}-05$ & $\leq 4.54 \mathrm{E}-05$ & $2.22 E-05$ & $\mu \mathrm{Ci} / \mathrm{g}$ \\
\hline Cm-244 & $1.38 \mathrm{E}-01$ & $1.32 \mathrm{E}-01$ & $1.34 \mathrm{E}-01$ & $1.30 \mathrm{E}-01$ & $1.20 \mathrm{E}-01$ & $6.67 \mathrm{E}-02$ & $1.20 \mathrm{E}-01$ & $2.69 E-02$ & $\mu \mathrm{Ci} / \mathrm{g}$ \\
\hline Cm-248 & $<5.41 \mathrm{E}-02$ & $<1.19 \mathrm{E}-01$ & $<4.46 \mathrm{E}-02$ & $<4.95 \mathrm{E}-02$ & $<4.64 \mathrm{E}-02$ & $<4.06 \mathrm{E}-02$ & $<5.91 \mathrm{E}-02$ & & $\mu \mathrm{Ci} / \mathrm{g}$ \\
\hline $\mathrm{H}-3$ & $<2.02 \mathrm{E}-03$ & $<4.27 \mathrm{E}-02$ & $<4.20 \mathrm{E}-02$ & $<3.17 \mathrm{E}-02$ & $<4.50 \mathrm{E}-02$ & $<1.00 \mathrm{E}-01$ & $<4.39 \mathrm{E}-02$ & & $\mu \mathrm{Ci} / \mathrm{g}$ \\
\hline C-14 & $1.31 \mathrm{E}-03$ & $1.70 \mathrm{E}-03$ & $1.82 \mathrm{E}-03$ & $2.14 \mathrm{E}-03$ & $1.86 \mathrm{E}-03$ & $2.25 \mathrm{E}-03$ & $1.84 \mathrm{E}-03$ & $3.34 E-04$ & $\mu \mathrm{Ci} / \mathrm{g}$ \\
\hline Ni-59 & $1.43 \mathrm{E}-02$ & $<3.62 \mathrm{E}-03$ & $6.44 \mathrm{E}-03$ & $6.80 \mathrm{E}-03$ & $3.98 \mathrm{E}-03$ & $8.83 \mathrm{E}-03$ & $\leq 7.33 \mathrm{E}-03$ & $3.91 E-03$ & $\mu \mathrm{Ci} / \mathrm{g}$ \\
\hline $\mathrm{Ni}-63$ & $9.01 \mathrm{E}-01$ & $<5.63 \mathrm{E}-01$ & $3.18 \mathrm{E}-01$ & $4.24 \mathrm{E}-01$ & $4.09 \mathrm{E}-01$ & $4.08 \mathrm{E}-01$ & $\leq 5.04 \mathrm{E}-01$ & $2.10 E-01$ & $\mu \mathrm{Ci} / \mathrm{g}$ \\
\hline Se-79 & $<4.59 \mathrm{E}-04$ & $<4.03 \mathrm{E}-04$ & $<9.28 \mathrm{E}-05$ & $<2.93 \mathrm{E}-04$ & $<1.90 \mathrm{E}-04$ & $<1.57 \mathrm{E}-04$ & $<2.66 \mathrm{E}-04$ & & $\mu \mathrm{Ci} / \mathrm{g}$ \\
\hline Tc-99 & $5.14 \mathrm{E}-02$ & $4.01 \mathrm{E}-02$ & $3.81 \mathrm{E}-02$ & $4.28 \mathrm{E}-02$ & $3.30 \mathrm{E}-02$ & $3.66 \mathrm{E}-02$ & $4.03 \mathrm{E}-02$ & $6.34 E-03$ & $\mu \mathrm{Ci} / \mathrm{g}$ \\
\hline I-129 & $<1.37 \mathrm{E}-05$ & $<8.74 \mathrm{E}-05$ & $<6.94 \mathrm{E}-05$ & $<1.87 \mathrm{E}-04$ & $<1.17 \mathrm{E}-04$ & $<8.24 \mathrm{E}-05$ & $<9.28 \mathrm{E}-05$ & & $\mu \mathrm{Ci} / \mathrm{g}$ \\
\hline Th-229 & $<1.54 \mathrm{E}-05$ & $<2.55 \mathrm{E}-05$ & $<3.92 \mathrm{E}-05$ & $<1.40 \mathrm{E}-04$ & $<4.16 \mathrm{E}-05$ & $<2.57 \mathrm{E}-05$ & $<4.27 \mathrm{E}-05$ & & $\mu \mathrm{Ci} / \mathrm{g}$ \\
\hline Th-230 & $<2.58 \mathrm{E}-05$ & $<1.50 \mathrm{E}-05$ & $<3.62 \mathrm{E}-05$ & $<6.24 \mathrm{E}-05$ & $<2.70$ E-05 & $<2.98 \mathrm{E}-05$ & $<3.02 \mathrm{E}-05$ & & $\mu \mathrm{Ci} / \mathrm{g}$ \\
\hline $\mathrm{Pa}-231$ & $<2.12 \mathrm{E}-02$ & $<4.58 \mathrm{E}-02$ & $<5.52 \mathrm{E}-02$ & NA & NA & NA & $<4.07 \mathrm{E}-02$ & & $\mu \mathrm{Ci} / \mathrm{g}$ \\
\hline
\end{tabular}


Table 8. Tank 18F South Hemisphere Combined Peroxide Fusion (PF) and Aqua Regia (AQR) Digestion Data for Solid Fractions (Analyses on a dried solids basis).

\begin{tabular}{|c|c|c|c|c|c|c|c|c|c|}
\hline Constituent & PF1 & PF2 & PF3 & AQR1 & AQR2 & AQR3 & Average & Stdev & Units \\
\hline Th-232 & $<4.36 \mathrm{E}-06$ & $<4.50 \mathrm{E}-06$ & $<4.95 \mathrm{E}-06$ & $1.04 \mathrm{E}-06$ & $1.24 \mathrm{E}-06$ & $<2.14 \mathrm{E}-06$ & $\leq 3.04 \mathrm{E}-06$ & $1.76 \mathrm{E}-06$ & $\mu \mathrm{Ci} / \mathrm{g}$ \\
\hline U-232 & $7.92 \mathrm{E}-05$ & $5.20 \mathrm{E}-05$ & $6.66 \mathrm{E}-05$ & 5.91E-05 & 5.91E-05 & $4.53 \mathrm{E}-05$ & $6.02 \mathrm{E}-05$ & $1.18 E-05$ & $\mu \mathrm{Ci} / \mathrm{g}$ \\
\hline U-233 & $9.61 \mathrm{E}-05$ & $1.13 \mathrm{E}-04$ & $9.97 \mathrm{E}-05$ & $3.91 \mathrm{E}-04$ & $4.50 \mathrm{E}-04$ & $3.89 \mathrm{E}-04$ & $2.56 \mathrm{E}-04$ & $1.70 E-04$ & $\mu \mathrm{Ci} / \mathrm{g}$ \\
\hline U-234 & $8.27 \mathrm{E}-04$ & $9.23 \mathrm{E}-04$ & $<8.26 \mathrm{E}-04$ & $3.36 \mathrm{E}-03$ & $3.69 \mathrm{E}-03$ & $3.22 \mathrm{E}-03$ & $\leq 2.14 \mathrm{E}-03$ & $1.41 E-03$ & $\mu \mathrm{Ci} / \mathrm{g}$ \\
\hline U-235 & $3.58 \mathrm{E}-05$ & $4.06 \mathrm{E}-05$ & $3.66 \mathrm{E}-05$ & $1.42 \mathrm{E}-04$ & $1.63 \mathrm{E}-04$ & $1.46 \mathrm{E}-04$ & $9.40 \mathrm{E}-05$ & $6.21 E-05$ & $\mu \mathrm{Ci} / \mathrm{g}$ \\
\hline U-236 & $3.02 \mathrm{E}-05$ & $3.28 \mathrm{E}-05$ & $2.94 \mathrm{E}-05$ & $1.23 \mathrm{E}-04$ & $1.31 \mathrm{E}-04$ & $1.15 \mathrm{E}-04$ & 7.69E-05 & $5.08 E-05$ & $\mu \mathrm{Ci} / \mathrm{g}$ \\
\hline $\mathrm{Np}-237$ & $5.58 \mathrm{E}-03$ & 4.49E-03 & $4.39 \mathrm{E}-03$ & $5.79 \mathrm{E}-03$ & $4.39 \mathrm{E}-03$ & $5.99 \mathrm{E}-03$ & $5.10 \mathrm{E}-03$ & $7.58 E-04$ & $\mu \mathrm{Ci} / \mathrm{g}$ \\
\hline U-238 & $8.56 \mathrm{E}-04$ & $9.19 \mathrm{E}-04$ & 7.07E-04 & $3.74 \mathrm{E}-03$ & $4.33 \mathrm{E}-03$ & $3.75 \mathrm{E}-03$ & $2.38 \mathrm{E}-03$ & $1.72 \mathrm{E}-03$ & $\mu \mathrm{Ci} / \mathrm{g}$ \\
\hline $\mathrm{Pu}-239$ & $9.29 \mathrm{E}+00$ & $8.48 \mathrm{E}+00$ & $8.88 \mathrm{E}+00$ & $9.47 \mathrm{E}+00$ & $1.09 \mathrm{E}+01$ & $1.12 \mathrm{E}+01$ & $9.70 \mathrm{E}+00$ & $1.11 \mathrm{E}+00$ & $\mu \mathrm{Ci} / \mathrm{g}$ \\
\hline $\mathrm{Pu}-242$ & $<4.49 \mathrm{E}-04$ & $<1.54 \mathrm{E}-04$ & $<1.60 \mathrm{E}-04$ & $<1.33 \mathrm{E}-03$ & $<4.78 \mathrm{E}-04$ & $<5.86 \mathrm{E}-04$ & $<5.26 \mathrm{E}-04$ & & $\mu \mathrm{Ci} / \mathrm{g}$ \\
\hline $\mathrm{Pu}-244$ & $<2.08 \mathrm{E}-06$ & $<3.93 \mathrm{E}-07$ & $<7.44 \mathrm{E}-07$ & $<6.16 \mathrm{E}-06$ & $<1.22 \mathrm{E}-06$ & $<2.72 \mathrm{E}-06$ & $<2.22 \mathrm{E}-06$ & & $\mu \mathrm{Ci} / \mathrm{g}$ \\
\hline $\mathrm{Pu}-241$ & $4.44 \mathrm{E}+00$ & $4.59 \mathrm{E}+00$ & $4.47 \mathrm{E}+00$ & NA & NA & NA & $4.50 \mathrm{E}+00$ & $8.09 E-02$ & $\mu \mathrm{Ci} / \mathrm{g}$ \\
\hline $\mathrm{Pu}-238$ & $3.97 \mathrm{E}+00$ & $3.53 \mathrm{E}+00$ & $4.06 \mathrm{E}+00$ & $3.88 \mathrm{E}+00$ & $4.23 \mathrm{E}+00$ & $4.68 \mathrm{E}+00$ & $4.06 \mathrm{E}+00$ & $3.84 E-01$ & $\mu \mathrm{Ci} / \mathrm{g}$ \\
\hline $\mathrm{Pu}-239 / 240$ & $1.14 \mathrm{E}+01$ & $1.04 \mathrm{E}+01$ & $1.09 \mathrm{E}+01$ & $1.16 \mathrm{E}+01$ & $1.33 \mathrm{E}+01$ & $1.37 \mathrm{E}+01$ & $1.19 \mathrm{E}+01$ & $1.35 E+00$ & $\mu \mathrm{Ci} / \mathrm{g}$ \\
\hline $\mathrm{Pu}-240$ & $8.50 \mathrm{E}-01$ & $8.80 \mathrm{E}-01$ & $8.29 \mathrm{E}-01$ & $<2.14 \mathrm{E}+0$ & $<2.62 \mathrm{E}+0$ & $<2.23 \mathrm{E}+0$ & $\leq 1.59 \mathrm{E}+00$ & $8.25 E-01$ & $\mu \mathrm{Ci} / \mathrm{g}$ \\
\hline Sr-90 & $3.81 \mathrm{E}+01$ & $4.08 \mathrm{E}+01$ & $4.47 \mathrm{E}+01$ & NA & NA & NA & $4.12 \mathrm{E}+01$ & $3.32 E+00$ & $\mu \mathrm{Ci} / \mathrm{g}$ \\
\hline $\mathrm{Y}-90$ & $3.81 \mathrm{E}+01$ & $4.08 \mathrm{E}+01$ & $4.47 \mathrm{E}+01$ & NA & NA & NA & $4.12 \mathrm{E}+01$ & $3.33 E+00$ & $\mu \mathrm{Ci} / \mathrm{g}$ \\
\hline Cs-134 & $<1.31 \mathrm{E}-01$ & $<1.52 \mathrm{E}-01$ & $<9.82 \mathrm{E}-02$ & NA & NA & NA & $<1.27 \mathrm{E}-01$ & & $\mu \mathrm{Ci} / \mathrm{g}$ \\
\hline Cs- 135 & $5.39 \mathrm{E}-03$ & $5.73 \mathrm{E}-03$ & $5.87 \mathrm{E}-03$ & NA & NA & NA & $5.66 \mathrm{E}-03$ & $2.49 E-04$ & $\mu \mathrm{Ci} / \mathrm{g}$ \\
\hline Cs-137 & $8.96 \mathrm{E}+02$ & $9.19 \mathrm{E}+02$ & $9.10 \mathrm{E}+02$ & NA & NA & NA & $9.08 \mathrm{E}+02$ & $1.13 \mathrm{E}+01$ & $\mu \mathrm{Ci} / \mathrm{g}$ \\
\hline Ba-137m & $8.49 \mathrm{E}+02$ & $8.70 \mathrm{E}+02$ & $8.62 \mathrm{E}+02$ & NA & NA & NA & $8.60 \mathrm{E}+02$ & $1.07 E+01$ & $\mu \mathrm{Ci} / \mathrm{g}$ \\
\hline
\end{tabular}

$*$ NA, Not Applicable means that analysis was not performed or not valid because of the nature of that method.

Table 9. Constituents Analyzed in Triplicate from Tank 18F South Hemisphere Solid Fraction (Analyses on a dried solids basis)

\begin{tabular}{|c|c|c|c|c|c|c|}
\hline Constituent & Run 1 & Run 2 & Run 3 & Average & Stdev & Units \\
\hline Pm-147\# & $<4.73 \mathrm{E}-01$ & $<2.47 \mathrm{E}-01$ & $<1.86 \mathrm{E}-01$ & $<3.02 \mathrm{E}-01$ & & $\mu \mathrm{Ci} / \mathrm{g}$ \\
\hline Sm-151 & $<2.14 \mathrm{E}+00$ & $1.18 \mathrm{E}+00$ & $1.11 \mathrm{E}+00$ & $\leq 1.48 \mathrm{E}+00$ & $5.71 \mathrm{E}-01$ & $\mu \mathrm{Ci} / \mathrm{g}$ \\
\hline Gross alpha & $<1.12 \mathrm{E}+08$ & $<5.07 \mathrm{E}+07$ & $<6.58 \mathrm{E}+07$ & $<7.62 \mathrm{E}+07$ & & $\mathrm{dpm} / \mathrm{g}$ \\
\hline Gross beta & $2.51 \mathrm{E}+09$ & $2.64 \mathrm{E}+09$ & $2.42 \mathrm{E}+09$ & $2.52 \mathrm{E}+09$ & $1.11 \mathrm{E}+08$ & $\mathrm{dpm} / \mathrm{g}$ \\
\hline
\end{tabular}

\# Detection limits for Pm-147 were limited by high activities of Sm-151 in the sample. 
Table 10. Elemental Constituents from Tank 18F South Hemisphere Combined Peroxide Fusion and Aqua Regia Digestions of Solid Fractions (Analyses on a dried solids basis).

\begin{tabular}{|c|c|c|c|c|c|c|c|c|c|}
\hline Analytes & PF1 & PF2 & PF3 & AQR1 & AQR2 & AQR3 & Average & Std. Dev & Units \\
\hline $\mathrm{Ag}$ & $6.95 \mathrm{E}-02$ & $9.35 \mathrm{E}-02$ & $1.28 \mathrm{E}-01$ & $1.17 \mathrm{E}-02$ & $3.95 \mathrm{E}-02$ & $1.11 \mathrm{E}-02$ & $5.88 \mathrm{E}-02$ & $4.67 E-02$ & Wt \% \\
\hline $\mathrm{Al}$ & $1.63 \mathrm{E}+01$ & $1.71 \mathrm{E}+01$ & $1.65 \mathrm{E}+01$ & $1.19 \mathrm{E}+01$ & $1.56 \mathrm{E}+01$ & $2.13 \mathrm{E}+01$ & $1.65 \mathrm{E}+01$ & $3.01 E+00$ & $\mathrm{Wt} \%$ \\
\hline B & $<4.55 \mathrm{E}-02$ & $<4.69 \mathrm{E}-02$ & $<5.20 \mathrm{E}-02$ & $<1.32 \mathrm{E}-02$ & $<1.32 \mathrm{E}-02$ & $<1.43 \mathrm{E}-02$ & $<3.09 \mathrm{E}-02$ & & $\mathrm{Wt} \%$ \\
\hline $\mathrm{Be}$ & $<3.19 \mathrm{E}-03$ & $<3.28 \mathrm{E}-03$ & $<3.64 \mathrm{E}-03$ & $<2.79 \mathrm{E}-03$ & $<2.79 \mathrm{E}-03$ & $<3.03 \mathrm{E}-03$ & $<3.12 \mathrm{E}-03$ & & Wt $\%$ \\
\hline $\mathrm{Ca}$ & $4.25 \mathrm{E}+00$ & $4.69 \mathrm{E}+00$ & $3.49 \mathrm{E}+00$ & $2.42 \mathrm{E}+00$ & $2.47 \mathrm{E}+00$ & $3.61 \mathrm{E}+00$ & $3.49 \mathrm{E}+00$ & $9.18 E-01$ & Wt $\%$ \\
\hline $\mathrm{Ce}$ & $<4.83 \mathrm{E}-02$ & $<4.98 \mathrm{E}-02$ & $<5.51 \mathrm{E}-02$ & $<2.13 \mathrm{E}-02$ & $<2.13 \mathrm{E}-02$ & $<2.31 \mathrm{E}-02$ & $<3.65 \mathrm{E}-02$ & & $\mathrm{Wt} \%$ \\
\hline $\mathrm{Cr}$ & $6.61 \mathrm{E}-02$ & $7.46 \mathrm{E}-02$ & $5.97 \mathrm{E}-02$ & $5.74 \mathrm{E}-02$ & $5.29 \mathrm{E}-02$ & $5.18 \mathrm{E}-02$ & $6.04 \mathrm{E}-02$ & $8.65 E-03$ & $\mathrm{Wt} \%$ \\
\hline $\mathrm{Cu}$ & $3.18 \mathrm{E}-02$ & $3.28 \mathrm{E}-02$ & $3.63 \mathrm{E}-02$ & $1.69 \mathrm{E}-02$ & $1.66 \mathrm{E}-02$ & $1.72 \mathrm{E}-02$ & $2.53 \mathrm{E}-02$ & $9.29 E-03$ & $\mathrm{Wt} \%$ \\
\hline $\mathrm{Fe}$ & $3.80 \mathrm{E}+00$ & $3.88 \mathrm{E}+00$ & $3.05 \mathrm{E}+00$ & $9.29 \mathrm{E}+00$ & $9.72 \mathrm{E}+00$ & $8.90 \mathrm{E}+00$ & $6.44 \mathrm{E}+00$ & $3.16 E+00$ & $\mathrm{Wt} \%$ \\
\hline $\mathrm{Gd}$ & $<1.14 \mathrm{E}-02$ & $<1.18 \mathrm{E}-02$ & $<1.30 \mathrm{E}-02$ & $<1.40 \mathrm{E}-02$ & $<1.40 \mathrm{E}-02$ & $<1.52 \mathrm{E}-02$ & $<1.32 \mathrm{E}-02$ & & Wt \% \\
\hline $\mathrm{Mn}$ & $1.19 \mathrm{E}+00$ & $1.16 \mathrm{E}+00$ & $1.11 \mathrm{E}+00$ & $1.42 \mathrm{E}+00$ & $1.60 \mathrm{E}+00$ & $1.25 \mathrm{E}+00$ & $1.29 \mathrm{E}+00$ & $1.86 E-01$ & $\mathrm{Wt} \%$ \\
\hline Mo & $<2.64 \mathrm{E}-02$ & $<2.72 \mathrm{E}-02$ & $<3.01 \mathrm{E}-02$ & $<7.44 \mathrm{E}-03$ & $<7.44 \mathrm{E}-03$ & $<8.08 \mathrm{E}-03$ & $<1.78 \mathrm{E}-02$ & & Wt $\%$ \\
\hline $\mathrm{Na}$ & NA & NA & NA & $4.34 \mathrm{E}+00$ & $3.97 \mathrm{E}+00$ & $4.68 \mathrm{E}+00$ & $4.33 \mathrm{E}+00$ & $3.55 E-01$ & Wt $\%$ \\
\hline $\mathrm{Ni}$ & $<7.43 \mathrm{E}-02$ & $<7.65 \mathrm{E}-02$ & $<8.48 \mathrm{E}-02$ & $1.09 \mathrm{E}-01$ & $1.19 \mathrm{E}-01$ & $1.06 \mathrm{E}-01$ & $\leq 9.49 \mathrm{E}-02$ & $1.88 E-02$ & $\mathrm{Wt} \%$ \\
\hline $\mathrm{P}$ & $1.08 \mathrm{E}-01$ & $1.11 \mathrm{E}-01$ & $1.23 \mathrm{E}-01$ & $1.57 \mathrm{E}-01$ & $1.60 \mathrm{E}-01$ & $1.44 \mathrm{E}-01$ & $1.34 \mathrm{E}-01$ & $2.29 E-02$ & Wt \% \\
\hline $\mathrm{Pb}$ & $3.45 \mathrm{E}-02$ & $3.50 \mathrm{E}-02$ & $2.86 \mathrm{E}-02$ & $4.81 \mathrm{E}-02$ & $4.30 \mathrm{E}-02$ & $5.12 \mathrm{E}-02$ & $4.01 \mathrm{E}-02$ & $8.76 E-03$ & $\mathrm{Wt} \%$ \\
\hline $\mathrm{S}$ & $<1.33 \mathrm{E}+00$ & $<1.37 \mathrm{E}+00$ & $<1.52 \mathrm{E}+00$ & $<1.80 \mathrm{E}-01$ & $<1.80 \mathrm{E}-01$ & $<1.96 \mathrm{E}-01$ & $<7.96 \mathrm{E}-01$ & & $\mathrm{Wt} \%$ \\
\hline $\mathrm{Sb}$ & $<6.86 \mathrm{E}-02$ & $<7.06 \mathrm{E}-02$ & $<7.82 \mathrm{E}-02$ & $<1.93 \mathrm{E}-02$ & $<1.93 \mathrm{E}-02$ & $<2.10 \mathrm{E}-02$ & $<4.62 \mathrm{E}-02$ & & Wt $\%$ \\
\hline $\mathrm{Si}$ & $9.17 \mathrm{E}+00$ & $9.10 \mathrm{E}+00$ & $9.19 \mathrm{E}+00$ & NA & NA & NA & $9.15 \mathrm{E}+00$ & $4.73 E-02$ & $\mathrm{Wt} \%$ \\
\hline $\mathrm{Sn}$ & $1.49 \mathrm{E}-02$ & $1.50 \mathrm{E}-02$ & $1.12 \mathrm{E}-02$ & $1.85 \mathrm{E}-03$ & $1.99 \mathrm{E}-03$ & $1.94 \mathrm{E}-03$ & $7.81 \mathrm{E}-03$ & $6.59 E-03$ & Wt \% \\
\hline $\mathrm{Se}$ & NA & NA & NA & $<3.07 \mathrm{E}-03$ & $<3.07 \mathrm{E}-03$ & $<3.33 \mathrm{E}-03$ & $<3.16 \mathrm{E}-03$ & & $\mathrm{Wt} \%$ \\
\hline $\mathrm{Hg}$ & NA & NA & NA & $6.01 \mathrm{E}-02$ & $2.84 \mathrm{E}-02$ & $3.05 \mathrm{E}-02$ & $3.97 \mathrm{E}-02$ & $1.77 E-02$ & $\mathrm{Wt} \%$ \\
\hline
\end{tabular}


Table 11. Amount of non-Radiological Constituents Leached per gram of Tank 18F South Hemisphere wet solid fraction. -Analysis in Triplicate.

\begin{tabular}{|c|c|c|c|c|c|c|}
\hline Analytes & Run-1 & Run-2 & Run-3 & Average & Std. Dev. & Unit \\
\hline $\mathrm{F}^{-1}$ & $3.11 \mathrm{E}+01$ & $2.89 \mathrm{E}+01$ & $3.40 \mathrm{E}+01$ & $3.13 \mathrm{E}+01$ & $2.55 \mathrm{E}+00$ & $\mu \mathrm{g} / \mathrm{g}$ \\
\hline $\mathrm{Cl}^{-1}$ & $5.98 \mathrm{E}+01$ & $6.94 \mathrm{E}+01$ & $6.80 \mathrm{E}+01$ & $6.58 \mathrm{E}+01$ & $5.22 \mathrm{E}+00$ & $\mu \mathrm{g} / \mathrm{g}$ \\
\hline $\mathrm{NO}_{3}^{-1}$ & $2.87 \mathrm{E}+02$ & $2.89 \mathrm{E}+02$ & $3.12 \mathrm{E}+02$ & $2.96 \mathrm{E}+02$ & $1.37 \mathrm{E}+01$ & $\mu \mathrm{g} / \mathrm{g}$ \\
\hline $\mathrm{NO}_{2}^{-1}$ & $4.07 \mathrm{E}+01$ & $4.63 \mathrm{E}+01$ & $4.82 \mathrm{E}+01$ & $4.50 \mathrm{E}+01$ & $3.92 \mathrm{E}+00$ & $\mu \mathrm{g} / \mathrm{g}$ \\
\hline $\mathrm{SO}_{4}^{-2}$ & $4.07 \mathrm{E}+01$ & $4.34 \mathrm{E}+01$ & $4.25 \mathrm{E}+01$ & $4.22 \mathrm{E}+01$ & $1.41 \mathrm{E}+00$ & $\mu \mathrm{g} / \mathrm{g}$ \\
\hline $\mathrm{C}_{2} \mathrm{O}_{4}^{-2}$ & $3.83 \mathrm{E}+01$ & $4.05 \mathrm{E}+01$ & $3.97 \mathrm{E}+01$ & $3.95 \mathrm{E}+01$ & $1.14 \mathrm{E}+00$ & $\mu \mathrm{g} / \mathrm{g}$ \\
\hline $\mathrm{CO}_{3}^{-2}$ & $7.34 \mathrm{E}+01$ & $7.84 \mathrm{E}+01$ & $8.16 \mathrm{E}+01$ & $7.78 \mathrm{E}+01$ & $4.14 \mathrm{E}+00$ & $\mu \mathrm{g} / \mathrm{g}$ \\
\hline $\mathrm{PO}_{4}^{-3}$ & $<2.39 \mathrm{E}+01$ & $<2.89 \mathrm{E}+01$ & $<2.83 \mathrm{E}+01$ & $<2.71 \mathrm{E}+01$ & & $\mu \mathrm{g} / \mathrm{g}$ \\
\hline $\mathrm{CHO}_{2}{ }^{-1}$ & $<2.39 \mathrm{E}+01$ & $<2.89 \mathrm{E}+01$ & $<2.83 \mathrm{E}+01$ & $<2.71 \mathrm{E}+01$ & & $\mu \mathrm{g} / \mathrm{g}$ \\
\hline
\end{tabular}




\subsection{Tank 18F Liquid Fraction-North and South Hemispheres}

Table 12. Elemental Constituents from Tank 18F North and South Hemisphere Liquid Fractions-Single Analysis.

\begin{tabular}{|c|c|c|}
\hline & North Hemisphere Sample & South Hemisphere Sample \\
\hline Constituent & Concentration, mg/L & Concentration, $\mathrm{mg} / \mathrm{L}$ \\
\hline Silver, Ag & $<1.40 \mathrm{E}+00$ & $<1.40 \mathrm{E}+00$ \\
\hline Aluminum, $\mathrm{Al}$ & $<1.0 \mathrm{E}+01$ & $<1.0 \mathrm{E}+01$ \\
\hline Boron, B & $<3.08 \mathrm{E}+00$ & $<3.08 \mathrm{E}+00$ \\
\hline Barium, $\mathrm{Ba}$ & $<2.80 \mathrm{E}-01$ & $<2.80 \mathrm{E}-01$ \\
\hline Beryllium, Be & $<4.66 \mathrm{E}-02$ & $<4.66 \mathrm{E}-02$ \\
\hline Calcium, $\mathrm{Ca}$ & $1.70 \mathrm{E}+00$ & $1.46 \mathrm{E}+00$ \\
\hline Cadmium, $\mathrm{Cd}$ & $<3.36 \mathrm{E}-01$ & $<3.36 \mathrm{E}-01$ \\
\hline Cerium, $\mathrm{Ce}$ & $<4.13 \mathrm{E}+00$ & $<4.13 \mathrm{E}+00$ \\
\hline Cobalt, Co & $6.77 \mathrm{E}+00$ & $7.84 \mathrm{E}+00$ \\
\hline Chromium, $\mathrm{Cr}$ & $8.05 \mathrm{E}-01$ & $8.69 \mathrm{E}-01$ \\
\hline Copper, $\mathrm{Cu}$ & $<1.46 \mathrm{E}+00$ & $<1.46 \mathrm{E}+00$ \\
\hline Iron, $\mathrm{Fe}$ & $<4.26 \mathrm{E}-01$ & $<4.26 \mathrm{E}-01$ \\
\hline Gadolinium, Gd & $<2.00 \mathrm{E}+00$ & $<2.00 \mathrm{E}+00$ \\
\hline Potassium, K & $4.87 \mathrm{E}+00$ & $5.56 \mathrm{E}+00$ \\
\hline Lanthanium, La & $<1.50 \mathrm{E}+00$ & $<1.50 \mathrm{E}+00$ \\
\hline Lithium, Li & $<1.02 \mathrm{E}+00$ & $<1.02 \mathrm{E}+00$ \\
\hline Magnesium, $\mathrm{Mg}$ & $<2.53 \mathrm{E}-01$ & $<2.53 \mathrm{E}-01$ \\
\hline Manganese, $\mathrm{Mn}$ & $<2.69 \mathrm{E}-01$ & $<2.69 \mathrm{E}-01$ \\
\hline Molybdenum, Mo & $<2.14 \mathrm{E}+00$ & $<2.14 \mathrm{E}+00$ \\
\hline Sodium, $\mathrm{Na}$ & $1.55 \mathrm{E}+03$ & $1.72 \mathrm{E}+03$ \\
\hline Nickel, Ni & $<1.60 \mathrm{E}+00$ & $<1.60 \mathrm{E}+00$ \\
\hline Phosphorous, P & $<1.09 \mathrm{E}+01$ & $<1.09 \mathrm{E}+01$ \\
\hline Lead, $\mathrm{Pb}$ & $<6.88 \mathrm{E}+00$ & $<6.88 \mathrm{E}+00$ \\
\hline Sulfur, S & $<1.35 \mathrm{E}+01$ & $<1.35 \mathrm{E}+01$ \\
\hline Antimony, Sb & $<6.92 \mathrm{E}+00$ & $<6.92 \mathrm{E}+00$ \\
\hline Silicon, Si & $<2.63 \mathrm{E}+00$ & $<2.63 \mathrm{E}+00$ \\
\hline Tin, Sn & $<3.26 \mathrm{E}+00$ & $<3.26 \mathrm{E}+00$ \\
\hline Strontium, $\mathrm{Sr}$ & $<5.40 \mathrm{E}-01$ & $<5.40 \mathrm{E}-01$ \\
\hline Titanium, Ti & $<6.05 \mathrm{E}-01$ & $<6.05 \mathrm{E}-01$ \\
\hline Total Uranium, U & $7.54 \mathrm{E}+02$ & $6.87 \mathrm{E}+02$ \\
\hline Vanadium, V & $<3.00 \mathrm{E}+00$ & $<3.00 \mathrm{E}+00$ \\
\hline Zinc, $Z n^{*}$ & $<3.59 \mathrm{E}-01$ & $<3.59 \mathrm{E}-01$ \\
\hline Zirconium, Zr & $<2.82 \mathrm{E}-01$ & $<2.82 \mathrm{E}-01$ \\
\hline Mercury, $\mathrm{Hg}$ & $1.06 \mathrm{E}+00$ & $2.80 \mathrm{E}-01$ \\
\hline
\end{tabular}


Table 13. Chemical Constituents from Tank 18F North and South Hemisphere Liquid Fraction-Single Analysis.

\begin{tabular}{|l|c|c|c|}
\hline & North Hemisphere Sample & $\begin{array}{c}\text { South Hemisphere } \\
\text { Sample }\end{array}$ & Units \\
\hline Constituent & Concentration & Concentration & \\
\hline Arsenic, $\mathrm{As}$ & $<2.75 \mathrm{E}-02$ & $<5.25 \mathrm{E}-02$ & $\mathrm{mg} / \mathrm{L}$ \\
\hline Selenium, $\mathrm{Se}$ & $<5.50 \mathrm{E}-02$ & $<5.50 \mathrm{E}-02$ & $\mathrm{mg} / \mathrm{L}$ \\
\hline Fluoride, $\mathrm{F}^{-1}$ & $2.80 \mathrm{E}+01$ & $2.10 \mathrm{E}+01$ & $\mathrm{mg} / \mathrm{L}$ \\
\hline Chloride, $\mathrm{Cl}^{-1}$ & $2.50 \mathrm{E}+01$ & $3.10 \mathrm{E}+01$ & $\mathrm{mg} / \mathrm{L}$ \\
\hline Nitrate, $\mathrm{NO}_{3}{ }^{-1}$ & $4.50 \mathrm{E}+01$ & $2.70 \mathrm{E}+01$ & $\mathrm{mg} / \mathrm{L}$ \\
\hline Nitrite, $\mathrm{NO}_{2}^{-}$ & $2.80 \mathrm{E}+01$ & $2.80 \mathrm{E}+01$ & $\mathrm{mg} / \mathrm{L}$ \\
\hline Sulfate, $\mathrm{SO}_{4}{ }^{-2}$ & $1.80 \mathrm{E}+01$ & $1.70 \mathrm{E}+01$ & $\mathrm{mg} / \mathrm{L}$ \\
\hline Oxalate, $\mathrm{C}_{2} \mathrm{O}_{4}^{-2}$ & $5.20 \mathrm{E}+01$ & $5.80 \mathrm{E}+01$ & $\mathrm{mg} / \mathrm{L}$ \\
\hline Carbonate, $\mathrm{CO}_{3}{ }^{-2}$ & $2.39 \mathrm{E}+03$ & $2.62 \mathrm{E}+03$ & $\mathrm{mg} / \mathrm{L}$ \\
\hline Phosphate, $\mathrm{PO}_{4}^{-3}$ & $6.00 \mathrm{E}+00$ & $6.00 \mathrm{E}+00$ & $\mathrm{mg} / \mathrm{L}$ \\
\hline Formate, $\mathrm{CHO}_{2}^{-1}$ & $<5.00 \mathrm{E}+00$ & $<5.00 \mathrm{E}+00$ & $\mathrm{mg} / \mathrm{L}$ \\
\hline
\end{tabular}


Table 14. Radiological Constituents from Tank $18 \mathrm{~F}$ North and South Hemisphere Liquid Fraction-Single Analysis.

\begin{tabular}{|c|c|c|c|}
\hline Constituent & Tank 18F North Hemisphere & Tank 18F South Hemisphere & Units \\
\hline Ni-59 & $<5.45 \mathrm{E}-05$ & $<5.27 \mathrm{E}-05$ & $\mu \mathrm{Ci} / \mathrm{mL}$ \\
\hline $\mathrm{Ni}-63$ & $<1.87 \mathrm{E}-05$ & $<1.50 \mathrm{E}-05$ & $\mu \mathrm{Ci} / \mathrm{mL}$ \\
\hline Se-79 & $<9.05 \mathrm{E}-06$ & $<7.16 \mathrm{E}-06$ & $\mu \mathrm{Ci} / \mathrm{mL}$ \\
\hline Cs-134 & $<1.36 \mathrm{E}-05$ & $<1.06 \mathrm{E}-05$ & $\mu \mathrm{Ci} / \mathrm{mL}$ \\
\hline Cs- 135 & $<3.78 \mathrm{E}-04$ & $<3.78 \mathrm{E}-04$ & $\mu \mathrm{Ci} / \mathrm{mL}$ \\
\hline Cs-137 & $9.55 \mathrm{E}-02$ & $7.21 \mathrm{E}-02$ & $\mu \mathrm{Ci} / \mathrm{mL}$ \\
\hline Sr-90 & $5.45 \mathrm{E}-03$ & $5.05 \mathrm{E}-03$ & $\mu \mathrm{Ci} / \mathrm{mL}$ \\
\hline Ba- $137 \mathrm{~m}$ & $9.04 \mathrm{E}-02$ & $6.83 \mathrm{E}-02$ & $\mu \mathrm{Ci} / \mathrm{mL}$ \\
\hline Y-90 & $5.45 \mathrm{E}-03$ & $5.05 \mathrm{E}-03$ & $\mu \mathrm{Ci} / \mathrm{mL}$ \\
\hline Tc-99 & $1.70 \mathrm{E}-04$ & $1.63 \mathrm{E}-04$ & $\mu \mathrm{Ci} / \mathrm{mL}$ \\
\hline Pm-147 & $<2.36 \mathrm{E}-03$ & $<2.43 \mathrm{E}-05$ & $\mu \mathrm{Ci} / \mathrm{mL}$ \\
\hline Sm-151 & $<1.32 \mathrm{E}-03$ & $<2.83 \mathrm{E}-05$ & $\mu \mathrm{Ci} / \mathrm{mL}$ \\
\hline $\mathrm{Pu}-238$ & 7.03E-05 & $1.41 \mathrm{E}-04$ & $\mu \mathrm{Ci} / \mathrm{mL}$ \\
\hline $\mathrm{Pu}-239 / 240$ & $2.30 \mathrm{E}-04$ & $4.55 \mathrm{E}-04$ & $\mu \mathrm{Ci} / \mathrm{mL}$ \\
\hline $\mathrm{Pu}-241$ & $<4.82 \mathrm{E}-04$ & $<8.51 \mathrm{E}-04$ & $\mu \mathrm{Ci} / \mathrm{mL}$ \\
\hline $\mathrm{Pu}-242$ & $<1.43 \mathrm{E}-03$ & $<1.91 \mathrm{E}-03$ & $\mu \mathrm{Ci} / \mathrm{mL}$ \\
\hline $\mathrm{Pu}-244$ & $<1.11 \mathrm{E}-05$ & $<8.87 \mathrm{E}-06$ & $\mu \mathrm{Ci} / \mathrm{mL}$ \\
\hline Am-241 & $<3.94 \mathrm{E}-06$ & $<2.04 \mathrm{E}-06$ & $\mu \mathrm{Ci} / \mathrm{mL}$ \\
\hline Am-243 & $<1.39 \mathrm{E}-06$ & $<9.77 \mathrm{E}-07$ & $\mu \mathrm{Ci} / \mathrm{mL}$ \\
\hline Am-242m & $<5.77 \mathrm{E}-08$ & $<1.64 \mathrm{E}-07$ & $\mu \mathrm{Ci} / \mathrm{mL}$ \\
\hline $\mathrm{Cm}-243$ & $<4.38 \mathrm{E}-06$ & $<3.27 \mathrm{E}-06$ & $\mu \mathrm{Ci} / \mathrm{mL}$ \\
\hline $\mathrm{Cm}-245$ & $<3.59 \mathrm{E}-06$ & $<2.69 \mathrm{E}-06$ & $\mu \mathrm{Ci} / \mathrm{mL}$ \\
\hline $\mathrm{Cm}-247$ & $<6.44 \mathrm{E}-06$ & $<4.73 \mathrm{E}-06$ & $\mu \mathrm{Ci} / \mathrm{mL}$ \\
\hline Cf-249 & $<5.99 \mathrm{E}-06$ & $<4.41 \mathrm{E}-06$ & $\mu \mathrm{Ci} / \mathrm{mL}$ \\
\hline Cf-251 & $<3.92 \mathrm{E}-06$ & $<2.85 \mathrm{E}-06$ & $\mu \mathrm{Ci} / \mathrm{mL}$ \\
\hline Cm-242 & $<4.77 \mathrm{E}-08$ & $<1.36 \mathrm{E}-07$ & $\mu \mathrm{Ci} / \mathrm{mL}$ \\
\hline $\mathrm{Cm}-244$ & $<6.62 \mathrm{E}-07$ & $<2.72 \mathrm{E}-07$ & $\mu \mathrm{Ci} / \mathrm{mL}$ \\
\hline $\mathrm{Cm}-248$ & $<4.39 \mathrm{E}-06$ & $<4.02 \mathrm{E}-06$ & $\mu \mathrm{Ci} / \mathrm{mL}$ \\
\hline Ra-226 & $<6.42 \mathrm{E}-05$ & $1.25 \mathrm{E}-04$ & $\mu \mathrm{Ci} / \mathrm{mL}$ \\
\hline $\mathrm{Pa}-231$ & $<6.44 \mathrm{E}-05$ & $<1.78 \mathrm{E}-04$ & $\mu \mathrm{Ci} / \mathrm{mL}$ \\
\hline I-129 & $<1.65 \mathrm{E}-06$ & $<8.96 \mathrm{E}-07$ & $\mu \mathrm{Ci} / \mathrm{mL}$ \\
\hline $\mathrm{Na}-22$ & $<2.69 \mathrm{E}-06$ & $<2.86 \mathrm{E}-06$ & $\mu \mathrm{Ci} / \mathrm{mL}$ \\
\hline Al-26 & $<2.53 \mathrm{E}-06$ & $<2.69 \mathrm{E}-06$ & $\mu \mathrm{Ci} / \mathrm{mL}$ \\
\hline Co-60 & $<3.65 \mathrm{E}-06$ & $<3.74 \mathrm{E}-06$ & $\mu \mathrm{Ci} / \mathrm{mL}$ \\
\hline Nb-94 & $<3.25 \mathrm{E}-06$ & $<3.02$ E-06 & $\mu \mathrm{Ci} / \mathrm{mL}$ \\
\hline Rh-106 & $<2.34 \mathrm{E}-05$ & $<2.49 \mathrm{E}-05$ & $\mu \mathrm{Ci} / \mathrm{mL}$ \\
\hline Ru-106 & $<2.34 \mathrm{E}-05$ & $<9.28 \mathrm{E}-06$ & $\mu \mathrm{Ci} / \mathrm{mL}$ \\
\hline Sb-125 & $<9.50 \mathrm{E}-06$ & $<9.28 \mathrm{E}-06$ & $\mu \mathrm{Ci} / \mathrm{mL}$ \\
\hline Sb-126 & $<3.24 \mathrm{E}-06$ & $<3.23 \mathrm{E}-06$ & $\mu \mathrm{Ci} / \mathrm{mL}$ \\
\hline Sn-126 & $<3.24 \mathrm{E}-06$ & $<3.23 \mathrm{E}-06$ & $\mu \mathrm{Ci} / \mathrm{mL}$ \\
\hline Sb-126m & $<3.24 \mathrm{E}-06$ & $<3.23 \mathrm{E}-06$ & $\mu \mathrm{Ci} / \mathrm{mL}$ \\
\hline Te-125m & $<9.50 \mathrm{E}-06$ & $<9.28 \mathrm{E}-06$ & $\mu \mathrm{Ci} / \mathrm{mL}$ \\
\hline Ce-144 & $<2.14 \mathrm{E}-05$ & $<2.22 \mathrm{E}-05$ & $\mu \mathrm{Ci} / \mathrm{mL}$ \\
\hline Pr-144 & $<2.14 \mathrm{E}-09$ & $<2.22 \mathrm{E}-09$ & $\mu \mathrm{Ci} / \mathrm{mL}$ \\
\hline Eu-152 & $<8.47 \mathrm{E}-06$ & $<8.60 \mathrm{E}-06$ & $\mu \mathrm{Ci} / \mathrm{mL}$ \\
\hline Eu-154 & $<5.81 \mathrm{E}-06$ & $<6.04 \mathrm{E}-06$ & $\mu \mathrm{Ci} / \mathrm{mL}$ \\
\hline Eu-155 & $<1.18 \mathrm{E}-05$ & $<1.19 \mathrm{E}-05$ & $\mu \mathrm{Ci} / \mathrm{mL}$ \\
\hline U-235 & $1.00 \mathrm{E}-05$ & $8.99 \mathrm{E}-06$ & $\mu \mathrm{Ci} / \mathrm{mL}$ \\
\hline Ra-228 & $<6.17 \mathrm{E}-06$ & $<6.26 \mathrm{E}-06$ & $\mu \mathrm{Ci} / \mathrm{mL}$ \\
\hline Ac-227 & $<3.18 \mathrm{E}-04$ & $<3.27 \mathrm{E}-04$ & $\mu \mathrm{Ci} / \mathrm{mL}$ \\
\hline Tritium & $<1.06 \mathrm{E}-04$ & $<1.06 \mathrm{E}-04$ & $\mu \mathrm{Ci} / \mathrm{mL}$ \\
\hline $\mathrm{C}-14$ & $1.71 \mathrm{E}-04$ & $6.22 \mathrm{E}-05$ & $\mu \mathrm{Ci} / \mathrm{mL}$ \\
\hline Gross alpha & $<1.76 \mathrm{E}+03$ & $<2.06 \mathrm{E}+03$ & $\mathrm{dpm} / \mathrm{mL}$ \\
\hline Gross beta & $2.80 \mathrm{E}+05$ & $2.12 \mathrm{E}+05$ & $\mathrm{dpm} / \mathrm{mL}$ \\
\hline
\end{tabular}


Table 14 (continued) Radiological Constituents from Tank 18F North and South Hemisphere Liquid Fraction-Single Analysis.

\begin{tabular}{|c|c|c|c|}
\hline Constituent & Tank 18F North Hemisphere & Tank 18F South Hemisphere & Units \\
\hline Th-229 & $<2.37 \mathrm{E}-07$ & $<5.90 \mathrm{E}-07$ & $\mu \mathrm{Ci} / \mathrm{mL}$ \\
\hline Th-230 & $<3.39 \mathrm{E}-07$ & $<7.02 \mathrm{E}-07$ & $\mu \mathrm{Ci} / \mathrm{mL}$ \\
\hline Th-232 & $<2.42 \mathrm{E}+01$ & $2.02 \mathrm{E}+01$ & $\mu \mathrm{Ci} / \mathrm{mL}$ \\
\hline $\mathrm{U}-232$ & $<8.32 \mathrm{E}-06$ & $<9.80 \mathrm{E}-06$ & $\mu \mathrm{Ci} / \mathrm{mL}$ \\
\hline $\mathrm{U}-233$ & $<2.42 \mathrm{E}-03$ & $<7.26 \mathrm{E}-03$ & $\mu \mathrm{Ci} / \mathrm{mL}$ \\
\hline $\mathrm{U}-234$ & $<2.34 \mathrm{E}-03$ & $<1.56 \mathrm{E}-03$ & $\mu \mathrm{Ci} / \mathrm{mL}$ \\
\hline $\mathrm{U}-235$ & $1.00 \mathrm{E}-05$ & $8.99 \mathrm{E}-06$ & $\mu \mathrm{Ci} / \mathrm{mL}$ \\
\hline $\mathrm{U}-236$ & $<3.23 \mathrm{E}-05$ & $<2.43 \mathrm{E}-05$ & $\mu \mathrm{Ci} / \mathrm{mL}$ \\
\hline $\mathrm{U}-238$ & $2.52 \mathrm{E}-04$ & $2.30 \mathrm{E}-04$ & $\mu \mathrm{Ci} / \mathrm{mL}$ \\
\hline Al-26 & $<2.53 \mathrm{E}-06$ & $<2.69 \mathrm{E}-06$ & $\mu \mathrm{Ci} / \mathrm{mL}$ \\
\hline Np-237 & $<3.52 \mathrm{E}-04$ & $<3.52 \mathrm{E}-04$ & \\
\hline
\end{tabular}

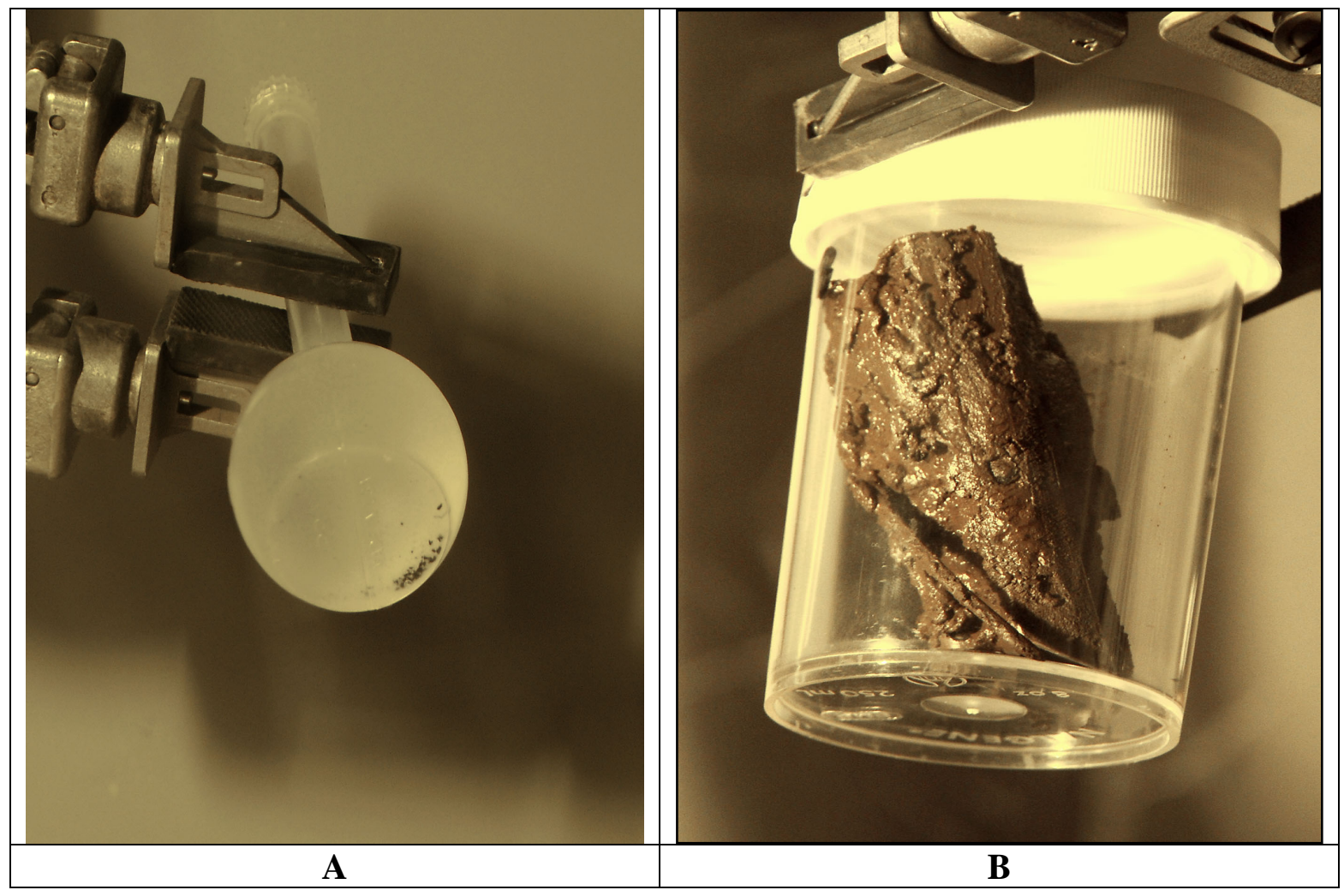

Figure 3: Insert (A) shows a picture of undigested Tank 18F South Hemisphere sample solids found at the bottom of a volumetric flask (undigested components are black solids) and insert (B) is a Tank 18F floor scrape bottom sample inside a PMP bottle container. 
SRNL-STI -2009-00625, Rev.0

Page 26 of 46

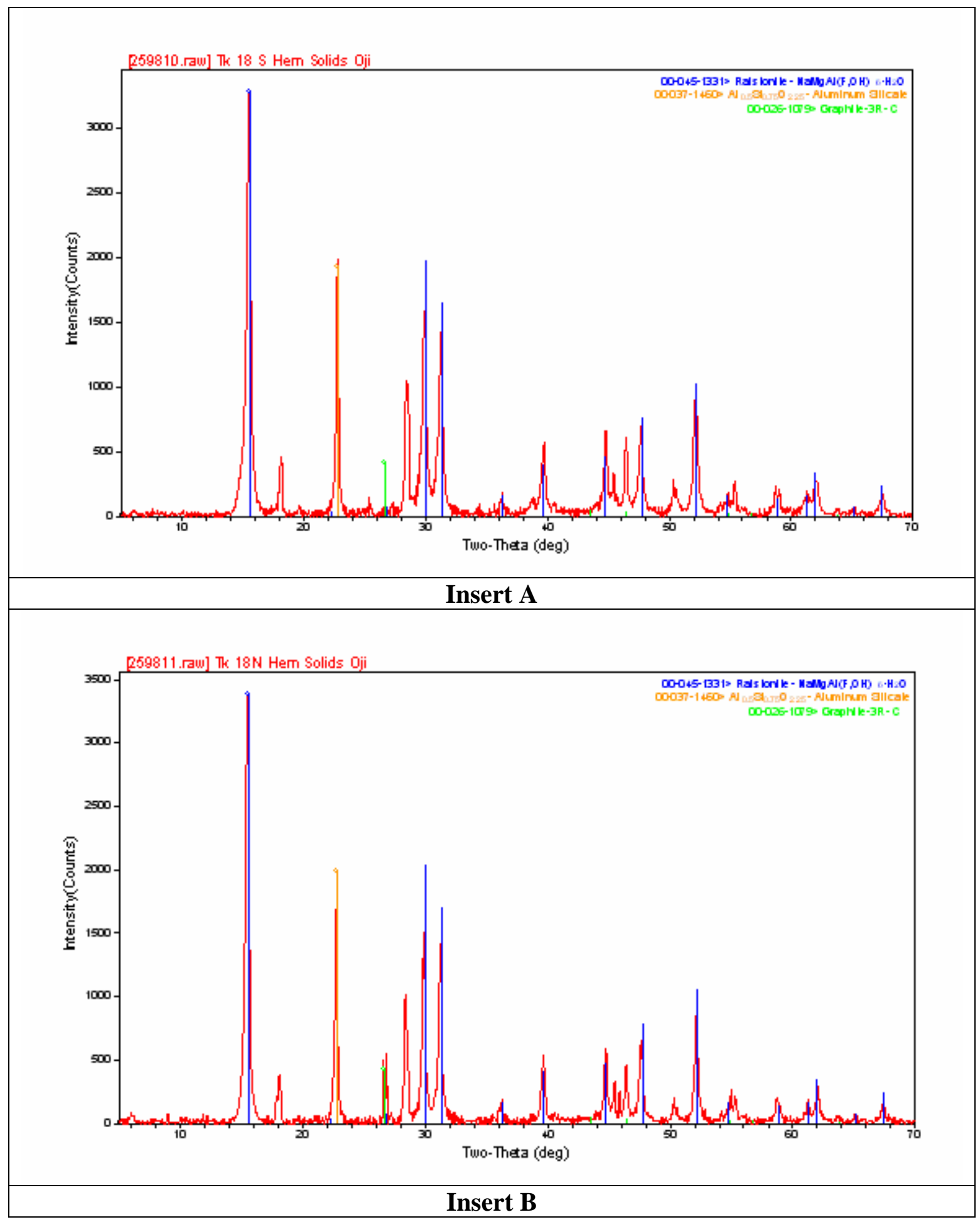

Figure 4. XRD spectra of black solids observed in AQR digestions for Tank 18 South (insert A) and North (insert B) Hemisphere dry solid samples. 


\subsection{Tank 18F Scrape Bottom Floor Sample}

Table 15 Analytical Result for Tank 18F Floor Scrape Bottom Sample Solids (Analyses on a dried solids basis).

\begin{tabular}{|c|c|c|c|c|c|c|}
\hline Constituent & Run-1 & Run-2 & Run-3 & Average & Std. Deviation & Units \\
\hline $\mathrm{Co}-60$ & $2.21 \mathrm{E}-02$ & $2.54 \mathrm{E}-02$ & $2.21 \mathrm{E}-02$ & $2.32 \mathrm{E}-02$ & $1.90 \mathrm{E}-03$ & $\mu \mathrm{Ci} / \mathrm{g}$ \\
\hline $\mathrm{Cs}-137$ & $3.65 \mathrm{E}+02$ & $3.55 \mathrm{E}+02$ & $3.87 \mathrm{E}+02$ & $3.69 \mathrm{E}+02$ & $1.64 \mathrm{E}+01$ & $\mu \mathrm{Ci} / \mathrm{g}$ \\
\hline $\mathrm{Np}-237$ & $1.22 \mathrm{E}-02$ & $1.31 \mathrm{E}-02$ & $1.45 \mathrm{E}-02$ & $1.33 \mathrm{E}-02$ & $1.16 \mathrm{E}-03$ & $\mu \mathrm{Ci} / \mathrm{g}$ \\
\hline $\mathrm{Am}-241$ & $3.23 \mathrm{E}+00$ & $4.68 \mathrm{E}+00$ & $4.27 \mathrm{E}+00$ & $4.06 \mathrm{E}+00$ & $7.46 \mathrm{E}-01$ & $\mu \mathrm{Ci} / \mathrm{g}$ \\
\hline $\mathrm{U}-232$ & $<1.64 \mathrm{E}-04$ & $<6.98 \mathrm{E}-04$ & $<5.61 \mathrm{E}-04$ & $<4.74 \mathrm{E}-04$ & & $\mu \mathrm{Ci} / \mathrm{g}$ \\
\hline $\mathrm{U}-233$ & $1.65 \mathrm{E}-03$ & $1.34 \mathrm{E}-03$ & $1.43 \mathrm{E}-03$ & $1.47 \mathrm{E}-03$ & $1.61 \mathrm{E}-04$ & $\mu \mathrm{Ci} / \mathrm{g}$ \\
\hline $\mathrm{U}-234$ & $9.66 \mathrm{E}-03$ & $7.84 \mathrm{E}-03$ & $8.31 \mathrm{E}-03$ & $8.60 \mathrm{E}-03$ & $9.44 \mathrm{E}-04$ & $\mu \mathrm{Ci} / \mathrm{g}$ \\
\hline $\mathrm{U}-235$ & $3.70 \mathrm{E}-04$ & $3.06 \mathrm{E}-04$ & $3.20 \mathrm{E}-04$ & $3.32 \mathrm{E}-04$ & $3.37 \mathrm{E}-05$ & $\mu \mathrm{Ci} / \mathrm{g}$ \\
\hline $\mathrm{U}-236$ & $3.66 \mathrm{E}-04$ & $2.93 \mathrm{E}-04$ & $3.10 \mathrm{E}-04$ & $3.23 \mathrm{E}-04$ & $3.85 \mathrm{E}-05$ & $\mu \mathrm{Ci} / \mathrm{g}$ \\
\hline $\mathrm{U}-238$ & $9.28 \mathrm{E}-03$ & $7.47 \mathrm{E}-03$ & $8.00 \mathrm{E}-03$ & $8.25 \mathrm{E}-03$ & $9.29 \mathrm{E}-04$ & $\mu \mathrm{Ci} / \mathrm{g}$ \\
\hline $\mathrm{Pu}-238$ & $6.49 \mathrm{E}+00$ & $8.09 \mathrm{E}+00$ & $8.07 \mathrm{E}+00$ & $7.55 \mathrm{E}+00$ & $9.14 \mathrm{E}-01$ & $\mu \mathrm{Ci} / \mathrm{g}$ \\
\hline $\mathrm{Pu}-239$ & $6.35 \mathrm{E}+00$ & $7.98 \mathrm{E}+00$ & $7.78 \mathrm{E}+00$ & $7.37 \mathrm{E}+00$ & $8.88 \mathrm{E}-01$ & $\mu \mathrm{Ci} / \mathrm{g}$ \\
\hline $\mathrm{Pu}-240$ & $1.40 \mathrm{E}+00$ & $<1.85 \mathrm{E}+00$ & $<1.73 \mathrm{E}+00$ & $\leq 1.66 \mathrm{E}+00$ & $2.30 \mathrm{E}-01$ & $\mu \mathrm{Ci} / \mathrm{g}$ \\
\hline $\mathrm{Pu}-241$ & $8.96 \mathrm{E}+00$ & $6.80 \mathrm{E}+00$ & $9.32 \mathrm{E}+00$ & $8.36 \mathrm{E}+00$ & $1.36 \mathrm{E}+00$ & $\mu \mathrm{Ci} / \mathrm{g}$ \\
\hline $\mathrm{Pu}-239 / 240$ & $7.93 \mathrm{E}+00$ & $9.95 \mathrm{E}+00$ & $9.86 \mathrm{E}+00$ & $9.25 \mathrm{E}+00$ & $1.15 \mathrm{E}+00$ & $\mu \mathrm{Ci} / \mathrm{g}$ \\
\hline $\mathrm{Pu}-242$ & $3.12 \mathrm{E}-04$ & $<5.71 \mathrm{E}-04$ & $<4.23 \mathrm{E}-04$ & $\leq 4.35 \mathrm{E}-04$ & $1.30 \mathrm{E}-04$ & $\mu \mathrm{Ci} / \mathrm{g}$ \\
\hline $\mathrm{Pu}-244$ & $<1.15 \mathrm{E}-06$ & $<2.66 \mathrm{E}-06$ & $<1.97 \mathrm{E}-06$ & $<1.92 \mathrm{E}-06$ & & $\mu \mathrm{Ci} / \mathrm{g}$ \\
\hline
\end{tabular}

\subsection{Wet Cake Sample Homogeneity for Tank 18F}

Tables 16 and 17 show selected new and old (italicized) Pu-239/240 and Pu-238 data obtained from the analyses of both North and South Hemisphere samples. These old data represent preliminary data from both $\mathrm{AQR}$ and $\mathrm{PF}$ digestions methods which showed significant difference between the two digestion methods. Additional digestions were available for both North and South Hemispheres to achieve low detection limits for neptunium. Small aliquots of these digestions were then submitted for plutonium measurements to evaluate this spread in data. The new plutonium data showed that digestions gave similar results to $\mathrm{AQR}$ digestions. The old preliminary data (italicized) in Tables 16 and 17 are not part of the data reported for the North and South Hemispheres as shown in Table 3 and 8 above. The newer results were included in the main report because the data is similar to the $\mathrm{AQR}$ digestions and the data are more conservative. 
Table 16 Selected Plutonium Analyses Results for Tank 18F North Hemisphere Samples -PUTTA and Mass spectroscopy Analysis Methods, $\mu \mathrm{Ci} / \mathrm{g}$ (dried solids).

\begin{tabular}{|l|c|c|c|}
\hline $\begin{array}{l}\text { Digested sample } \\
\text { source- }\end{array}$ & $\begin{array}{l}\text { Pu-239/240 } \\
\text { PuTTA }\end{array}$ & $\begin{array}{l}\text { Pu-238 } \\
\text { PuTTA }\end{array}$ & Digestion \\
\hline tube \# N-7 & $8.87 \mathrm{E}+00$ & $3.25 \mathrm{E}+00$ & PF-1 \\
\hline tube \# N-7 & $6.13 \mathrm{E}+00$ & $2.51 \mathrm{E}+00$ & PF-2 \\
\hline tube \#N-7 & $6.26 \mathrm{E}+00$ & $2.73 \mathrm{E}+00$ & PF-3 \\
\hline tube \# N-5 & $5.45 \mathrm{E}+00$ & $2.15 \mathrm{E}+00$ & AQR-1 \\
\hline tube \# N-5 & $1.19 \mathrm{E}+01$ & $4.45 \mathrm{E}+00$ & AQR-2 \\
\hline tube \# N-5 & $9.59 \mathrm{E}+00$ & $3.77 \mathrm{E}+00$ & AQR-3 \\
\hline tube \# N-1 \& N-2 & $9.73 E+00$ & $3.60 \mathrm{E}+00$ & PF-1 \\
\hline tube \# N-1 \& N-2 & $1.11 E+01$ & $3.96 E+00$ & PF-2 \\
\hline tube \# N-2 & $4.91 E+00$ & $1.90 \mathrm{E}+00$ & PF-3 \\
\hline Avg. & $8.22 \mathrm{E}+00$ & $3.15 \mathrm{E}+00$ & \\
\hline Std Dev. & $2.58 E+00$ & $8.73 E-01$ & \\
\hline
\end{tabular}

Table 17 Selected Plutonium Analyses Results for Tank 18F South Hemisphere Samples -PUTTA and Mass spectroscopy Analysis Methods, $\mu \mathrm{Ci} / \mathrm{g}$ (dried solids).

\begin{tabular}{|l|c|c|c|}
\hline $\begin{array}{l}\text { Digested sample } \\
\text { source }\end{array}$ & $\begin{array}{l}\text { Pu-239/240 } \\
\text { PUTTA }\end{array}$ & $\begin{array}{l}\text { Pu-238 } \\
\text { PUTTA }\end{array}$ & Digestion \\
\hline tube \# S-1 & $1.14 \mathrm{E}+01$ & $3.97 \mathrm{E}+00$ & PF-1 \\
\hline tube \# S-1 & $1.04 \mathrm{E}+01$ & $3.53 \mathrm{E}+00$ & PF-2 \\
\hline tube \# S-1 & $1.09 \mathrm{E}+01$ & $4.06 \mathrm{E}+00$ & PF-3 \\
\hline tube \# S-1, S-2, S-4 & $1.16 \mathrm{E}+01$ & $3.88 \mathrm{E}+00$ & AQR-1 \\
\hline tube \# S-1, S-2, S-4 & $1.33 \mathrm{E}+01$ & $4.23 \mathrm{E}+00$ & AQR-2 \\
\hline tube \# S-1, S-2, S-4 & $1.37 \mathrm{E}+01$ & $4.68 \mathrm{E}+00$ & AQR-3 \\
\hline tube \# S-11 & $4.25 E+00$ & $1.81 E+00$ & PF-1 \\
\hline tube \# S-11 & $4.40 E+00$ & $2.06 E+00$ & PF-2 \\
\hline tube \# S-11 & $4.14 E+00$ & $1.99 E+00$ & PF-3 \\
\hline Avg. & $9.34 \mathrm{E}+00$ & $3.36 \mathrm{E}+00$ & \\
\hline Std Dev. & $3.95 E+00$ & $1.10 E+00$ & \\
\hline
\end{tabular}

\subsection{Blank Evaluations and Detection Limits}

To verify the absence of sample contamination during processing, analytical blank (reagent and zeolite blanks) results were compared to sample analytical results (mainly $\mathrm{Am} / \mathrm{Cm}$, gamma scan and other methods) as presented in Appendix C (Tables C1 through C8). With the exception of $\mathrm{Cm}-247$ reagent blank analysis result in Table $\mathrm{C} 3$, blank measurements as shown in Tables $\mathrm{C} 1$ through $\mathrm{C} 6$ for various analytical methods and various constituents, indicate that there is significantly less of the constituent in the reagent blank as there is in the samples. In other words, the blank analytical results for the different species of interest are all well below the sample analytical results. Thus, there were no measurable cross contamination issues either from the environment of the shielded cell staging and operation areas or the reagents used in sample preparations.

However, in Tables C7 and C8 (gamma scan) there is as much of the constituent in the zeolite blanks as there is in the sample. These blanks could not be re-analyzed because of 
the lack of sufficient amounts of zeolite blanks taken out of the shielded cell at the same time the samples were prepared, however, re-analyses of corresponding reagent blanks indicate there was no cross contamination. It is believed, as confirmed with data tracking information, that samples were mistakenly analyzed as blank samples in these cases.

While many of the minimum detection limits, as specified in the Technical Task Request and Task Technical and Quality Assurance Plans (1E-04 $\mu \mathrm{Ci} / \mathrm{g}$ for most radionuclides and $1 \mathrm{E}-05 \mu \mathrm{Ci} / \mathrm{g}$ for I-129, Pa-231, Np-237 and Ra-226) were met for the species characterized for Tank 18, some were not met. In a number of cases, the high levels of radioactive species of the same element or a chemically similar element precluded the ability to measure an isotope to low levels. For example, the high activities of Am-241 and $\mathrm{Cm}-244$ in the sample matrix raised the alpha spectroscopy instrumental backgrounds for $\mathrm{Cm}-248$, having a detrimental effect on the detection limit for that isotope. The 2.6 year half-life Pm-147 co-extracts with the 90 year half-life Sm-151. Both have overlapping beta spectrum, with slightly higher continuum beta end-point energy for Pm147. The Sm-151 levels in these samples were relatively high, substantially raising the detection limit achievable for Pm-147. A number of gamma emitting radionuclides were analyzed using a Cs-137 removed gamma analysis; Cs-137 was expected to be the main contributor to background levels which would lower the sensitivity of the gamma analysis for other species. While that was true, the samples also contained measurable quantities of other gamma emitting isotopes (i.e. Co-60, Eu-154, Eu-155, etc...) which raised the background and thus the detection limits for gamma emitting species not observed (i.e. $\mathrm{Nb}-94, \mathrm{Sb}-125$, etc...). In cases where small improvements to detection limits could have been made, discussions with the customer indicated there was no need to re-run the methods with archived samples because impacts were negligible.

\subsection{CONCLUSIONS}

The Tank 18F samples were analyzed for radiological, elemental and chemical constituents. Where analytical methods yielded additional contaminants other than those requested by the customer, these results were also reported. The target detection limits for parameters analyzed were $1 \mathrm{E}-04 \mu \mathrm{Ci} / \mathrm{g}$ for most radionuclides and customer desired detection limits of $1 \mathrm{E}-05 \mu \mathrm{Ci} / \mathrm{g}$ for I-129, Pa-231, Np-237, and Ra-226. These detection limits were not met for all the isotopes analyzed because of spectral interferences. In a number of cases, the relatively high levels of radioactive species of the same element or a chemically similar element precluded the ability to measure some isotopes to low levels. SRNL, in conjunction with the plant customer, reviewed all these cases and determined that the impacts were negligible. 


\subsection{Quality Assurance}

The Task Technical and Quality Assurance Plan details the planned activities for the characterization of Tank 18F slurry samples- TTP/QA SRNL-RP-2008-01202, Rev. 1. Laboratory Notebook SRNL-NB-2009-00045 and various AD notebooks contain the experimental data.

\subsection{Acknowledgements}

The authors thank Analytical Development Section personnel, in particular, C. Johnson, and C. Diprete, for performing actinide and other metal analyses. We also thank the shielded cell operations personnel, in particular, Debbie Burckhalter, Mary H. Beasley and Rita Sullivan for their work with the Tank 18 and 19F samples in the shielded cells. 


\section{APPENDIX A}

Table AP-1. Radiological Constituents Analyzed.

\begin{tabular}{|c|c|c|c|c|c|c|c|}
\hline Nuclide & Methods & Nuclide & Method & Nuclide & Method & Nuclide & Method \\
\hline $\mathrm{H}-3$ & H-3 & Cs-134 & $\begin{array}{c}\mathrm{AQR} / \mathrm{PF} \\
\gamma\end{array}$ & $\mathrm{Np}-237$ & $\begin{array}{l}\mathrm{AQR} / \mathrm{PF} \\
\mathrm{ICP}-\mathrm{MS} \text { or } \\
\text { special prep. }\end{array}$ & Eu-155 & $\begin{array}{c}\text { Cs-removed } \\
\gamma\end{array}$ \\
\hline C-14 & $\begin{array}{l}\text { C-14 } \\
\text { Special } \\
\text { prep. }\end{array}$ & Cs-135 & $\begin{array}{c}\text { PF } \\
\text { special prep } \\
\text { ICPMS }\end{array}$ & $\mathrm{Pu}-238$ & $\begin{array}{c}\text { AQR, PF/ Pu- } \\
238 / 241\end{array}$ & Ra-226 & $\mathrm{Ra}$ \\
\hline Co-60 & $\begin{array}{c}\text { Cs- } \\
\text { removed } \gamma\end{array}$ & Cs-137 & $\begin{array}{c}\mathrm{AQR} / \mathrm{PF} \\
\gamma\end{array}$ & Pu-239 & $\begin{array}{c}\mathrm{AQR}, \mathrm{PF} / \mathrm{Pu}- \\
238 / 241\end{array}$ & Ra-228 & $\begin{array}{c}\text { Cs-removed } \\
\gamma\end{array}$ \\
\hline $\mathrm{Ni}-59 * *$ & Ni 59/63 & Ba-137m & Cs-removed $\gamma$ & $\mathrm{Pu}-240$ & $\begin{array}{c}\mathrm{AQR}, \mathrm{PF} / \mathrm{Pu}- \\
238 / 241\end{array}$ & Ac-227 & $\begin{array}{c}\text { Cs-removed } \\
\gamma\end{array}$ \\
\hline $\mathrm{Ni}-63 * *$ & Ni $59 / 63$ & $\mathrm{Ce}-144$ & Cs-removed $\gamma$ & $\mathrm{Pu}-241$ & $\begin{array}{c}\mathrm{AQR}, / \mathrm{PF} / \\
\mathrm{Pu}-238 / 241\end{array}$ & Th-229 & Th-229 \\
\hline $\mathrm{Se}-79 * *$ & Se-79 & Pr-144 & Cs-removed $\gamma$ & $\mathrm{Pu}-242$ & $\begin{array}{l}\mathrm{AQR} / \mathrm{PF} / \\
\mathrm{ICP}-\mathrm{MS}\end{array}$ & Th-230 & Th-230 \\
\hline Sr-90 & $\begin{array}{c}\text { PF } \\
\text { Sr-90 }\end{array}$ & Pm-147 & $\begin{array}{c}\mathrm{PF} \\
\mathrm{Pm}-147, \mathrm{Sm}- \\
151\end{array}$ & Am-241 & $\mathrm{Am} / \mathrm{Cm}$ & $\mathrm{Pa}-231$ & $\mathrm{~Pa}-231$ \\
\hline Y-90 & $\begin{array}{c}\text { PF } \\
\text { Sr-90 }\end{array}$ & Eu-154 & Cs-removed $\gamma$ & Am-242m & $\mathrm{Am} / \mathrm{Cm}$ & $\mathrm{Pu}-244$ & $\begin{array}{c}\text { PF } \\
\text { special prep } \\
\text { ICP-MS }\end{array}$ \\
\hline $\mathrm{Nb}-94$ & $\begin{array}{l}\text { Cs- } \\
\text { removed } \gamma\end{array}$ & Th-232 & $\begin{array}{c}\mathrm{AQR} / \mathrm{PF} / \\
\mathrm{ICP}-\mathrm{MS}\end{array}$ & $\mathrm{Cm}-244$ & $\mathrm{Am} / \mathrm{Cm}$ & Am-243 & $\mathrm{Am} / \mathrm{Cm}$ \\
\hline Tc-99 & Tc-99 & U-232 & U-232 & $\mathrm{Cm}-245$ & $\mathrm{Am} / \mathrm{Cm}$ & $\mathrm{Cm}-242$ & $\mathrm{Am} / \mathrm{Cm}$ \\
\hline Ru-106 & $\begin{array}{c}\text { Cs- } \\
\text { removed } \gamma\end{array}$ & U-233 & $\begin{array}{c}\text { PF } \\
\text { special prep } \\
\text { ICPMS }\end{array}$ & Te-125m & $\begin{array}{c}\text { Cs-removed } \\
\gamma\end{array}$ & $\mathrm{Cm}-243$ & $\mathrm{Am} / \mathrm{Cm}$ \\
\hline Rh-106 & $\begin{array}{c}\text { Cs } \\
\text { removed } \gamma\end{array}$ & U-234 & $\begin{array}{c}\text { PF } \\
\text { special prep } \\
\text { ICPMS }\end{array}$ & Sb-126 & $\begin{array}{c}\text { Cs-removed } \\
\gamma\end{array}$ & $\mathrm{Cm}-247$ & $\mathrm{Am} / \mathrm{Cm}$ \\
\hline $\mathrm{Sb}-125$ & $\begin{array}{c}\text { Cs- } \\
\text { removed } \gamma\end{array}$ & U-235 & $\begin{array}{l}\text { AQR/PF } \\
\text { ICP-MS } \\
\end{array}$ & Sb-126m & $\begin{array}{c}\text { Cs-removed } \\
\gamma \\
\end{array}$ & $\mathrm{Cm}-248$ & $\mathrm{Am} / \mathrm{Cm}$ \\
\hline Sn-126 & $\begin{array}{l}\text { Cs- } \\
\text { removed } \gamma\end{array}$ & U-236 & $\begin{array}{c}\text { PF } \\
\text { special prep } \\
\text { ICPMS }\end{array}$ & Sm-151 & $\begin{array}{c}\mathrm{PF} \\
\mathrm{Pm}-147 / \mathrm{Sm}- \\
151\end{array}$ & Cf-249 & $\mathrm{Am} / \mathrm{Cm}$ \\
\hline I-129 & $\begin{array}{c}\text { I-129 } \\
\text { Special } \\
\text { prep. }\end{array}$ & U-238 & $\begin{array}{l}\text { AQR/PF } \\
\text { ICP-MS }\end{array}$ & Eu-152 & $\begin{array}{c}\text { Cs-removed } \\
\gamma\end{array}$ & Cf-252 & $\mathrm{Am} / \mathrm{Cm}$ \\
\hline $\mathrm{Na}-22$ & $\begin{array}{c}\text { Cs- } \\
\text { removed } \gamma\end{array}$ & Al-26 & Cs-removed $\gamma$ & Cf-251 & $\mathrm{Am} / \mathrm{Cm}$ & & \\
\hline
\end{tabular}

** These constituents analyzed only in triplicate 
SRNL-STI -2009-00625, Rev.0

Page 32 of 46

Table AP-2. Chemical Constituents analyzed for.

\begin{tabular}{|c|c|c|c|c|c|c|c|}
\hline Constituent & Method & Constituent & Method & Constituent & Method & Constituent & Method \\
\hline $\mathrm{Ag}$ & $\begin{array}{l}\text { AQR,PF/ } \\
\text { ICPES/ICPMS }\end{array}$ & $\mathrm{Gd}$ & $\begin{array}{c}\text { AQR, PF } \\
\text { ICPES }\end{array}$ & $\mathrm{Sb}$ & $\begin{array}{l}\mathrm{AQR}, \\
\mathrm{PF} / \mathrm{ICPES}\end{array}$ & As & $\begin{array}{c}\mathrm{AA} \\
\mathrm{AQR}\end{array}$ \\
\hline $\mathrm{Al}$ & $\begin{array}{l}\text { AQR, PF/ } \\
\text { ICPES }\end{array}$ & $\mathrm{La}$ & $\begin{array}{c}\text { AQR, PF } \\
\text { ICPES }\end{array}$ & $\mathrm{Si}$ & $\begin{array}{l}\text { AQR, } \\
\text { PF/ICPES }\end{array}$ & $\mathrm{Se}$ & $\begin{array}{c}\mathrm{AA} \\
\mathrm{AQR}\end{array}$ \\
\hline $\mathrm{B}$ & $\begin{array}{l}\text { AQR, } \\
\text { PF/ICPES }\end{array}$ & $\mathrm{Li}$ & $\begin{array}{c}\text { AQR, } \\
\text { PF/ICPES }\end{array}$ & $\mathrm{Sn}$ & $\begin{array}{l}\text { AQR, } \\
\text { PF/ICPES }\end{array}$ & $\mathrm{F}$ & $\begin{array}{c}\mathrm{IC} \\
\text { anion/WL** }\end{array}$ \\
\hline $\mathrm{Ba}$ & $\begin{array}{l}\text { AQR, PF/ } \\
\text { ICPES }\end{array}$ & $\mathrm{Mg}$ & $\begin{array}{c}\text { AQR, } \\
\text { PF/ICPES }\end{array}$ & $\mathrm{Sr}$ & $\begin{array}{l}\text { AQR, } \\
\text { PF/ICPES }\end{array}$ & Chloride & $\begin{array}{l}\text { WL/IC } \\
\text { anion }\end{array}$ \\
\hline $\mathrm{Ca}$ & $\begin{array}{l}\text { AQR, PF/ } \\
\text { ICPES }\end{array}$ & $\mathrm{Mn}$ & $\begin{array}{c}\text { AQR, } \\
\text { PF/ICPES }\end{array}$ & $\mathrm{Ti}$ & $\begin{array}{l}\text { AQR, } \\
\text { PF/ICPES }\end{array}$ & Nitrate & $\begin{array}{l}\text { WL/IC } \\
\text { anion }\end{array}$ \\
\hline $\mathrm{Cd}$ & $\begin{array}{l}\text { AQR, PF/ } \\
\text { ICPES }\end{array}$ & Mo & $\begin{array}{c}\text { AQR, } \\
\text { PF/ICPES }\end{array}$ & $\mathrm{U}$ & $\begin{array}{l}\text { AQR,PF/ } \\
\text { ICPES/ICPMS }\end{array}$ & Nitrite & $\begin{array}{l}\text { WL/IC } \\
\text { anion }\end{array}$ \\
\hline $\mathrm{Ce}$ & $\begin{array}{l}\mathrm{AQR}, \mathrm{PF} / \\
\mathrm{ICPES}\end{array}$ & $\mathrm{Na}$ & $\begin{array}{c}\text { AQR, } \\
\text { ICPES }\end{array}$ & $\mathrm{V}$ & $\begin{array}{l}\mathrm{AQR}, \\
\mathrm{PF} / \mathrm{ICPES}\end{array}$ & Sulfate & $\begin{array}{l}\text { WL/IC } \\
\text { anion }\end{array}$ \\
\hline $\mathrm{Co}$ & $\begin{array}{l}\text { AQR,PF/ } \\
\text { ICP-MS }\end{array}$ & $\mathrm{Ni}$ & $\begin{array}{c}\text { AQR, PF } \\
\text { ICPES }\end{array}$ & $\mathrm{Zn}$ & $\begin{array}{l}\text { AQR, } \\
\text { PF/ICPES }\end{array}$ & Oxalate & $\begin{array}{l}\text { WL/IC } \\
\text { anion }\end{array}$ \\
\hline $\mathrm{Cr}$ & $\begin{array}{l}\text { AQR, PF/ } \\
\text { ICPES }\end{array}$ & $\mathrm{P}$ & $\begin{array}{c}\text { AQR, PF } \\
\text { ICPES }\end{array}$ & $\mathrm{Zr}$ & \begin{tabular}{|l} 
AQR, \\
PF/ICPES \\
\end{tabular} & Carbonate & $\begin{array}{c}\text { TIC/TOC } \\
\text { WL } \\
\end{array}$ \\
\hline $\mathrm{Cu}$ & $\begin{array}{l}\text { AQR, PF/ } \\
\text { ICPES }\end{array}$ & $\mathrm{Pb}$ & $\begin{array}{c}\text { AQR, } \\
\text { PF/ICPES }\end{array}$ & $\mathrm{Hg}$ & AQR-CVHg, & Phosphate & $\begin{array}{l}\text { WL/IC } \\
\text { anion }\end{array}$ \\
\hline $\mathrm{Fe}$ & $\begin{array}{l}\text { AQR, PF/ } \\
\text { ICPES }\end{array}$ & $\mathrm{S}$ & $\begin{array}{c}\text { AQR, } \\
\text { PF/ICPES }\end{array}$ & $\mathrm{K}$ & $\begin{array}{l}\text { AQR, } \\
\text { PF/ICPES }\end{array}$ & Formate & $\begin{array}{l}\text { WL/IC } \\
\text { anion }\end{array}$ \\
\hline
\end{tabular}


Table AP-3. Solid Fraction Composite North Hemisphere Peroxide Fusion and Aqua Regia Digestion Data which did not meet the requested detection limits or where another set of analytical results were better in terms of less interference.

(Analyses on a dried solids basis) ${ }^{1}$

\begin{tabular}{|c|c|c|c|c|c|c|c|c|c|}
\hline Constituent & PF1 & PF2 & PF3 & AQR1 & AQR2 & AQR3 & Average & Stdev & Units \\
\hline & & & & & & & & & \\
\hline $\mathrm{U}-233$ & $<1.24 \mathrm{E}-01$ & $<1.28 \mathrm{E}-01$ & $<1.00 \mathrm{E}-01$ & $<3.81 \mathrm{E}-02$ & $<4.87 \mathrm{E}-02$ & $<4.85 \mathrm{E}-02$ & $8.14 \mathrm{E}-02$ & & $\mu \mathrm{Ci} / \mathrm{g}$ \\
\hline $\mathrm{U}-234$ & $<8.02 \mathrm{E}-02$ & $<8.29 \mathrm{E}-02$ & $<6.49 \mathrm{E}-02$ & $<3.68 \mathrm{E}-02$ & $<4.71 \mathrm{E}-02$ & $<4.68 \mathrm{E}-02$ & $5.98 \mathrm{E}-02$ & & $\mu \mathrm{Ci} / \mathrm{g}$ \\
\hline $\mathrm{U}-236$ & $<8.33 \mathrm{E}-05$ & $<8.65 \mathrm{E}-04$ & $<6.76 \mathrm{E}-04$ & $3.84 \mathrm{E}-04$ & $4.90 \mathrm{E}-04$ & $<4.88 \mathrm{E}-04$ & $\leq 4.98 \mathrm{E}-04$ & $2.65 \mathrm{E}-04$ & $\mu \mathrm{Ci} / \mathrm{g}$ \\
\hline $\mathrm{Np}-237$ & $<1.36 \mathrm{E}-02$ & $<1.41 \mathrm{E}-02$ & $<1.10 \mathrm{E}-02$ & $2.90 \mathrm{E}-03$ & $4.87 \mathrm{E}-03$ & $4.41 \mathrm{E}-03$ & $\leq 8.49 \mathrm{E}-03$ & $5.01 \mathrm{E}-03$ & $\mu \mathrm{Ci} / \mathrm{g}$ \\
\hline $\mathrm{Pu}-238$ & $3.60 \mathrm{E}+00$ & $3.96 \mathrm{E}+00$ & $1.90 \mathrm{E}+00$ & NA & NA & NA & $3.15 \mathrm{E}+00$ & $1.10 \mathrm{E}+00$ & $\mu \mathrm{Ci} / \mathrm{g}$ \\
\hline $\mathrm{Pu}-239 / 240$ & $9.73 \mathrm{E}+00$ & $1.11 \mathrm{E}+01$ & $4.91 \mathrm{E}+00$ & NA & NA & NA & $8.59 \mathrm{E}+00$ & $3.26 \mathrm{E}+00$ & $\mu \mathrm{Ci} / \mathrm{g}$ \\
\hline $\mathrm{Am}-241$ & $2.74 \mathrm{E}+00$ & $4.41 \mathrm{E}+00$ & $4.55 \mathrm{E}+00$ & NA & NA & NA & $3.90 \mathrm{E}+00$ & $1.01 E+00$ & $\mu \mathrm{Ci} / \mathrm{g}$ \\
\hline $\mathrm{Pu}-242$ & $<5.09 \mathrm{E}-02$ & $<5.27 \mathrm{E}-02$ & $<4.10 \mathrm{E}-02$ & $<1.56 \mathrm{E}-05$ & $<1.99 \mathrm{E}-02$ & $<1.98 \mathrm{E}-02$ & $<3.07 \mathrm{E}-02$ & & $\mu \mathrm{Ci} / \mathrm{g}$ \\
\hline $\mathrm{Pu}-244$ & $<3.55 \mathrm{E}-04$ & $<3.66 \mathrm{E}-04$ & $<2.86 \mathrm{E}-04$ & $<7.24 \mathrm{E}-05$ & $<9.25 \mathrm{E}-05$ & $<9.21 \mathrm{E}-05$ & $<2.11 \mathrm{E}-04$ & & $\mu \mathrm{Ci} / \mathrm{g}$ \\
\hline $\mathrm{Cs}-135$ & $1.98 \mathrm{E}-03$ & $1.87 \mathrm{E}-03$ & $2.40 \mathrm{E}-03$ & NA & NA & NA & $2.08 \mathrm{E}-03$ & $2.80 \mathrm{E}-04$ & $\mu \mathrm{Ci} / \mathrm{g}$ \\
\hline $\mathrm{Ag}$ & $<1.80 \mathrm{E}-02$ & $<1.86 \mathrm{E}-02$ & $<1.45 \mathrm{E}-02$ & $<9.90 \mathrm{E}-03$ & $7.46 \mathrm{E}-02$ & $5.31 \mathrm{E}-02$ & $\leq 3.145 \mathrm{E}-02$ & $2.619 \mathrm{E}-02$ & $\mathrm{Wt} \%$ \\
\hline $\mathrm{Pb}$ & $<8.87 \mathrm{E}-02$ & $<9.15 \mathrm{E}-02$ & $<7.15 \mathrm{E}-02$ & $2.87 \mathrm{E}-02$ & $2.20 \mathrm{E}-02$ & $2.54 \mathrm{E}-02$ & $\leq 5.46 \mathrm{E}-02$ & $3.29 \mathrm{E}-02$ & $\mathrm{Wt} \%$ \\
\hline $\mathrm{Sn}$ & $<2.52 \mathrm{E}-01$ & $<2.59 \mathrm{E}-01$ & $<2.03 \mathrm{E}-01$ & $<6.46 \mathrm{E}-03$ & $<8.25 \mathrm{E}-03$ & $<8.19 \mathrm{E}-03$ & $<1.23 \mathrm{E}-01$ & & $\mathrm{Wt} \%$ \\
\hline
\end{tabular}

Table AP-4. Solid Fraction Composite South Hemisphere Peroxide Fusion and Aqua Regia Digestion Data which did not meet the requested detection limits or where another set of analytical results were better in terms of less interference.

(Analyses on a dried solids basis)

\begin{tabular}{|c|c|c|c|c|c|c|c|c|c|}
\hline Constituent & PF1 & PF2 & PF3 & AQR1 & AQR2 & AQR3 & Average & Stdev & Units \\
\hline U-233 & $<9.55 \mathrm{E}-02$ & $<9.82 \mathrm{E}-02$ & $<1.09 \mathrm{E}-01$ & $<2.69 \mathrm{E}-02$ & $<2.69 \mathrm{E}-02$ & $<6.26 \mathrm{E}-02$ & $<6.99 \mathrm{E}-02$ & & $\mu \mathrm{Ci} / \mathrm{g}$ \\
\hline $\mathrm{U}-234$ & $<9.23 \mathrm{E}-02$ & $<9.50 \mathrm{E}-02$ & $<1.05 \mathrm{E}-01$ & $<1.73 \mathrm{E}-02$ & $<1.73 \mathrm{E}-02$ & $<4.04 \mathrm{E}-02$ & $<6.13 \mathrm{E}-02$ & & $\mu \mathrm{Ci} / \mathrm{g}$ \\
\hline $\mathrm{U}-236$ & $<1.60 \mathrm{E}-03$ & $<1.65 \mathrm{E}-03$ & $<1.83 \mathrm{E}-03$ & $2.10 \mathrm{E}-04$ & $2.09 \mathrm{E}-04$ & $4.20 \mathrm{E}-04$ & $\leq 9.87 \mathrm{E}-04$ & $7.82 \mathrm{E}-04$ & $\mu \mathrm{Ci} / \mathrm{g}$ \\
\hline $\mathrm{Np}-237$ & $<6.98 \mathrm{E}-03$ & $<7.21 \mathrm{E}-03$ & $<7.97 \mathrm{E}-03$ & $3.47 \mathrm{E}-03$ & $4.55 \mathrm{E}-04$ & $4.91 \mathrm{E}-03$ & $\leq 5.17 \mathrm{E}-03$ & $2.84 \mathrm{E}-03$ & $\mu \mathrm{Ci} / \mathrm{g}$ \\
\hline $\mathrm{Cs}-135$ & $5.39 \mathrm{E}-03$ & $5.73 \mathrm{E}-03$ & $5.87 \mathrm{E}-03$ & $<1.43 \mathrm{E}-02$ & $<1.60 \mathrm{E}-02$ & $<1.69 \mathrm{E}-02$ & $\leq 5.66 \mathrm{E}-03$ & $2.47 \mathrm{E}-04$ & $\mu \mathrm{Ci} / \mathrm{g}$ \\
\hline $\mathrm{Pu}-238$ & $1.81 \mathrm{E}+00$ & $2.06 \mathrm{E}+00$ & $1.99 \mathrm{E}+00$ & NA & NA & NA & $1.95 \mathrm{E}+00$ & $1.30 \mathrm{E}-01$ & $\mu \mathrm{Ci} / \mathrm{g}$ \\
\hline $\mathrm{Pu}-239 / 240$ & $4.25 \mathrm{E}+00$ & $4.40 \mathrm{E}+00$ & $4.14 \mathrm{E}+00$ & NA & NA & NA & $4.27 \mathrm{E}+00$ & $1.29 \mathrm{E}-01$ & $\mu \mathrm{Ci} / \mathrm{g}$ \\
\hline $\mathrm{Cs}-134$ & $<9.82 \mathrm{E}-02$ & $<1.31 \mathrm{E}-01$ & $<1.52 \mathrm{E}-01$ & NA & NA & NA & $<1.27 \mathrm{E}-01$ & & $\mu \mathrm{Ci} / \mathrm{g}$ \\
\hline $\mathrm{Ag}$ & $<1.38 \mathrm{E}-02$ & $<1.43 \mathrm{E}-02$ & $<1.58 \mathrm{E}-02$ & $3.08 \mathrm{E}-02$ & $<1.40 \mathrm{E}-02$ & $<1.52 \mathrm{E}-02$ & $\leq 1.73 \mathrm{E}-02$ & $6.65 \mathrm{E}-03$ & $\mathrm{Wt} \%$ \\
\hline $\mathrm{Co}$ & NA & NA & NA & $1.27 \mathrm{E}-02$ & $1.30 \mathrm{E}-02$ & $1.37 \mathrm{E}-02$ & $1.31 \mathrm{E}-02$ & $5.13 \mathrm{E}-04$ & $\mathrm{Wt} \%$ \\
\hline $\mathrm{Sn}$ & $<1.93 \mathrm{E}-01$ & $<1.99 \mathrm{E}-01$ & $<2.20 \mathrm{E}-01$ & $<9.10 \mathrm{E}-03$ & $<9.10 \mathrm{E}-03$ & $<9.88 \mathrm{E}-03$ & $<1.07 \mathrm{E}-01$ & & $\mathrm{Wt} \%$ \\
\hline $\mathrm{Pb}$ & $<6.81 \mathrm{E}-02$ & $<7.02 \mathrm{E}-02$ & $<7.77 \mathrm{E}-02$ & $3.56 \mathrm{E}-02$ & $3.84 \mathrm{E}-02$ & $3.27 \mathrm{E}-02$ & $\leq 5.38 \mathrm{E}-02$ & $2.03 \mathrm{E}-02$ & $\mathrm{Wt} \%$ \\
\hline
\end{tabular}

\footnotetext{
${ }^{1}$ The target detection limits for isotopes analyzed were based on $1 \mathrm{E}-04 \mu \mathrm{Ci} / \mathrm{g}$ for most radionuclides and customer desired detection values of $1 \mathrm{E}-05 \mu \mathrm{Ci} / \mathrm{g}$ for I-129, Pa-231, Np-237, and Ra-226. The original data reported in the Tables AP-3 and AP-4 above are from PF and AQR digestions which did not meet requested detection limit or where better detection limits were attainable. Special methods were developed and used to meet the detection limits cited above (See Appendix B-special methods).
} 
Table AP-5. Quadrant Samples from Tank 18F North Hemisphere Received at SRNL*

\begin{tabular}{|c|c|c|c|}
\hline North Quandrant Sample & Estimated wt. of wet cake, $g$ & Date received & Comments \\
\hline FTF-07-09-09-1 & 1 & $2-3-2009$ & Sample archived \\
\hline FTF-07-09-09-2 & 0.5 & $2-3-2009$ & Sample archived \\
\hline FTF-07-09-09-3 & 2 & $2-3-2009$ & Sample archived \\
\hline FTF-07-09-10-1 & 1 & $2-3-2009$ & Sample archived \\
\hline FTF-07-09-10-2 & 2 & $2-3-2009$ & Sample archived \\
\hline FTF-07-09-10-3 & 0.5 & $2-3-2009$ & Sample archived \\
\hline FTF-07-09-18-1 & 1 & $3-2-2009$ & Sample archived \\
\hline FTF-07-09-18-2 & 1 & $3-2-2009$ & Sample archived \\
\hline FTF-07-09-18-3 & 0.5 & $3-2-2009$ & Sample archived \\
\hline FTF-07-09-18-4 & 1 & $3-2-2009$ & Sample archived \\
\hline FTF-07-09-18-5 & 0.5 & $3-2-2009$ & Sample archived \\
\hline FTF-07-09-18-6 & 0.5 & $3-2-2009$ & Sample archived \\
\hline FTF-07-09-18-7 & 2 & $3-2-2009$ & Sample archived \\
\hline FTF-07-09-18-8 & 2 & $3-2-2009$ & Sample archived \\
\hline FTF-07-09-18-9 & 1 & $3-2-2009$ & Sample archived \\
\hline FTF-07-09-18-10 & 0.5 & $3-2-2009$ & Sample archived \\
\hline FTF-07-09-18-11 & 1 & $3-2-2009$ & Sample archived \\
\hline FTF-07-09-18-12 & 0.5 & $3-2-2009$ & Sample archived \\
\hline FTF-07-09-18-13 & 1 & $3-2-2009$ & Sample archived \\
\hline FTF-07-09-18-14 & 2 & $3-2-2009$ & Sample archived \\
\hline FTF-07-09-18-15 & 1 & $3-2-2009$ & Sample archived \\
\hline FTF-07-09-20-1 & 2 & $3-16-2009$ & Sample composite \\
\hline FTF-07-09-20-2 & 2 & $3-16-2009$ & Sample composite \\
\hline FTF-07-09-20-3 & 3 & $3-16-2009$ & Sample composite \\
\hline FTF-07-09-20-4 & 3 & $3-16-2009$ & Sample composite \\
\hline FTF-07-09-20-5 & 1 & $3-16-2009$ & Sample composite \\
\hline FTF-07-09-20-6 & 3 & $3-16-2009$ & Sample composite \\
\hline FTF-07-09-20-7 & 4 & $3-16-2009$ & Sample composite \\
\hline FTF-07-09-20-8 & 3 & $3-16-2009$ & Sample composite \\
\hline FTF-07-09-20-9 & 3 & $3-16-2009$ & Sample composite \\
\hline FTF-07-09-20-10 & 0.5 & $3-16-2009$ & Sample composite \\
\hline FTF-07-09-20-11 & 1 & $3-16-2009$ & Sample composite \\
\hline FTF-07-09-20-12 & 0.5 & $3-16-2009$ & Sample composite \\
\hline FTF-07-09-20-13 & 4 & $3-16-2009$ & Sample composite \\
\hline FTF-07-09-20-14 & 6 & $3-16-2009$ & Sample composite \\
\hline FTF-07-09-20-15 & 4 & $3-16-2009$ & Sample composite \\
\hline
\end{tabular}

*All samples transported to SRNL in paint cans. 
SRNL-STI -2009-00625, Rev.0

Page 35 of 46

Table AP-5 continued. Quadrant Samples from Tank 18F South Hemisphere Received at SRNL.

\begin{tabular}{|c|c|c|c|}
\hline South Quandrant Sample & Estimated wt. of wet cake, g & Date received & Comments \\
\hline FTF-07-09-11-1 & 2 & $2-3-2009$ & Sample composite \\
\hline FTF-07-09-11-2 & 6 & $2-3-2009$ & Sample composite \\
\hline FTF-07-09-11-3 & 3 & $2-3-2009$ & Sample composite \\
\hline FTF-07-09-12-1 & 3 & $2-3-2009$ & Sample composite \\
\hline FTF-07-09-12-2 & 4 & $2-3-2009$ & Sample composite \\
\hline FTF-07-09-12-3 & 8 & $2-3-2009$ & Sample composite \\
\hline FTF-07-09-19-1 & 2 & $3-2-2009$ & Sample archived \\
\hline FTF-07-09-19-2 & 1 & $3-2-2009$ & Sample composite \\
\hline FTF-07-09-19-3 & 0 & $3-2-2009$ & Sample composite \\
\hline FTF-07-09-21-1 & 6 & $3-11-2009$ & Door stop, sample composite \\
\hline FTF-07-09-21-2 & 8 & $3-11-2009$ & Door stop-archived \\
\hline FTF-07-09-21-3 & 6 & $3-11-2009$ & Door stop, sample composite \\
\hline
\end{tabular}




\section{APPENDIX B \\ Summary of Analytical Methods}

\section{Inductively Coupled Plasma - Atomic Emission Spectroscopy (ICP-ES)}

Samples are diluted as necessary to bring analytes within the instrument range. A scandium internal standard is added to all samples after dilution at a concentration of 2 $\mathrm{mg} / \mathrm{L}$. The instrument is calibrated daily with a blank and two standards: 5 and $10 \mathrm{mg} / \mathrm{L}$ NIST traceable multi-element standards in dilute acid. Background and internal standard correction were applied to the results.

\section{Ion Chromatography for Anions (IC-Anions)}

For IC Anions, samples were diluted with a carbonate/bicarbonate diluent as necessary to bring analytes to within instrument calibration. A 3-point calibration curve is run daily on the instrument with concentrations of 10,25 and $50 \mu \mathrm{g} / \mathrm{mL}$.

\section{Atomic Absorption Spectroscopy (AA)}

Arsenic, selenium, potassium (ICP-ES or AA), and mercury are analyzed by AA. The mercury was determined using the cold vapor technique. Samples were diluted as necessary to bring analytes within the instrument calibration range. An instrument calibration is performed daily with a blank and two or three point standard. The standard is run for each element at the beginning of the day, after each five sample runs and at the end of the day.

\section{Inductively Coupled Plasma - Mass Spectroscopy (ICP-MS)}

Samples were run concurrently with a laboratory control standard (LCS) containing V, $\mathrm{Co}, \mathrm{As}, \mathrm{Sr}, \mathrm{Mo}, \mathrm{Ru}, \mathrm{Ag}, \mathrm{Cd}, \mathrm{Sb}, \mathrm{Cs}, \mathrm{Ba}, \mathrm{La}, \mathrm{Eu}, \mathrm{Ho}, \mathrm{Yb}, \mathrm{Tl}, \mathrm{Pb}$, Th, and U. This LCS provided a mass response covering most of the mass range of interest. The following describes the calculation of the analytes of interest from the mass values:

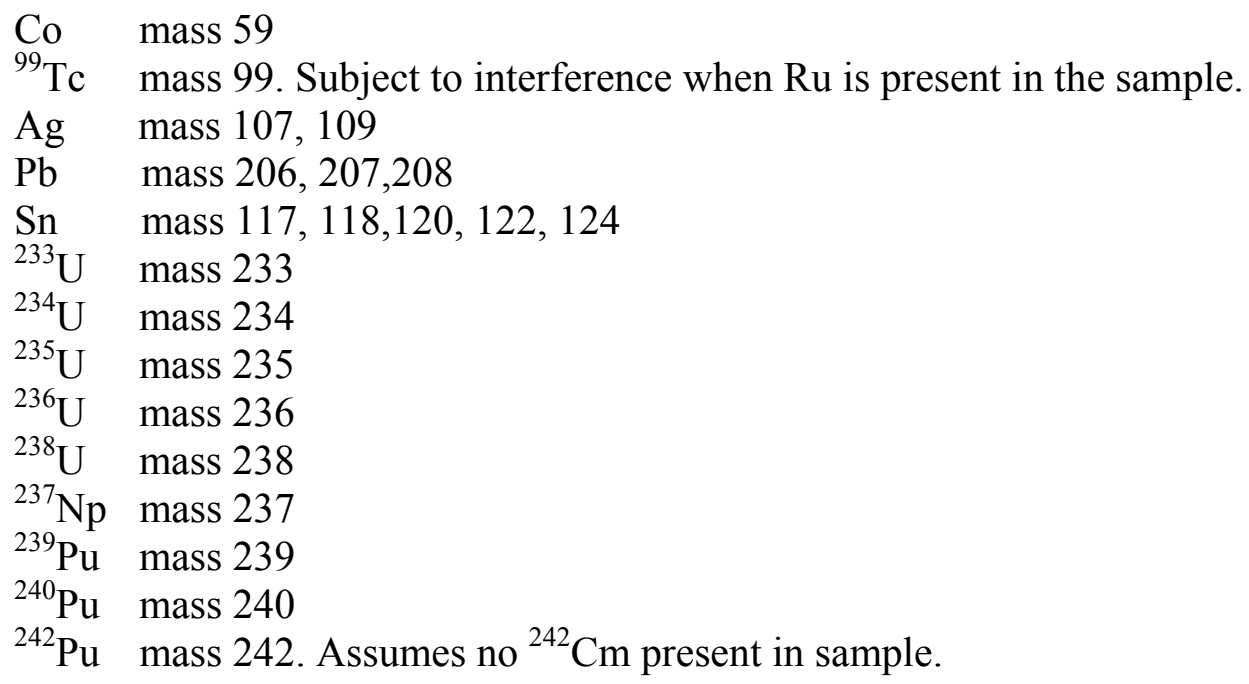




\section{Other Specialty Separations and Preparations.}

\section{Ni-59/63}

Sub-samples of solid material were weighed out, spiked with an elemental nickel carrier and digested in concentrated acid. The nickel species were extracted from the matrix using dimethylglyoxime (DMG) based extractant. Ni-59 concentrations were measured using low energy photon/x-ray, thin-windowed, semi-planar high purity germanium spectrometers. Ni-63 concentrations were measured by liquid scintillation analysis. Elemental nickel carrier yields were measured by ICP-ES, and were used to correct the radioactive nickel species' analyses for any nickel losses from the radiochemical separations.

\section{Se-79}

Sub-samples of solid material were weighed out, spiked with an elemental selenium carrier and digested in concentrated acid. The selenium species were extracted from the matrix using a combination of resin decontamination, selenium metal precipitation, and TBP-based liquid-liquid extractions. The purified selenium products were analyzed by liquid scintillation to measure Se-79, and by neutron activation analysis to measure elemental selenium carrier yields. The selenium carrier yields were used to correct the Se-79 analyses for any selenium losses from the radiochemical separations.

\section{Cs-137/Cs-134}

The solid material was too concentrated in radioactive cesium to be measured directly. Aliquots of peroxide fusion dissolution and $\mathrm{AQR}$ were analyzed by coaxial high purity germanium gamma-ray spectrophotometers to measure Cs-137 and Cs-134.

\section{Sr-90}

The solid material was too concentrated in Sr-90 to be analyzed directly. Aliquots of peroxide fusion and $\mathrm{AQR}$ dissolutions were spiked with an elemental strontium carrier. The strontium species were extracted from the matrix using a crown-ether-based solid phase extractant. Sr-90 concentrations were measured by liquid scintillation analysis. Elemental strontium carrier yields were measured by neutron activation analysis, and were used to correct the Sr-90 analyses for any strontium losses from the radiochemical separations.

\section{Tc-99}

Tc-99m tracer was generated in the SRNL Cf-252 neutron activation analysis facility by activating Mo-99 to Tc-99m via neutron irradiation. The Tc-99m was extracted from the Mo-99 target material with methyl isobutyl ketone (MIBK). Subsamples of solid material were weighed out, and digested in concentrated acid. Aliquots of Tc-99m tracer were added. The technetium species were extracted from the matrix using an Aliquat-336 based solid phase extractant. Tc-99 concentrations were measured by liquid scintillation analysis. Tc-99m yields were measured with a NaI well gamma spectrometer, and were used to correct the Tc-99 analyses for any technetium losses from the radiochemical separations. 


\section{Pm-147/Sm-151}

The solid material was too concentrated in Sm-151 to be analyzed directly. Aliquots of peroxide fusion and $\mathrm{AQR}$ dissolution were spiked with an elemental samarium carrier. The promethium and samarium species were extracted from the matrix using a combination of resins Octylphenyl-N,N-di-isobutyl carbamoylphosphine oxide/tri-n-butyl phosphate (one CMPO/TBP) and di(2-ethylhexyl) orthophosphoric acid (one HDEHP based). Sm-151 and Pm-147 concentrations were measured by liquid scintillation analysis. The matrix was high in Sm-151, but the short-lived Pm-147 component of the material had decayed below noise levels of the analysis. Elemental samarium carrier yields were measured by neutron activation analysis, and were used to correct the analyses for any samarium losses from the radiochemical separations. The separation was designed to extract both Sm and Pm together; a Pm spike was run with the samples to confirm this.

\section{Pu-238, 239/240, 241}

The solid material was too concentrated in plutonium to be analyzed directly. Aliquots of peroxide fusion and $\mathrm{AQR}$ dissolutions were spiked with $\mathrm{Pu}-236$ tracer. The plutonium was extracted from the matrix using thenoyltrifluoroacetone (TTA) following a series of oxidation-state adjustments. The TTA extracts were mounted on stainless steel counting plates and counted for $\mathrm{Pu}-238, \mathrm{Pu}-239$, and $\mathrm{Pu}-240$ using PIPs detectors. Each separation was traced based on the Pu-236 recovery. Aliquots of sample were also subjected to Csremoval with Bio-Rad AMP resin and extracted using TEVA columns (TEVA Brand name for one of Eichrom's resins). The Pu-containing extracts were measured by liquid scintillation analysis to determine $\mathrm{Pu}-241$ concentration.

Am-241, 242m, 243, Cm-242, 243, 244, 245, 247, 248, Cf-249, 251, 252

Six sub-samples of solids material were weighed out, spiked with an Am-243 radioactive tracer and digested in concentrated acid. Six additional sub-samples of solid materials were weighed out and digested in concentrated acid with no tracer added. The americium, curium and californium species were extracted from the matrix using a CMPO/TBP based solid phase extractant and purified further with an HDEHP based solid phase extractant. Am-241, 243, Cm-243, 245, 247, Cf-249 and 251 concentrations were measured using low energy photon/x-ray, thin-windowed, semi-planar high purity germanium spectrometers. Cm-242, 244, 248, Cf-252 concentrations were measured using passivated, implanted, planar silicon (PIPS) alpha spectrometers. In cases where Am-241 quantities had been measured from the cesium removed gamma analyses, all results were traced with the Am-241 present in the sample matrix. In cases where Am241 quantities were too low to be measured (in this case for the blanks run with the analyses), the Am-243 tracer was used to trace the analysis. These samples were so high in Am-241 concentrations that all of the Am-243 tracers were overwhelmed from the Am-241 background. The tracer yields were used to correct the various analytes analyses for any losses from the radiochemical separations. 


\section{Ra-226}

Sub-samples of solid material were weighed out and digested in concentrated acid. The Ra-226 was extracted from the matrix using a combination of resin decontamination and ion exchange. A blank spiked sample of Ra-226 was run through the extraction to serve as a separation yield monitor. The purified Ra-226 was sealed in polypropylene tubes and stored for several daughter Rn-222 half-lives. The Ra-226 progeny daughter isotope $\mathrm{Pb}-$ 214 was then analyzed for using a high purity germanium well gamma ray spectrophotometer and results were corrected for the blank spike Ra-226 recoveries.

\section{Pa-231}

Sub-samples of solid material were weighed out, spiked with a Pa-233 tracer and digested in concentrated acid. The dissolutions were decontaminated with ammonium phosphomolybdate and quaternary amine based resins. Protactinium species were then extracted from the matrix using a CMPO/TBP based extractant. Pa-231 and $\mathrm{Pa}-233$ concentrations were measured using low energy photon/x-ray, thin-windowed, semi-planar high purity germanium spectrometers. The Pa-233 tracer yields were decay corrected and then used to correct the $\mathrm{Pa}-231$ analyses for any losses from the radiochemical separations.

\section{Gross Alpha/Gross Beta}

The solid material was too concentrated to be analyzed directly. Aliquots of peroxide fusion dissolution were added to liquid scintillation cocktail and analyzed for gross alpha and gross beta activity using liquid scintillation analysis. Alpha/beta spillover was determined for each aliquot analyzed, and subsequently used for accurately determining alpha and beta activity, via the addition of a known amount of plutonium to an identical aliquot of each sample.

\section{I-129}

The solid material was used for the I-129 separation and analysis. KI carrier was added to aliquots of the solid material and nitric acid. Actinide and Ammonium Molybdophosphate (AMP) resins were then added to the mixture to facilitate removal of interfering isotopes. Sodium sulfite is added to the material to reduce the iodine. Silver nitrate is added to the solution to precipitate the iodine as AgI, which is separated via filtration. The filtrate is analyzed for I-129 content using low energy photon/x-ray, thinwindowed, semi-planar high purity germanium spectrometers. Elemental iodine yields were measured by neutron activation analysis, and were used to correct the I-129 analyses for any iodine losses from the radiochemical separation.

Na-22, Al-26, Co-60, Nb-94, Rh-106, Ru-106, Sb-125, Sb-126, Sn-126, Sb-126m, Te125m, Ce-144, Pr-144, Eu-152, Eu-154, Eu-155, Am-241, Ra-228, Ac-227-Aliquots of the solid material were dissolved using a mixture of concentrated hydrochloric, nitric, and hydrofluoric acid. Following digestion, the solutions were subjected to a Cs-removal process utilizing Bio Rad AMP-1 resin. The Cs-removed digestates were analyzed by coaxial high purity germanium spectrophotometers to measure the gamma-emitting radionuclides listed above. 


\section{C-14}

The solid material was used for the $\mathrm{C}-14$ separation and analysis. The material was added to a mixture of sodium hydroxide, and sodium carbonate/sodium hydroxide. A series of oxidation and reduction steps designed to liberate C-14 containing carbon dioxide were carried out, which selectively trapped the $\mathrm{C}-14$ in various solutions. Finally, C-14 containing carbon dioxide was captured in Carbosorb E and measured by liquid scintillation analysis.

\section{Th-229/230}

Six sub-samples of solid materials were weighed out, spiked with a Th-229 radioactive tracer and digested in concentrated acid. Six additional sub-samples of solid materials were weighed out and digested in concentrated acid with no tracer added. Thorium was extracted from the matrix using two stages of a quaternary amine based solid phase extraction and purified further via co-precipitation with cerium. Th-229 and Th-230 concentrations were measured using passivated, implanted, planar silicon (PIPS) alpha spectrometers. The Th-229 tracer yields were used to correct the various analytes analyses for any thorium losses from the radiochemical separations.

\section{U-232}

Six sub-samples of solid materials were weighed out, spiked with a U-233 radioactive tracer and digested in concentrated acid. Six additional sub-samples of solids material were weighed out and digested in concentrated acid with no tracer added. For the South hemisphere samples, there were insufficient solids remaining to run the analyses, so those analyses were run off aliquots of peroxide fusion. Uranium was extracted from the matrix using two stages of a diamyl, amylphosphonate (DAAP)-based solid phase extraction and purified further via co-precipitation with cerium. U-232, U-233, and U-238 activities were measured using passivated, implanted, planar silicon (PIPS) alpha spectrometers. The Tank 19 samples were so high in U-234, the U-233 tracers (which have the same alpha energy as U-234) were swamped out. U-232/U-238 activity ratios were generated and were multiplied to U-238 activities measured with the ICP-MS to determine U-232 activities in the samples.

\section{U Separation for MS}

To lower detection limits for U-233, 234, and 236 from the ICP-MS analyses on peroxide fusion dissolution of Tank 19 solids, aliquots of dissolution were purified with a DAAP based solid phase extraction. The purified aliquots were analyzed by the ICP-MS to measure U-233/U-235, U-234/U-235, and U-236/U-235 mass ratios. Those ratios were applied to U-235 concentrations measured by the ICP-MS directly on aliquots of dissolution to quantify U-233, U-234, and U-236 concentrations.

\section{Pu Separation for MS}

To lower detection limits for Pu-242 and Pu-244 from the ICP-MS analyses on peroxide fusion dissolution of Tank 19 solids, aliquots of dissolution were purified with a quaternary amine based solid phase extraction. The purified aliquots were analyzed by the ICP-MS to measure $\mathrm{Pu}-242 / \mathrm{Pu}-239$, and $\mathrm{Pu}-244 / \mathrm{Pu}-239$ mass ratios. Those ratios 
were applied to $\mathrm{Pu}-239$ concentrations measured by the ICP-MS directly on aliquots of dissolution to quantify $\mathrm{Pu}-242$ and $\mathrm{Pu}-244$ concentrations.

\section{Cs-135 Separation for MS}

To lower detection limits for Cs-135 from the ICP-MS analyses on peroxide fusion dissolution of Tank 19 solids, aliquots of dissolution were purified with a solvent-solvent Caustic Side Solvent Extraction (CSSX)-based extraction system. The purified aliquots were analyzed by the ICP-MS to measure Cs-135/Cs-137 mass ratios. Those ratios were converted to activity ratios and applied to the Cs-137 activities measured by coaxial high purity germanium gamma-ray spectrophotometers directly on aliquots of dissolution to quantify Cs-135 concentrations.

\section{Np-237}

To lower detection limits for Np-237 from the ICP-MS analyses on peroxide fusion dissolution of Tank 19 solids, aliquots of dissolution were spiked with Np-239 and then purified with a quaternary amine based solid phase extraction. The purified aliquots were analyzed by low energy photon/x-ray, thin-windowed, semi-planar high purity germanium spectrometers to yield the Np-239 recoveries and by the ICP-MS to measure $\mathrm{Np}-237$. The Np-237 values were corrected with the decay-corrected Np-239 recovories.

\section{Tritium}

Sub-samples of solid material were weighed out and leached using nitric acid. The acid leachates were subjected to tritium separations via steam distillation, and aliquots of the tritium-containing distillate were analyzed by liquid scintillation analysis.

\section{Weight Fraction Solids Analysis}

The weight percent total solids in the sample were measured in the Shielded Cells using a conventional drying oven at $110{ }^{\circ} \mathrm{C}$. An aliquot of the slurry composite sample was placed in a container. The container was placed in the oven. The weights of the dried sample were checked periodically over 72 hours until two consecutive weights yield comparable results. The weight fraction solid was calculated by dividing the dry weight of the sample by the initial wet weight of the sample.

\section{Density Analysis}

The density of the Tank 19F composite slurry was measured in the SRNL shielded cells. Using a 5.0-mL volumetric pipette an aliquot of the composite slurry was pipetted into a pre-weight Teflon flask and the weight of the container and $5 \mathrm{~mL}$ slurry sample determined. The weight of the $5 \mathrm{ml}$ sample was determined by difference. The density of the slurry was determined by dividing the weight of the sample by the volume of the sample delivered. These measurements were performed three times and the average of the density valued calculated. The density of the wet solid fraction, obtained by centrifuging in calibrated $50-\mathrm{mL}$ capacity centrifuge tubes which were transparent, were determined by measuring the weight of the wet solid cakes in each centrifuge tube after decanting and removing the liquid phase from the solid wet cakes. This was attained by carefully tilting and overturning each centrifuge tube into a secondary container so that the liquids droplets could be removed without disturbing the surface of the wet cake in each 
centrifuge tube. The volume of the wet cake was read off the calibrated centrifuge tube and the density calculated by dividing the weight of the wet cake by the volume of the wet cake in the centrifuge tube.

\section{Aqua Regia Digestions (AQR)}

Samples were digested according to procedure L16.1, ADS-2226. In a typical digestion, $\sim 0.3 \mathrm{~g}$ of wet material from a Tank 18 sample tube was placed into a Teflon ${ }^{\circledR}$ digestion vessel. Then, $9 \mathrm{~mL}$ (hydrochloric acid) $\mathrm{HCl}, 3 \mathrm{~mL}$ (nitric acid) $\mathrm{HNO}_{3}$ and $1 \mathrm{~mL}$ (hydrofluoric acid) HF was added to the Teflon ${ }^{\circledR}$ vessel. The Teflon ${ }^{\circledR}$ vessel was sealed and heated for a period of no more than 4 hours at $115^{\circ} \mathrm{C}$. The sample was then cooled and diluted to $50 \mathrm{~mL}$ (for samples to undergo a preparation step for Np-237 followed by inductively coupled plasma mass spectroscopy analysis, three samples in total) or $100 \mathrm{~mL}$ (for samples to undergo inductively coupled atomic emission spectroscopy, atomic absorption, and inductively coupled plasma mass spectroscopy analysis, three samples in total) using a volumetric flask. Six samples, in total, from each hemisphere were digested by aqua regia. Concurrently, as each Tank 18 sample tube was being sampled to grab $\sim 0.3$ grams of wet material for digestion purposes, $\sim 0.3$ grams of additional wet material was taken from the same Tank 18 sample tube and placed in an alumina crucible and dried at $110^{\circ} \mathrm{C}$ until two consecutive weights were within \pm 0.02 grams. This process was repeated for each digestion. The process was performed to determine the weight percent dried solids in each digestion for comparison to the peroxide fusion digestions.

\section{Sodium Peroxide/Hydroxide Fusions (PF)}

Samples were digested according to procedure L16.1, ADS 2502. In a typical digestion, $\sim 0.3$ grams of wet material from a Tank 18 sample tube was placed into a zirconium $(\mathrm{Zr})$ crucible with a known weight. The material in the crucible was dried until two consecutive weights were within \pm 0.02 grams. The remaining material in the crucible was fused at $675{ }^{\circ} \mathrm{C}$ using a mixture of sodium peroxide (1.5 grams) and sodium hydroxide (1.0 grams). After the sample was cooled, water was added to dissolve the fused material and the solution was acidified by the addition of $25 \mathrm{~mL} \mathrm{HCl}$. The sample was diluted to $100 \mathrm{~mL}$. Six samples were digested for each hemisphere for analysis (three samples for a preparation step for Np-237 followed by inductively coupled plasma mass spectroscopy analysis, and three samples for inductively coupled atomic emission spectroscopy and inductively coupled plasma mass spectroscopy analysis). 


\section{APPENDIX C}

Table C1. Comparison of select Tank 18F North Hemisphere results (sample average) with the results of the analysis of a zeolite blank for mass 233 to mass 244 .

\begin{tabular}{|c|c|c|c|}
\hline Mass-ICP-MS & $\begin{array}{c}\text { North Sample } \\
\text { Average }\end{array}$ & Zeolite Blank & Units \\
\hline 233 & $1.33 \mathrm{E}+01$ & $<6.41 \mathrm{E}+00$ & $\mu \mathrm{g} / \mathrm{g}$ \\
\hline 234 & $<1.33 \mathrm{E}+01$ & $<6.41 \mathrm{E}+00$ & $\mu \mathrm{g} / \mathrm{g}$ \\
\hline 235 & $1.32 \mathrm{E}+02$ & $<6.41 \mathrm{E}+00$ & $\mu \mathrm{g} / \mathrm{g}$ \\
\hline 236 & $<1.33 \mathrm{E}+01$ & $<6.41 \mathrm{E}+00$ & $\mu \mathrm{g} / \mathrm{g}$ \\
\hline 237 & $<2.00 \mathrm{E}+01$ & $<9.62 \mathrm{E}+00$ & $\mu \mathrm{g} / \mathrm{g}$ \\
\hline 238 & $2.23 \mathrm{E}+04$ & $<7.37 \mathrm{E}+01$ & $\mu \mathrm{g} / \mathrm{g}$ \\
\hline 239 & $2.67 \mathrm{E}+02$ & $<9.62 \mathrm{E}+00$ & $\mu \mathrm{g} / \mathrm{g}$ \\
\hline 240 & $2.12 \mathrm{E}+01$ & $<6.41 \mathrm{E}+00$ & $\mu \mathrm{g} / \mathrm{g}$ \\
\hline 241 & $<2.00 \mathrm{E}+01$ & $<9.62 \mathrm{E}+00$ & $\mu \mathrm{g} / \mathrm{g}$ \\
\hline 242 & $<1.33 \mathrm{E}+01$ & $<6.41 \mathrm{E}+00$ & $\mu \mathrm{g} / \mathrm{g}$ \\
\hline 243 & $<1.33 \mathrm{E}+01$ & $<6.41 \mathrm{E}+00$ & $\mu \mathrm{g} / \mathrm{g}$ \\
\hline 244 & $<2.00 \mathrm{E}+01$ & $<9.62 \mathrm{E}+00$ & $\mu \mathrm{g} / \mathrm{g}$ \\
\hline
\end{tabular}

Table C2. Comparison of select Tank 18F South Hemisphere results (sample average) with the results of the analysis of a zeolite blank for mass 233 to mass 244 .

\begin{tabular}{|c|c|c|c|}
\hline Mass-ICP-MS & $\begin{array}{c}\text { South Sample } \\
\text { Average }\end{array}$ & Zeolite Blank & Units \\
\hline 233 & $<1.13 \mathrm{E}+01$ & $<3.89 \mathrm{E}+00$ & $\mu \mathrm{g} / \mathrm{g}$ \\
\hline 234 & $<1.69 \mathrm{E}+01$ & $<5.84 \mathrm{E}+00$ & $\mu \mathrm{g} / \mathrm{g}$ \\
\hline 235 & $<1.69 \mathrm{E}+01$ & $<5.84 \mathrm{E}+00$ & $\mu \mathrm{g} / \mathrm{g}$ \\
\hline 236 & $<2.82 \mathrm{E}+01$ & $<9.73 \mathrm{E}+00$ & $\mu \mathrm{g} / \mathrm{g}$ \\
\hline 237 & $<1.13 \mathrm{E}+01$ & $<3.89 \mathrm{E}+00$ & $\mu \mathrm{g} / \mathrm{g}$ \\
\hline 238 & $2.11 \mathrm{E}+03$ & $3.96 \mathrm{E}+00$ & $\mu \mathrm{g} / \mathrm{g}$ \\
\hline 239 & $4.16 \mathrm{E}+01$ & $<5.84 \mathrm{E}+00$ & $\mu \mathrm{g} / \mathrm{g}$ \\
\hline 240 & $<1.13 \mathrm{E}+01$ & $<3.89 \mathrm{E}+00$ & $\mu \mathrm{g} / \mathrm{g}$ \\
\hline 241 & $<1.69 \mathrm{E}+01$ & $<5.84 \mathrm{E}+00$ & $\mu \mathrm{g} / \mathrm{g}$ \\
\hline 242 & $<1.13 \mathrm{E}+01$ & $<3.89 \mathrm{E}+00$ & $\mu \mathrm{g} / \mathrm{g}$ \\
\hline 243 & $<1.69 \mathrm{E}+01$ & $<5.84 \mathrm{E}+00$ & $\mu \mathrm{g} / \mathrm{g}$ \\
\hline 244 & $<1.13 \mathrm{E}+01$ & $<3.89 \mathrm{E}+00$ & $\mu \mathrm{g} / \mathrm{g}$ \\
\hline
\end{tabular}


Table C3. Comparison of select Tank 18F North Hemisphere results (sample average) with the results of the analysis of a reagent blank for Am/Cm counting method.

\begin{tabular}{|c|c|c|c|}
\hline Constituent & $\begin{array}{c}\text { North Sample } \\
\text { Average }\end{array}$ & Reagent Blank & Units \\
\hline$A m-241$ & $3.59 \mathrm{E}+00$ & $5.50 \mathrm{E}-03$ & $\mu \mathrm{Ci} / \mathrm{g}$ \\
\hline$A m-243$ & $2.08 \mathrm{E}-03$ & $<3.52 \mathrm{E}-04$ & $\mu \mathrm{Ci} / \mathrm{g}$ \\
\hline$A m-242 m$ & $1.39 \mathrm{E}-05$ & $<2.92 \mathrm{E}-05$ & $\mu \mathrm{Ci} / \mathrm{g}$ \\
\hline $\mathrm{Cm}-243$ & $<1.80 \mathrm{E}-03$ & $<1.08 \mathrm{E}-03$ & $\mu \mathrm{Ci} / \mathrm{g}$ \\
\hline $\mathrm{Cm}-245$ & $<1.50 \mathrm{E}-03$ & $<8.87 \mathrm{E}-04$ & $\mu \mathrm{Ci} / \mathrm{g}$ \\
\hline $\mathrm{Cm}-247$ & $<6.22 \mathrm{E}-04$ & $1.44 \mathrm{E}-03$ & $\mu \mathrm{Ci} / \mathrm{g}$ \\
\hline $\mathrm{Cf}-252$ & $<1.15 \mathrm{E}-05$ & $<2.41 \mathrm{E}-05$ & $\mu \mathrm{Ci} / \mathrm{g}$ \\
\hline $\mathrm{Cm}-242$ & $1.15 \mathrm{E}-05$ & $<2.41 \mathrm{E}-05$ & $\mu \mathrm{Ci} / \mathrm{g}$ \\
\hline $\mathrm{Cm}-244$ & $1.61 \mathrm{E}-01$ & $2.73 \mathrm{E}-04$ & $\mu \mathrm{Ci} / \mathrm{g}$ \\
\hline $\mathrm{Cm}-248$ & $<8.24 \mathrm{E}-02$ & $<7.30 \mathrm{E}-04$ & $\mu \mathrm{Ci} / \mathrm{g}$ \\
\hline
\end{tabular}

Table C4. Comparison of select Tank 18F South Hemisphere results (sample average) with the results of the analysis of a reagent blank for Am/Cm counting method.

\begin{tabular}{|c|c|c|c|}
\hline Constituent & $\begin{array}{c}\text { South Sample } \\
\text { Average }\end{array}$ & Reagent Blank & \multicolumn{1}{l|}{} \\
\hline Am-241 & $3.12 \mathrm{E}+00$ & $6.96 \mathrm{E}-05$ & $\mu \mathrm{Ci} / \mathrm{g}$ \\
\hline Am-243 & $1.84 \mathrm{E}-03$ & $<3.64 \mathrm{E}-05$ & $\mu \mathrm{Ci} / \mathrm{g}$ \\
\hline Am-242m & $\leq 5.49 \mathrm{E}-05$ & $<3.19 \mathrm{E}-06$ & $\mu \mathrm{Ci} / \mathrm{g}$ \\
\hline Cm-243 & $<9.99 \mathrm{E}-04$ & $<1.51 \mathrm{E}-04$ & $\mu \mathrm{Ci} / \mathrm{g}$ \\
\hline Cm-245 & $<3.40 \mathrm{E}-04$ & $<1.24 \mathrm{E}-04$ & $\mu \mathrm{Ci} / \mathrm{g}$ \\
\hline Cm-247 & $<1.03 \mathrm{E}-04$ & $<1.68 \mathrm{E}-04$ & $\mu \mathrm{Ci} / \mathrm{g}$ \\
\hline Cf-249 & $<1.11 \mathrm{E}-04$ & $<1.66 \mathrm{E}-04$ & $\mu \mathrm{Ci} / \mathrm{g}$ \\
\hline Cf-251 & $<1.22 \mathrm{E}-04$ & $<1.39 \mathrm{E}-04$ & $\mu \mathrm{Ci} / \mathrm{g}$ \\
\hline Cf-252 & $<4.54 \mathrm{E}-05$ & $<2.64 \mathrm{E}-06$ & $\mu \mathrm{Ci} / \mathrm{g}$ \\
\hline Cm-242 & $\leq 4.54 \mathrm{E}-05$ & $<2.64 \mathrm{E}-06$ & $\mu \mathrm{Ci} / \mathrm{g}$ \\
\hline Cm-244 & $1.20 \mathrm{E}-01$ & $<2.11 \mathrm{E}-05$ & $\mu \mathrm{Ci} / \mathrm{g}$ \\
\hline Cm-248 & $<5.91 \mathrm{E}-02$ & $<6.82 \mathrm{E}-05$ & $\mu \mathrm{Ci} / \mathrm{g}$ \\
\hline
\end{tabular}

Table C5. Comparison of select Tank 18F North Hemisphere results (sample average) with the results of the analysis of a reagent blank for various analytical methods.

\begin{tabular}{|c|c|c|c|}
\hline Constituent & $\begin{array}{c}\text { North Sample } \\
\text { Average }\end{array}$ & Reagent Blank & Units \\
\hline H-3 & $<1.58 \mathrm{E}-02$ & $<2.50 \mathrm{E}-04$ & $\mu \mathrm{Ci} / \mathrm{g}$ \\
\hline $\mathrm{Ni}-59$ & $3.28 \mathrm{E}-03$ & $<1.55 \mathrm{E}-04$ & $\mu \mathrm{Ci} / \mathrm{g}$ \\
\hline $\mathrm{Ni}-63$ & $4.27 \mathrm{E}-01$ & $<1.95 \mathrm{E}-04$ & $\mu \mathrm{Ci} / \mathrm{g}$ \\
\hline $\mathrm{Tc}-99$ & $3.56 \mathrm{E}-02$ & $<4.25 \mathrm{E}-05$ & $\mu \mathrm{Ci} / \mathrm{g}$ \\
\hline $\mathrm{I}-129$ & $<6.13 \mathrm{E}-05$ & $<9.01 \mathrm{E}-07$ & $\mu \mathrm{Ci} / \mathrm{g}$ \\
\hline
\end{tabular}


Table C6. Comparison of select Tank 18F South Hemisphere results (sample average) with the results of the analysis of a reagent blank for various methods.

\begin{tabular}{|c|c|c|c|}
\hline Constituent & $\begin{array}{c}\text { South Sample } \\
\text { Average }\end{array}$ & Reagent Blank & Units \\
\hline Ni-59 & $\leq 7.33 \mathrm{E}-03$ & $<7.97 \mathrm{E}-04$ & $\mu \mathrm{Ci} / \mathrm{g}$ \\
\hline $\mathrm{Ni}-63$ & $\leq 5.04 \mathrm{E}-01$ & $<2.94 \mathrm{E}-04$ & $\mu \mathrm{Ci} / \mathrm{g}$ \\
\hline $\mathrm{C}-14$ & $1.84 \mathrm{E}-03$ & $<4.68 \mathrm{E}-05$ & $\mu \mathrm{Ci} / \mathrm{g}$ \\
\hline Tc-99 & $4.31 \mathrm{E}-02$ & $<4.25 \mathrm{E}-05$ & $\mu \mathrm{Ci} / \mathrm{g}$ \\
\hline $\mathrm{I}-129$ & $<9.28 \mathrm{E}-05$ & $<9.01 \mathrm{E}-07$ & $\mu \mathrm{Ci} / \mathrm{g}$ \\
\hline Np-237 & $4.82 \mathrm{E}-03$ & $<7.86 \mathrm{E}-06$ & $\mu \mathrm{Ci} / \mathrm{g}$ \\
\hline Pm-147 & $<4.20 \mathrm{E}-01$ & $<4.55 \mathrm{E}-03$ & $\mu \mathrm{Ci} / \mathrm{g}$ \\
\hline Sm147 & $2.62 \mathrm{E}+00$ & $<6.49 \mathrm{E}-03$ & $\mu \mathrm{Ci} / \mathrm{g}$ \\
\hline
\end{tabular}

Table C7. Comparison of select Tank 18F North Hemisphere results (sample average) with the results of the analysis of a reagent blank for gamma scan.*

\begin{tabular}{|c|c|c|c|}
\hline Constituent & $\begin{array}{c}\text { North Sample } \\
\text { Average }\end{array}$ & Reagent Blank & Units \\
\hline $\mathrm{Na}-22$ & $<6.22 \mathrm{E}-04$ & $<5.54 \mathrm{E}-04$ & $\mu \mathrm{Ci} / \mathrm{g}$ \\
\hline $\mathrm{Al}-26$ & $<8.33 \mathrm{E}-05$ & $<8.87 \mathrm{E}-05$ & $\mu \mathrm{Ci} / \mathrm{g}$ \\
\hline $\mathrm{Co}-60$ & $2.04 \mathrm{E}-02$ & $<1.88 \mathrm{E}-02$ & $\mu \mathrm{Ci} / \mathrm{g}$ \\
\hline $\mathrm{Nb}-94$ & $<3.04 \mathrm{E}-04$ & $<3.12 \mathrm{E}-04$ & $\mu \mathrm{Ci} / \mathrm{g}$ \\
\hline $\mathrm{Ru}-106$ & $<3.03 \mathrm{E}-03$ & $<3.27 \mathrm{E}-03$ & $\mu \mathrm{Ci} / \mathrm{g}$ \\
\hline $\mathrm{Rh}-106$ & $<3.03 \mathrm{E}-03$ & $<3.27 \mathrm{E}-03$ & $\mu \mathrm{Ci} / \mathrm{g}$ \\
\hline $\mathrm{Sb}-125$ & $<1.15 \mathrm{E}-03$ & $<1.22 \mathrm{E}-03$ & $\mu \mathrm{Ci} / \mathrm{g}$ \\
\hline $\mathrm{Sb}-126$ & $3.64 \mathrm{E}-04$ & $3.43 \mathrm{E}-04$ & $\mu \mathrm{Ci} / \mathrm{g}$ \\
\hline $\mathrm{Sn}-126$ & $3.64 \mathrm{E}-04$ & $3.43 \mathrm{E}-04$ & $\mu \mathrm{Ci} / \mathrm{g}$ \\
\hline $\mathrm{Sb}-126 \mathrm{~m}$ & $3.64 \mathrm{E}-04$ & $3.43 \mathrm{E}-04$ & $\mu \mathrm{Ci} / \mathrm{g}$ \\
\hline $\mathrm{Te}-125 \mathrm{~m}$ & $<1.15 \mathrm{E}-03$ & $<1.22 \mathrm{E}-03$ & $\mu \mathrm{Ci} / \mathrm{g}$ \\
\hline $\mathrm{Ce}-144$ & $<5.32 \mathrm{E}-03$ & $<5.59 \mathrm{E}-03$ & $\mu \mathrm{Ci} / \mathrm{g}$ \\
\hline $\mathrm{Pr}-144$ & $<5.32 \mathrm{E}-03$ & $<5.59 \mathrm{E}-03$ & $\mu \mathrm{Ci} / \mathrm{g}$ \\
\hline $\mathrm{Eu}-152$ & $<7.12 \mathrm{E}-04$ & $<7.07 \mathrm{E}-04$ & $\mu \mathrm{Ci} / \mathrm{g}$ \\
\hline $\mathrm{Eu}-154$ & $1.65 \mathrm{E}-02$ & $1.47 \mathrm{E}-02$ & $\mu \mathrm{Ci} / \mathrm{g}$ \\
\hline $\mathrm{Eu}-155$ & $5.95 \mathrm{E}-03$ & $5.72 \mathrm{E}-03$ & $\mu \mathrm{Ci} / \mathrm{g}$ \\
\hline $\mathrm{Ra}-226$ & $<1.12 \mathrm{E}-02$ & $<1.37 \mathrm{E}-02$ & $\mu \mathrm{Ci} / \mathrm{g}$ \\
\hline $\mathrm{Ra}-228$ & $<9.73 \mathrm{E}-04$ & $<3.29 \mathrm{E}+00$ & $\mu \mathrm{Ci} / \mathrm{g}$ \\
\hline $\mathrm{Ac}-227$ & $<9.14 \mathrm{E}-02$ & $<1.02 \mathrm{E}-03$ & $\mu \mathrm{Ci} / \mathrm{g}$ \\
\hline
\end{tabular}

*Activity in reagent blank about the same order of magnitude as in samples because samples were mistakenly analyzed as blanks. 
Table C8. Comparison of select Tank 18F South Hemisphere results (sample average) with the results of the analysis of a reagent blank-gamma scan*

\begin{tabular}{|c|c|c|c|}
\hline Constituent & $\begin{array}{c}\text { South Sample } \\
\text { Average }\end{array}$ & Reagent Blank & Units \\
\hline $\mathrm{Na}-22$ & $<5.00 \mathrm{E}-04$ & $<5.05 \mathrm{E}-04$ & $\mu \mathrm{Ci} / \mathrm{g}$ \\
\hline $\mathrm{Al}-26$ & $<8.49 \mathrm{E}-05$ & $<7.75 \mathrm{E}-05$ & $\mu \mathrm{Ci} / \mathrm{g}$ \\
\hline $\mathrm{Co}-60$ & $1.76 \mathrm{E}-02$ & $1.30 \mathrm{E}-02$ & $\mu \mathrm{Ci} / \mathrm{g}$ \\
\hline $\mathrm{Nb}-94$ & $<2.90 \mathrm{E}-04$ & $<3.05 \mathrm{E}-04$ & $\mu \mathrm{Ci} / \mathrm{g}$ \\
\hline $\mathrm{Ru}-106$ & $<2.70 \mathrm{E}-03$ & $<2.45 \mathrm{E}-03$ & $\mu \mathrm{Ci} / \mathrm{g}$ \\
\hline $\mathrm{Rh}-106$ & $<2.70 \mathrm{E}-03$ & $<2.45 \mathrm{E}-03$ & $\mu \mathrm{Ci} / \mathrm{g}$ \\
\hline $\mathrm{Sb}-125$ & $<1.13 \mathrm{E}-03$ & $<1.27 \mathrm{E}-03$ & $\mu \mathrm{Ci} / \mathrm{g}$ \\
\hline $\mathrm{Sb}-126$ & $3.80 \mathrm{E}-04$ & $5.59 \mathrm{E}-04$ & $\mu \mathrm{Ci} / \mathrm{g}$ \\
\hline $\mathrm{Sn}-126$ & $3.80 \mathrm{E}-04$ & $5.59 \mathrm{E}-04$ & $\mu \mathrm{Ci} / \mathrm{g}$ \\
\hline $\mathrm{Sb}-126 \mathrm{~m}$ & $3.80 \mathrm{E}-04$ & $5.59 \mathrm{E}-04$ & $\mu \mathrm{Ci} / \mathrm{g}$ \\
\hline $\mathrm{Te}-125 \mathrm{~m}$ & $<1.13 \mathrm{E}-03$ & $<1.27 \mathrm{E}-03$ & $\mu \mathrm{Ci} / \mathrm{g}$ \\
\hline $\mathrm{Ce}-144$ & $<5.20 \mathrm{E}-03$ & $<5.95 \mathrm{E}-03$ & $\mu \mathrm{Ci} / \mathrm{g}$ \\
\hline $\mathrm{Pr}-144$ & $<5.20 \mathrm{E}-03$ & $<5.95 \mathrm{E}-03$ & $\mu \mathrm{Ci} / \mathrm{g}$ \\
\hline $\mathrm{Eu}-152$ & $<6.56 \mathrm{E}-04$ & $<6.40 \mathrm{E}-04$ & $\mu \mathrm{Ci} / \mathrm{g}$ \\
\hline $\mathrm{Eu}-154$ & $1.46 \mathrm{E}-02$ & $1.74 \mathrm{E}-02$ & $\mu \mathrm{Ci} / \mathrm{g}$ \\
\hline $\mathrm{Eu}-155$ & $\leq 5.08 \mathrm{E}-03$ & $<6.31 \mathrm{E}-03$ & $\mu \mathrm{Ci} / \mathrm{g}$ \\
\hline $\mathrm{Ra}-226$ & $<2.55 \mathrm{E}-04$ & $<1.45 \mathrm{E}-02$ & $\mu \mathrm{Ci} / \mathrm{g}$ \\
\hline $\mathrm{Ra}-228$ & $<9.50 \mathrm{E}-04$ & $1.82 \mathrm{E}+00$ & $\mu \mathrm{Ci} / \mathrm{g}$ \\
\hline $\mathrm{Ac}-227$ & $<8.63 \mathrm{E}-02$ & $<1.08 \mathrm{E}-03$ & $\mu \mathrm{Ci} / \mathrm{g}$ \\
\hline
\end{tabular}

*Activity in reagent blank about the same order of magnitude as in samples because samples were mistakenly analyzed as blanks. 